This PDF is a selection from an out-of-print volume from the National Bureau of Economic Research

Volume Title: NBER Macroeconomics Annual 1998, volume 13

Volume Author/Editor: Ben S. Bernanke and Julio Rotemberg, editors

Volume Publisher: MIT Press

Volume ISBN: 0-262-52271-3

Volume URL: http://www.nber.org/books/bern99-1

Publication Date: January 1999

Chapter Title: A Frictionless View of U.S. Inflation

Chapter Author: John H. Cochrane

Chapter URL: http://www.nber.org/chapters/c11250

Chapter pages in book: (p. 323 - 421) 


\section{John H. Cochrane}

University of Chicago, Federal Reserve Bank of Chicago, and NBER

\section{A Frictionless View of U.S. Inflation}

\section{Introduction}

The standard, quantity-theoretic approach to the price level is based on a transactions demand for money. Financial innovation challenges the foundations of this monetary theory: More and more transactions are handled electronically or via credit and debit cards, while ATMs, sweep accounts, and banking by computer have a major influence on cash management. Meanwhile, a wide array of privately provided, liquid, interest-paying, and often nonreservable assets have been created, leaving the supply of transaction-facilitating assets beyond the Fed's control. The quantity theory has also not had much success in describing the history of postwar U.S. inflation: Inflation seems to have very little to do with the history of monetary aggregates or interest rates. Money demand relations are dominated by velocity shocks, unrelated to changes in financial structure. Recent inflation has been remarkably stable despite continuing financial innovation.

Motivated by these observations, I ask: Can we understand the history of U.S. inflation using a framework that ignores monetary frictions? Until recently, there was no coherent way to think about this question: some friction seemed necessary to determine any value for unbacked fiat money. Recently, however, a series of authors including Leeper (1991), Sims (1994, 1997), and Woodford (1995, 1996, 1997) have advocated a fiscal theory of the price level. The analytical content of the fiscal theory is just the government's intertemporal budget constraint, versions of

I thank Henning Bohn, Eric Leeper, Julio Rotemberg, and Mike Woodford for many helpful comments, and I thank Andrea Eisfeldt for research assistance. My research is supported by the CRSP, Graduate School of Business, and by a grant from the National Science Foundation administered by the NBER. Data used in this paper can be found at http: // wwu-gab.uchicago.edu/fac/john. cochrane/. 
$\frac{\text { nominal debt }}{\text { price level }}=$ present value of real surpluses.

In a fiscal analysis, this equation determines the price level in much the same way that $M v=p y$ determines the price level in the quantity theory. However, since total government debt rather than the supply of transactions-facilitating assets appears on the left, fiscal price-level determination is immune to financial innovation, including elastically provided private media of exchange, and even a cashless or frictionless economy. More generally, as I will show below, the budget constraint provides an implicit backing or commodity standard for even apparently unbacked fiat money; equivalently, the fiscal theory regards money together with nominal debt as a (non-voting) equity claim on the flow of surpluses; these sources of value are transparently independent of financial structure or any special exchange or liquidity properties of money.

Since we see money and frictions, why abstract from them in studying the price level? First, monetary frictions have at best second-order effects on the price level in fiscal models, so why not start with the simple model? Second, a frictionless economy with lots of inside, privately provided media of exchange is, at the level of ingredients, a much more plausibleabstraction for the U.S. economy than an economy with rigidly separate liquid "money" used for transactions and illiquid "bonds" used for saving. Now that we can determine the price level in a frictionless model, it seems sensible to do it. Third, though economic theorists have a great deal of experience with analytically convenient devices with which to introduce monetary frictions - cash-in-advance, money in the utility function, overlapping generations-none of these devices provides an empirically successful description of money demand or inflation. If we had a realistic and empirically successful monetary theory - a stable, exploitable, and wellunderstood money demand function, a well-defined and agreed-on monetary aggregate, and an empirically successful account of U.S. inflationmost of our interest in the fiscal theory would vanish. The fiscal theory would be a small dusty corner in which theorists battle over "foundations" of a successful empirical framework. Finally, the fiscal theory cannot hope to say much as an alternative solution concept for given models, especially models with strong enough monetary frictions to determine the price level. Its greatest promise is precisely that it allows us to determine the price level in different models, without monetary frictions.

In this paper, I first exposit a frictionless economy with fiscal pricelevel determination. Though the formal theory is well worked out by the above-cited authors, the interpretation, applicability, and plausibility of the fiscal theory are still disputed. I show how the fiscal theory describes 
a backed commodity standard and a tax-based theory of value. I clarify the vexing red herring of "Ricardian" and "non-Ricardian" regimes, and budget constraints that do or don't hold at off-equilibrium prices. I review the extension of the fiscal theory to long-term debt, which tells us when a shortfall in future surpluses can be met by a decline in long-term bond prices rather than an increase in the price level, and I show how explicit monetary frictions make small changes to the fiscal-theoretic description of the price level.

I then interpret the history of U.S. inflation with a fiscal-theory, frictionless view. This is potentially a tough assignment. The history of postwar U.S. inflation does not have obvious fiscal roots, nor does it offer the kind of clean exogenous movements in debt or surpluses that one hopes for in a test. Also, the fiscal theory (with short-term debt) relates the price level to the present value of future surpluses. In contrast, the quantity theory relates the price level to the flow of transactions or income. Present values are notoriously hard to measure. Most importantly, the correlations in the data seem wrong: The 1970 s were a decade of low deficits and high inflation, while the 1980 s saw a dramatic increase in government debt with low inflation. Large deficits also occur in the depths of recessions with low, not high inflation, and with rising, not declining, values of the debt. The centerpiece of the empirical work is to show how one can plausibly understand these correlations.

On the other hand, interpreting U.S. inflation history is potentially much too easy an assignment. One's first impulse is to test the fiscal theory; perhaps to run some vector autoregressions (VARs) to see whether surplus shocks rather than monetary shocks affect the price level. However, I show that the fiscal theory per se has no testable implications for the joint time series of prices, debt, and surpluses. Briefly, the identity (1) holds, in equilibrium, whether fiscal or monetary considerations determine the price level. Therefore, one can always rationalize the price level by reference to debt and subsequent surpluses. Additional identifying assumptions are not easy to find in U.S. experience. For this reason, the main focus of the empirical work is to construct a plausible story for the time series rather than pursue a test. The fiscal theory does predict that open market operations should have little effect on the price level, and this implication is fairly easy to see in the data.

I construct a detailed dataset on total outstanding federal debt, broken down by maturity on a zero-coupon basis. I infer the surplus from debt transactions, rather than use accounting data. I start by documenting the patterns of surpluses, debt, and inflation in the U.S. since 1960 (when useful data start). I find some surprises. For example, the biggest primary deficit occurs in 1975, along with the onset of serious inflation. The 
primary "Reagan deficits" are surprisingly small, and even those are largely accounted for by the dramatic recessions of 1980-1982. I also find that fluctuations in the rate of return of government bonds are as large as fluctuations in surpluses, so the rate at which future surpluses are discounted may be as important to the present value of the surplus as are changing expectations about future surpluses. I find interesting variations in maturity structure, correlated with inflation: maturities were very short in the 1970s, but have lengthened since long-term bond sales were reemphasized in 1975 . Longer maturities have led to wider fluctuations in the rate of return on government debt, and they allow debt sales to immediately affect the price level.

The central issue is understanding fluctuations in the real value of the debt. The fiscal theory requires a forward-looking story: the value of the debt is determined by the present value of future surpluses. The standard story is backward-looking: the value of the debt is determined by the accumulation of past deficits and a money-determined price level. To tell the forward-looking story, I pursue models with exogenous surpluses that replicate important correlations in the data. The important ingredient of the models is that extra nominal debt sales in recessions must come with implicit promises to increase subsequent surpluses. Finally, I consider whether expected return variation and maturity structure are important elements of the story.

I ask what policies could have avoided postwar inflation. I find that fiscal policy already does a lot of price-level smoothing, and that variation in inflation comes from comparatively small failures to smooth. Even larger fluctuations in nominal debt would have been required to stabilize inflation; on the other hand, a $k \%$ rule would have resulted in disastrously fluctuating inflation.

\section{The Fiscal Theory of the Price Level}

\subsection{A SIMPLE FRICTIONLESS ECONOMY}

Start with a simple frictionless economy with one-period government debt. At the beginning of each period $t$, nominal bonds $B_{t-1}(t)$ are left outstanding from period $t-1$ and will mature at $t$. Bondholders can use the maturing bonds to pay net real taxes (net of government spending and transfers) $s_{t}$ or to acquire new bonds at price $Q_{t}(t+1)$. (I use capital letters for nominal quantities and lowercase letters for real quantities.) Accounting for the flow of bonds, then, we have

$B_{t-1}(t)-Q_{t}(t+1) B_{t}(t+1)=p_{t} s_{t}$. 
Fiscal price determination is easiest to see in a terminal period, or a period in which the government sells no new debt. Then, the budget constraint simplifies to

$\frac{B_{t-1}(t)}{p_{t}}=s_{t}$

Nominal debt $B_{t-1}(t)$ is predetermined, so the price level must adjust to equate the real value of the debt to the real value of surpluses that will retire the debt.

To extend the analysis to infinite-period economies, define the ex post real return on government bonds

$r_{t+1}^{b}=\frac{1}{Q_{t}(t+1)} \frac{p_{t}}{p_{t+1}}$.

Then we can write the accounting identity (2) as

$\frac{B_{t-1}(t)}{p_{t}}-\frac{1}{r_{t+1}^{b}} \frac{B_{t}(t+1)}{p_{t+1}}=s_{t}$.

Iterating forward and imposing the usual transversality condition or taking the limit of finitely lived economies with a terminal period described by (3), we obtain

$\frac{B_{t-1}(t)}{p_{t}}=\sum_{j=0}^{\infty} \prod_{k=1}^{j} \frac{1}{r_{t+k}^{b}} s_{t+j}$

These accounting identities hold ex post for each realization, so they also hold ex ante, after taking time-t conditional expectations. We can write

$\frac{B_{t-1}(t)}{p_{t}}=E_{t} \sum_{j=0}^{\infty} \prod_{k=1}^{j} \frac{1}{r_{t+k}^{b}} s_{t+j}$.

Equation (7) is the multiperiod analogue of (3). The price level adjusts to equate the real value of nominal debt to the present value of the surpluses that will retire it.

It is often a convenient simplification to assume a constant expected real return $r$ on government bonds. With this assumption, we can take expectations of (4) and find that the price of new debt is 
$Q_{t}(t+1)=\frac{1}{r} E_{t}\left(\frac{1}{p_{t+1}}\right) p_{t}$

the flow budget constraint is

$\frac{B_{t-1}(t)}{p_{t}}-\frac{1}{r} E_{t}\left(\frac{1}{p_{t+1}}\right) B_{t}(t+1)=s_{t}$

and the present-value budget constraint is

$\frac{B_{t-1}(t)}{p_{t}}=E_{t} \sum_{j=0}^{\infty} \frac{1}{r^{j}} s_{t+j}$

Equations (8) or (9) determine the sequence of prices $\left\{p_{t}\right\}$ given an exogenous sequence of surpluses $\left\{s_{t}\right\}$ and of nominal debt $\left\{B_{t-1}(t)\right\}$. I emphasize the determination of the sequence $\left\{p_{t}\right\}$ from the sequences $\left\{B_{t-1}(t), s_{t}\right\}$ to avoid an analysis that distinguishes between "date zero" events and subsequent history.

The reader may be uncomfortable that the rest of the economy is not specified-where are preferences, technology, and shocks? The answer is that a wide specification of models includes equations such as (8)-(9); those equations will determine the price level no matter what the rest of the economy looks like, so we don't have to spell it out.

"Budget constraint" is a poor term for equation (8) or (9). The whole point of the theory is that these equations are not constraints on the government's actions; instead they describe price-level determination. However, the form of these equations is so associated with the name "budget constraint" that I will continue to use this phrase to describe them.

The budget constraints become more complicated as one includes money (potentially held overnight despite an interest-rate penalty), long-term debt, and other realistic complications. In general, we add real or indexed assets and liabilities such as social security on the right-hand side, and other nominal claims including money and long-term debt to the left-hand side. Policy rules with feedback can be included, for example by writing $s_{t}\left(p_{t}, p_{t-1}, \ldots\right)$. Then one solves for the price-level sequence that solves the budget constraint at each date. In these more general situations, this solution for the price-level sequence will not be the same as the present-value budget constraint equation (9).

\subsection{INTERPRETATIONS}

The claim that fiscal considerations can determine the price level, even in a completely frictionless economy, is so strange at first that it merits closer 
examination. The fiscal mechanisms and equations apply to a wide variety of different institutional arrangements. Spelling out some of those arrangements makes fiscal price determination much more plausible and understandable, and makes it easier to apply the fiscal theory in practice.

\subsubsection{Money in Frictionless Economies A frictionless economy need not} be a cashless economy. The budget constraints and hence the price level are completely unaffected if the government redeems some maturing bonds for cash during the period, and if this cash rather than maturing bonds is used for transactions, tax payments, and the purchase of new bonds. The split between cash and maturing bonds at any moment in time-a form of open-market operation-similarly has no effect at all on the budget constraint and hence on the price level.

Furthermore, the government can provide cash elastically with no effect on the price level. If the government prints a dollar and issues it as an interest-free intraday loan, that dollar is used for transactions, and then the loan is repaid by the end of the day, the budget constraints are again unaffected. Since Fedwire transactions are netted at the end of the day, this is in fact close to the current institutional arrangement. Unlimited inside moneys-private claims to reserves, cash, or maturing government bonds-can also be created and used to make transactions, with no effect on the budget constraint and hence on the price level.

The above timing and budget constraints are the same as those in a cash-in-advance economy in which the security market is always open. One can add a cash-in-advance constraint that bonds must be exchanged for cash in order to make purchases with no effect on the price level. "Frictionless" means the security market is always open; transactions may still require cash. The friction in typical cash-in-advance models is that the security market is only open part of the day, requiring people to hold some cash overnight to make transactions.

\subsubsection{Commodity Standards Credible commodity standards or exchange-} rate pegs are intuitively transparent instances of the fiscal theory of the price level. The fiscal theory looks past the promised price level or exchange rate and past any official backing such as gold stocks or reserves to the overall real resources that in the end back the promises.

Suppose the government stands ready to exchange each dollar for a bushel of wheat, and that it maintains a warehouse with enough wheat to do so. The classical (100\% backed) gold standard embodies this idea. Currency boards that peg exchange rates are more recently popular implementations.

This regime would seem to nail the price level at $\$ 1 /$ bushel by 
arbitrage. Furthermore, the price level under a commodity standard is transparently immune to financial innovation. Any amount of privately issued, interest-paying, liquid assets or private banknotes can be created with no effect on the price level. Private banknotes are valued by their own fiscal theory, and may trade at a discount due to default risk. In a cashless economy, electronic claims to "dollars" are valued as claims to "one bushel wheat." Even monetary frictions are at most important for determining interest-rate spreads and quantities of liquid assets; they have no effect on the price level.

A commodity standard is an instance of the fiscal theory. Credibility is the crucial issue with a commodity standard or a peg. $100 \%$ backing regimes-warehouses full of wheat, a Ft. Knox full of gold, or a currency board holding foreign securities-are thought to provide such credibility, since the last dollar can be extinguished just as the backing vanishes. Such backing is an asset on the right-hand side of the budget identity, put there to guarantee that the budget constraint can always hold at the promised price level.

On closer inspection, however, we see that the overall government budget constraint is what really matters, not the backing, reserves, or the promised rate. For this reason, we write the fiscal theory with overall real resources on the right-hand side, not just whatever resources are explicitly devoted to backing. If a government is in financial trouble, it will try to appropriate the real assets or currency-board backing that is "uselessly" sitting in a warehouse, or (equivalently) it will devalue. On the other hand, a government with healthy finances can peg an exchange rate or commodity standard with no reserves-buying reserves on the spot market as needed, raising taxes, selling real assets, or borrowing against future surpluses to do so. Exchange-rate pegs do not fall to speculative attack when the government "runs out of reserves"; they fall apart when the government becomes unable or unwilling to buy reserves.

Furthermore, the government must back the entire stock of nominal debt, not just whatever currency is currently outstanding. For this reason, we write the fiscal theory with all government debt on the left-hand side, not just currency or the monetary base. If the currency outstanding is $100 \%$ backed, but there is a large stock of maturing nominal debt relative to real assets and current and future real surpluses, everyone can see that the backing promise or peg must soon be broken.

By pointing out that the overall budget matters and that all nominal debt must be backed, I do not mean to deny that $100 \%$ backing schemes, run by suitably independent agents with explicit rules and public accounting, are useful precommitment devices for government finance. These considerations do suggest however that their operation is really a 
matter of political economy or game theory, not, as is often argued, simple accounting.

\subsubsection{Tax and Demand Interpretations The fiscal theory of the price level} also formalizes an old view that fiat money is valued because the government requires its use for tax payments. Since the U.S. no longer follows an explicit commodity standard, a tax-based theory of value is a more plausible description of current institutions.

Consider a terminal period, or any period in which the government does not sell new debt. To tell the simplest story, suppose that the government redeems all the outstanding debt $B_{t-1}(t)$ for cash $M_{t}$ at the beginning of the period, and that the government has no assets or explicit backing left. Now, the budget constraint simplifies to

$$
\frac{M_{t}}{p_{t}}=s_{t}
$$

The government's surplus $s_{t}$ is the private sector's net real tax liability, which must be paid with cash.

Suppose the price level is too high. There is too little cash around to pay taxes, so taxpayers try to sell goods for cash, which lowers the price level. Alternatively, suppose the price level is too low. Taxpayers have more cash than they need to pay taxes, so they try to buy more goods, driving up the price level. The same story applies to the multiperiod model, strung out through time.

These stories have a familiar feel: Inflation results from too much money chasing too few goods; money is a hot potato that individuals can try to get rid of, but in aggregate such actions only change the price level. Intuition and observations that inflation occurs in periods of high "aggregate demand" for goods and services are perfectly consistent with a fiscal theory. The crucial change, and one that would be easy to miss in analyzing the data, is that an excess of cash is measured relative to tax liabilities that soak it up, not relative to a transactions-based demand.

A tax-based theory of value is also transparently immune to financial innovation: the economy may operate cashlessly, and/or any amount of inside liquid assets may be created, with no change in the price level. To operate cashlessly, the government can simply accept maturing government bonds directly for tax liabilities, or may electronically convert them to dollars for a nanosecond before accepting them. (This is what happens now if you pay your tax bill with a check on a money-market mutual fund.) Tax liabilities define dollars as a unit of account, and taxes 
give meaning to a bond's promise to pay 100 "dollars" at maturity in a cashless economy. Inside moneys do not matter, for in the end taxes must be paid with government-issued nominal claims. Like the commodity standard, the tax-based story suggests that even monetary frictions will have at best second-order effects on the price level: The basic valuation story is not much affected if people obtain money to pay taxes a day or two in advance, suffering an interest penalty.

2.2.4 A Stylized History and Dramatic Implications We started with a commodity standard. Then we realized that the overall real resources that back nominal debt matter in the end, not the promised redemption rate. Finally, when the resources are in place, the promise can vanish as well, as in the tax story.

This progression of ideas is also a useful stylized history. Early economies used raw metal or coins for transactions, and the price level was understood primarily in terms of the commodity content. Then, banknotes, checks, and government-issued paper claims to gold or silver were created. At first, people worried that these devices would not maintain their value relative to the commodity unit of account. However, $100 \%$ backed notes that explicitly promised redemption in commodity terms did in fact have stable values. Next, it was found that most of the backing was gathering dust in a warehouse. Why insist on $100 \%$ reserves? Despite reservations about price-level stability that remain to this day, it was gradually found that lower reserve ratios could be used and still maintain the value of the notes, if the issuing entity was in sound enough financial condition so that it could always purchase enough backing if required (and, often dramatically, not conversely). Eventually, the explicit promises in the form of the gold standard, also disappeared. Observers again worried (and still do) that removing the promise would lead to price-level explosion. But nothing worse than the slow postwar inflation has occurred in the United States.

The quantity theory offers an explanation for the last experience. In the quantity theory, an unbacked fiat money has value if and only if there is an inventory demand for it due to a special use in transactions, and if it and competing special assets are limited in supply. The price level did not explode when the gold standard was dropped, because its quantity-theoretic liquidity value already accounted for its value under the gold standard.

The fiscal theory offers an alternative explanation. In a fiscal theory, the backing is all that matters to a commodity standard in the first place. The price level did not explode when the gold standard was dropped, because it was already at its fiscal equilibrium level. A tax-based determi- 
nation of value has the additional advantage over the gold standard that the implicit "commodity" is the full basket of government purchases, so changes in the relative price of gold do not disturb the price level.

As described above, we are in the midst of a new round of financial innovation. Quantity theorists are once again worried that this new set of financial innovations will destabilize the price level. This worry has even led to proposals to limit financial innovation in order to maintain price-level control. However, the price level has remained remarkably stable given the level of financial innovation. At best, a quantity theorist explains this fact by noting that the Fed follows an interest-rate policy, allowing money supply to accommodate shifts in velocity. However, the shifts in velocity are not traceable to financial innovation. A fiscal theorist is not surprised: financial innovations should have no effect at all on the price level.

This argument has dramatic implications. The fiscal theory is at heart a repudiation of (at least) 100 years of the quantity theory, and a return to backing theories of the value of money. It denies any sharp distinction between commodity backing regimes and unbacked fiat money. Apparently unbacked fiat money can be valued, and apparently was all along, through the implicit backing of overall government surpluses.

While a promised exchange rate or price level does not matter to the theory, the theory will be easiest to apply when there is an explicit promise. Then, we just have to evaluate whether the promise is credible given current and future government revenues. When promises are implicit, as in the case of the U.S. economy, we can only look at the actual history of overall surpluses to see if the price level does indeed correspond to its fundamental backing.

\subsection{RICARDIAN AND NON-RICARDIAN REGIMES}

2.3.1 A Simple Example In the one-period example,

$$
\frac{B_{t-1}(t)}{p_{t}}=\mathrm{s}_{t}
$$

we can see right away a special case in which the fiscal theory may not determine prices. If the government sets a nominal surplus $S_{t}$ rather than a real surplus $s_{t}$, then the budget constraint is

$B_{t-1}(t)=S_{t}$

Either the government commits to redeem the outstanding stock of nominal debt, $S_{t}=B_{t-1}(t)$, or it does not, $S_{t} \neq B_{t-1}(t)$. In the former case the 
price level is indeterminate, while in the latter case no value of the price level can eliminate the discrepancy.

In fact, the government determines real rather than nominal surpluses. Nominal tax liabilities are given by a rate $\theta$ times nominal income, $\theta p y$, and thus real tax liabilities $\theta y$ are determined. If either the tax rate or the output is non-neutral, so that $\theta y$ declines one for one with $p$, we could have a Ricardian regime. But if anything, nominal tax brackets mean that the real tax rate $\theta$ is higher with a higher price level, and nonneutralities are usually thought to give higher output with higher price level. Perhaps more importantly, the limits on tax collection are real; the top of the Laffer curve is real, and government can't tax more than $100 \%$ of real GDP, no matter what the price level.

\subsubsection{Ricardian Regimes The above example with a fixed nominal surplus} is a Ricardian regime. [This is Woodford's (1995) terminology. Canzoneri, Cumby, and Diba (1997) call the same thing a money-determined regime.] If we think of the two sides of (11) as two curves (functions of price) that determine the price level, a Ricardian regime is the special case in which the curves happen to fall right on top of each other. A Ricardian regime is the fiscal analogue to interest-rate targets or accommodative moneysupply rules that can leave the price level indeterminate in the quantity theory. More generally, I use the following definition:

A Ricardian regime is any policy rule $\left\{B_{t}(t+j), s_{t}\right\}$ in which the sequence of government budget constraints holds for any sequence of price levels.

In an infinite-period context, when some new debt is sold every period, the present-value budget constraint is

$$
\frac{B_{t-1}(t)}{p_{t}}=E_{t} \sum_{j=0}^{\infty} \frac{1}{r^{j}} s_{t+j}
$$

If the surplus $\left\{s_{t+j}\right\}$ reacts to $p_{t}$ in such a way that (12) would hold for any $p_{t}$, then we have a Ricardian regime and (12) can no longer determine the price level. If the surplus does not react in just this way, then the price level must adjust to bring (12) into balance, and we have a fiscal regime.

2.3.3 The Quantity Theory as a Ricardian Regime The quantity theory is a particularly important case of a Ricardian regime. In the quantity theory, we add another equation, $M v=p y$. Fixing $v$ and $y$, and with government control of $M$, the quantity equation now determines the price level. (I 
discuss more general cases with varying velocity and interest-rate policies below.)

However, the budget constraint (12) is still part of the system. (Strictly speaking, one must account for the interest advantage to the government of money held overnight; I do so below, and the difference is not important to the current discussion.) Since nominal debt $B_{t-1}(t)$ and $p_{t}$ are now determined, the budget constraint is interpreted as a constraint on fiscal policy $\left\{s_{t+j}\right\}$. If the right-hand side of (12) is insufficient for a given real value of the debt, the government must raise future surpluses, by seignorage if explicit taxation is insufficient. Thus, the quantity theory is a Ricardian regime.

Quantity theorists have long recognized the tension between two equations, $M v=p y$ and the budget constraint, each of which seems to determine the price level. Therefore, fiscal considerations have long been important in the quantity theory. Sargent (1986) interprets Friedman's $k \%$ rules in part as a way of precommitting the monetary authority in a game of chicken with the Treasury over whether surpluses would be met by taxes or seignorage. Cash-in-advance models following Lucas (1980) (or see Sargent 1987, p. 162) explicitly rebate seignorage revenues. These models assume fiscal policies in which the government follows a Ricardian regime by choice, so that the budget constraint will not fight with the quantity theory for price-level determination.

In fact, the intellectual history of the fiscal theory comes precisely from thinking hard about the government budget constraint in the quantity theory. Leeper (1991), Sims (1994), and Woodford (1994) asked: what happens to a cash-in-advance model if the government does not choose to follow a fiscal policy that renders the budget constraint vacuous? As the above analysis shows, the budget constraint and a non-Ricardian regime can determine the price level in a cash-in-advance model, even if the security market is always open.

2.3.4 Equilibrium and Off-Equilibrium: Is a Fiscal Regime Possible? A long and rather confusing debate pervades the fiscal theory over whether the government must follow a Ricardian regime. We usually derive demand curves by having the auctioneer announce a price vector, and then finding utility- or profit-maximizing quantities that satisfy the budget constraint at those prices. Demands satisfy budget constraints, even at offequilibrium prices. This logic suggests that the government must adjust . future surpluses in response to an off-equilibrium price level, so there is a fundamental mistake in using the budget constraint as we do to determine the price level given surpluses. 
There must be a flaw in the reasoning: what happens if the auctioneer calls out such a low price level that the required surpluses are impossible, for example twice real GDP, forever? To think about this issue, return to a $100 \%$-backed commodity standard as an instance of a fiscal regime. One dollar equals one bushel of wheat. The government keeps a warehouse with enough wheat to back the entire nominal debt open 24 hours a day. Institutional arrangements are strong enough that the government can never raid the warehouse. This arrangement would seem to decisively nail the price level at $\$ 1 /$ bushel. Yet a Ricardian regime advocate would argue that it does nothing to determine the price level. He would argue that if the Walrasian auctioneer were to announce a price of $\$ 0.50$ per bushel, the government would not have enough wheat to back the debt. It would then be forced to raise taxes to obtain more wheat, selling it at and validating the lower price.

In the example, it's easy to see that the argument is false. There is nothing that prevents the government from sticking to a $\$ 1 /$ bushel redemption rate no matter what the auctioneer or secondary market announces. If the secondary market price is $\$ 0.50$, the government will buy lots of wheat; but there is no limit to the amount of nominal bonds or cash it can create in exchange for wheat. On the other hand, if the secondary-market price is $\$ 2$, the government will sell lots of wheat at $\$ 1$. The last ounce of wheat leaves the warehouse just as the last cent of nominal government debt is redeemed. The policy might seem foolish: the government wastes resources by selling wheat at $\$ 1$ when the secondary market price is $\$ 2$, or by buying it at $\$ 1$ when the secondary market price is $\$ 0.50$. But the argument is about constraints, not objectives; if the government wants to freely buy and sell at $\$ 1 /$ bushel, there is no constraint that stops it from doing so.

The argument does not hinge on the commodity standard or promised redemption rate. Suppose there are 100 bushels of wheat in the warehouse, $\$ 100$ in notes outstanding, and no further taxes or assets on the last day of an economy, but the government will accept its notes for wheat at the market (auctioneer) price rather than posting a price. If the market price is $\$ 2 /$ bushel, the government will wind up with unsold wheat at the end of the day. If the price is $\$ 0.50 /$ bushel, the government may run out of wheat before consumers have redeemed all the money. There is nothing wrong with either outcome. The government can certainly waste or consume wheat at the end of the period. Similarly, the budget constraint must allow consumers to keep some money. The facts that money is not intrinsically valuable to consumers and that wheat is not valuable to the government must be reflected in preferences, not constraints. 
The mistake, from a Walrasian view, is in insisting that government debt must be paid off because of budget constraints. The government starts with an endowment of wheat, and consumers start with an endowment of money. The budget constraint says that trades away from the endowment points must take place at or at worse than market (auctioneer) prices. This constraint is satisfied in both of the above examples.

What about previous dates, at which the money is issued or bonds are sold? The same points extend to multiperiod models. Though money and bonds at each date are the result of previous period's trades, we always come down to an initial period with endowments outstanding, and then each period markets reopen as if the previous period's outcomes were endowments.

Similarly, there is a longstanding suspicion that one must assume something special about a government in a fiscal theory; that the government is a special agent that can announce demands that do not satisfy budget constraints or repay debts at off-equilibrium prices; that it enjoys a special first-mover status in some game with the private sector. As the examples make clear, there is nothing special about the government. If I give away 100 IOUs saying "John Cochrane will pay the bearer $\$ 1$ on demand," I have $\$ 100$ in my wallet that I will only use for repaying IOUs, and all this is perfectly credible, visible, etc., I can nail the price of my IOUs at $\$ 1$ each. If for some reason they become worth more (if the auctioneer announces a different price), I can (and will!) print up IOUs like mad; if they become worth less I can redeem them all. I may not choose to, but I can. I can also issue "equity claims on John Cochrane's wallet," and then repurchase them via auction. If the auctioneer announces the wrong price, I can leave the room when IOUs or dollars in my wallet run out.

In the same way, private entities as well as multiple governments can create nominal claims, with or without explicit promises about redemption in dollars or real baskets of goods. The only special thing about the government is the convention or legal restriction that the rest of the economy uses its IOUs as numeraire.

This is reassuring. If we relied on the government being able to violate budget constraints, nonsensical conclusions would follow. The government could announce lots of spending and zero taxes, ${ }^{1}$ the budget constraint be damned.

1. I thank Larry Christiano and Martin Eichenbaum for repeatedly stressing this point, when I thought one did have to assume something special about the government. 


\subsection{TESTING FOR FISCAL DETERMINATION}

Even though governments can follow non-Ricardian regimes in which fiscal theory determines the price level, they may not choose to do so. Looking forward to our task of bringing a fiscal theory to data, one's natural impulse is to "test" the fiscal theory, and the natural "test" is whether the government has chosen to follow a Ricardian or a nonRicardian policy regime.

Unfortunately, the fiscal theory of the price level per se has no testable implications for the time series of debt, surplus, and price level.

The budget constraint (12) holds in equilibrium for both fiscal and Ricardian regimes. The issue is whether, in determining or adjusting towards equilibrium, the price level adjusts to expected future surpluses, or whether the path of surpluses adjusts in response to the price level. All we ever observe is an equilibrium; we do not observe who adjusted to bring about that equilibrium, or what off-equilibrium behavior looks like. Analogously, if one observes a market, one sees the transactions price and quantity, but not the slopes of the underlying supply and demand curves.

It is tempting to test "who adjusted" by looking at dynamic responses to shocks as in a VAR. But the (state-contingent) sequence of price levels, surplus, and debt $\left\{p_{t}, s_{t}, B_{t-1}(t+j)\right\}$ is a single equilibrium. It is not a sequence of equilibria, and even less a tatônnement process for the formation of an equilibrium. The issue is which sequence, $\left\{p_{t}\right\}$ or $\left\{s_{t}\right\}$, adjusts to the other sequence, not whether shocks to $p_{t}$ precede those to $s_{t}$ in an equilibrium sequence.

Woodford's (1995) analysis argues even more strongly that a test for fiscal determination is meaningless. As I will review below, Woodford argues that all monetary regimes (money demand specification and monetary policy rule) that are vaguely plausible descriptions of the U.S. economy leave the price level indeterminate. Therefore, Woodford's analysis implies that if the price level is determined at all it must be determined by fiscal means. There is no coherent alternative.

Clear as these points are in the abstract, it is helpful to apply them to empirical approaches one might attempt and see how those approaches break down.

\subsubsection{Feedback Rules?}

FEEDBACK RULES TO GENERATE RICARDIAN REGIMES We often think of policy in terms of rules plus innovations. Fixing a nominal surplus is equivalent to a feedback rule $s_{t}\left(p_{t}\right)=S_{t} / p_{t}$ that increases the real surplus 
$1 \%$ for every $1 \%$ decrease in the price level. The budget constraint in the one-period case now reads

$\frac{B_{t-1}(t)}{p_{t}}=s_{t}\left(p_{t}\right)=\frac{S_{t}}{p_{t}}$

and the price level drops out as before. We can also think of this case as a commitment to adjust the real surplus to soak up the real value of outstanding debt, a rule $s_{t}=B_{t-1}(t) / p_{t}$.

We retain fiscal price-level determination if the government follows a policy rule with some feedback, so long as the feedback is not exactly one-for-one. If the government responds linearly to real debt,

$s_{t}=s+\alpha \frac{B_{t-1}(t)}{p_{t}}$,

only the case $s=0, \alpha=1$ implies that the budget constraint is vacuous.

In an infinite-period context with one-period debt, the constraint is

$$
\frac{B_{t-1}(t)}{p_{t}}=E_{t} \sum_{j=0}^{\infty} \frac{1}{r^{j}} s_{t+j}
$$

The constraint holds for any price level and the regime is Ricardian if $\left\{\Sigma_{j=0}^{\infty}\left(1 / r^{j}\right) s_{t+j}\right\}$ reacts to $p_{t}$ in a one-for-one manner.

It is more common to think about feedback rules for the one-period surplus than rules for the discounted value of future surpluses. Generally speaking, policies in which surpluses adjust to the price level in such a way that real debt does not grow faster than the real interest rate generate a Ricardian regime. The constraint

$\frac{B_{t-1}(t)}{p_{t}}=\sum_{j=0}^{k} \prod_{t=1}^{j} \frac{1}{r_{t+l}^{b}} s_{t+j}+\prod_{t=1}^{k} \frac{1}{r_{t+l}^{b}} \frac{B_{t+k}(t+k+1)}{p_{t+k}}$

holds as an accounting identity, and if the last term or its expectation converges to zero for any $p_{t}$, the budget constraint holds for any $p_{t}$. This statement is the natural infinite-period counterpart to the one-period example in which real surpluses adjust to soak up the real value of the debt.

As a specific example, consider linear feedback rules that raise the surplus in response to increases in real debt: 
$s_{t}=\alpha \frac{B_{t-1}(t)}{p_{t}}+\epsilon_{t}$

The one-period identity is then

$\frac{B_{t}(t+1)}{p_{t+1}}=r_{t+1}^{b}\left(\frac{B_{t-1}(t)}{p_{t}}-s_{t}\right)=r_{t+1}^{b}(1-\alpha) \frac{B_{t-1}(t)}{p_{t}}+r_{t+1}^{b} \epsilon_{t}$.

Thus, any $\alpha>0$ implies real debt that grows at a rate less than the interest rate and so a Ricardian regime.

One may wish to be a bit more restrictive, if one wants to consider only infinite-period results that are the limits of finite-lived economies. If $0<\alpha<r-1$, real debt still explodes, though at a rate less than the interest rate. Feedback $\alpha \geqslant r-1$ is necessary to keep real debt bounded, and $\alpha \geqslant r-$ (GDP growth) is necessary to keep the debt/GDP ratio bounded. Canzoneri, Cumby, and Diba (1997) derive these results as special cases of considerably more general feedback rules.

TESTING FEEDBACK RULES? Given these feedback restrictions, it is natural to test for a Ricardian regime by running regressions of surpluses on real debt to see if surpluses do adjust enough in response to real debt. The trouble is, this is always true in the data. In the one-period context, the constraint

$s_{t}=\frac{B_{t-1}(t)}{p_{t}}$

does hold, in equilibrium. We cannot tell which variable-p or $s-$ adjusted to the other in order to produce the equilibrium. We could run the regression with $s$ on the left and interpret the results as an estimation of (13), giving the Ricardian result, or we could put $p$ on the left and interpret the result as confirmation of fiscal price determination from $B$ and $s$.

Similarly, it is tempting in an infinite-period context to run a regression of (14), and test whether surpluses adjust to the value of debt, $\alpha>0$ (or $\alpha$ $>r-1)$. Alas, this coefficient again tells us nothing about the regime. For example, suppose the surplus is completely exogenous, $s_{t}=\rho s_{t-1}+\epsilon_{t}$ and $B$ is constant. In a "fiscal" regime, prices are then

$p_{t}=\frac{B_{t-1}(t)}{E_{t} \sum\left(1 / r^{\prime}\right) s_{t+j}}=\frac{B}{s_{t}}\left(1-\frac{\rho}{r}\right)$ 
In this example, a low surplus leads to a low real value of the debt,

$\frac{B}{p_{t}}=\frac{1}{1-\rho / r} s_{r}$

But one could easily put $s$ on the left and, mistakenly, find a surplus feedback rule that generates a Ricardian regime. I give an explicit example below in which an exogenous surplus process generates a VAR in which debt forecasts future surpluses.

FEEDBACK ON EQUILIBRIUM VS. OFF-EQUILIBRIUM PRICE LEVELS Even more fundamentally, the government can distinguish the nominal quantity of debt from the price level. Therefore, it can follow a policy which systematically responds to the real value of debt for the equilibrium price level while refusing to validate out-of-equilibrium price levels.

To give a precise example, suppose the government wants to attain a price level $p^{*}$. It may follow a one-for-one feedback rule, promising to change taxes so as to soak up the real value of any debt $B_{t-1}(t)$ that happens to be outstanding due to stochastic variation in debt or surplus along the way -it may follow the feedback rule $s_{t}=B_{t-1}(t) / p^{*}$. However, it does not promise to validate an out-of-equilibrium price $p_{t} \neq p^{*}$; it will not change taxes to $s_{t}=B_{t-1}(t) / p_{t}$ for $p_{t} \neq p^{*}$. We observe a one-for-one feedback rule, over time and across states of nature, but the price level is determinate at $p^{*}$.

2.4.2 AVAR? With words like "exogeneity" and "causality" around, it is tempting to examine "who adjusts" in the context of a VAR, watching the response of variables to innovations. But again, since we are watching the evolution over time of one equilibrium, a fiscal regime poses no restrictions on such VARs.

A SUGGESTION BASED ON THE SURPLUS $\rightarrow$ DEBT RESPONSE FUNCTION Canzoneri, Cumby, and Diba (1997) propose the following test for a fiscal regime. If a positive surplus shock leads to higher surpluses but lower real value of the debt, they find a Ricardian or "money-determined" regime. If it leads to higher real value of the debt, they find a nonRicardian or "fiscal-determined" regime. Not surprisingly, they find that positive shocks to surpluses reduce the real value of debt, and hence a "money-determined" regime.

These restrictions flow from the central idea that the value of the debt is forward-looking in the fiscal theory (debt is the present value of future 
surpluses) and backward-looking in a Ricardian or monetary regime (debt is the accumulation of past surpluses). Denote the real value of debt by $v_{t+1}=B_{t}(t+1) / p_{t+1}$. Then, the identity

$v_{t+1}=r_{t+1}^{b}\left(v_{t}-s_{t}\right)$

motivates the idea that a positive surplus shock should lower next period's real debt. The time- $(t+1)$ present-value constraint

$v_{t+1}=E_{t+1} \sum_{j=0}^{\infty} \frac{1}{r^{j}} s_{t+1+j}$

motivates the idea that a positively autocorrelated surplus shock should raise the real value of the debt.

One should of course be suspicious, since both equations hold in both regimes. In fact, the response-function sign prediction requires a different surplus driving process, not a difference in regime. The time-t present-value constraint is

$v_{t}=\frac{B_{t}(t)}{p_{t}}=E_{t} \sum_{j=0}^{\infty} \frac{1}{r^{j}} s_{t+j}$.

$B_{t}(t)$ is predetermined. In a money-determined regime, the price level is set by $p_{t}=M_{t} v / y$ and therefore does not change. If $s_{t}$ rises and $\left\{E_{t} s_{t+j}\right\}$ do not decline, the budget constraint no longer holds. The only way to salvage the budget constraint is if the Fed agrees to monetize-if $M$ moves with the innovation in $s$-producing exactly the price-level rise that would be predicted by the fiscal theory. Then, the ex post real interest rate in (15) adjusts so that the real value of the debt can rise next period. If the Fed does not monetize the deficit, future surpluses must decline.

\subsubsection{Budget Explosions? Hamilton and Flavin (1986) pursue interesting} tests for present-value budget balance. Essentially, they test whether the debt or debt/GDP ratio is explosive. This seems a natural test for a nonRicardian regime. But the non-Ricardian regime only specifies explosive paths for real debt (the infinite-period counterpart to resources or money left at the end of single period economies) in response to never observed, off-equilibrium prices. In equilibrium, the budget constraint holds, and we do not observe explosive debt. 
2.4.4 Identification and Nontestability It may seem that I have made too much of the lack of testable restrictions. The pure quantity theory does not have testable implications either: $M v=p y$ is also an accounting identity-a definition of velocity. It too requires additional assumptions; that velocity is not affected by some variable or shock; that some monetary or income shocks are exogenous, etc. Every economic theory requires some extra assumptions; why pick on the fiscal theory?2

With identifying assumptions, the fiscal theory does make predictions. Again, look at the budget constraint,

$$
\frac{B_{t-1}(t)}{p_{t}}=E_{t} \sum_{j=0}^{\infty} \frac{1}{r i} s_{t+j}
$$

If we could find a shock to nominal debt that leaves future surpluses unchanged, the fiscal theory does predict that the price level should rise. If we find a shock to surpluses with no effect on nominal debt, the price level should decline. Shocks to the composition of nominal debt that leave its value the same, such as open-market operations, should have no effect on the price level if they are not associated with changes in future surpluses.

All of these are valid predictions of the theory. The trouble is that the constraint (16) holds under all of the alternatives as well. For example, the quantity theory includes $M v=p y$ and the constraint (16). A shock to nominal debt with no change in future surpluses must come with just enough increase in $M$ to give the same price-level prediction as the fiscal theory; if not, the shock must lead to a change in future surpluses. If one showed that neither happened, then one could reject the $M v=p y$ part of the quantity theory. But there is no way to reject the fiscal part of the theory.

\subsection{UNCERTAINTY AND LONGER-MATURITY DEBT}

So far, I have simplified the analysis by assuming one-period debt. In addressing the data, it is important to consider longer-maturity debt as well. In perfect-foresight models, the addition of long-term debt makes no difference, but with uncertainty, long-term debt changes the fiscal theory in some crucial ways. For example, news of future deficits can be met by a decline in long-term bond prices rather than by a rise in the price level.

\section{I thank Benjamin Friedman for raising this point emphatically at the conference.}


2.5.1 Statement of the Budget Constraints Suppose a full spectrum of bonds is outstanding at the beginning of period $t$, and let

$B_{t-1}(t+j)=$ bonds outstanding at the beginning of $t$ that mature at $t+j$, $Q_{t}(t+j)=$ price at $t$ of bonds that mature at $t+j$.

Again, we start from the accounting identity that just-maturing bonds plus net revenue from the purchase or sale of long-term bonds must add up to the nominal net-of-interest surplus,

$B_{t-1}(t)-\sum_{j=1}^{\infty} Q_{t}(t+j)\left[B_{t}(t+j)-B_{t-1}(t+j)\right]=p_{t} s_{t}$.

We can express the ex post real rate of return on government bonds equivalently as (value at tomorrow's prices) /(value today) or as a weighted sum of individual bond returns. The generalization of (4) is thus

$$
\begin{aligned}
r_{t+1}^{b} & \equiv \frac{p_{t}}{p_{t+1}} \frac{\sum_{j=1}^{\infty} Q_{t+1}(t+j) B_{t}(t+j)}{\sum_{j=1}^{\infty} Q_{t}(t+j) B_{t}(t+j)} \\
& =\frac{p_{t}}{p_{t+1}} \sum_{j=1}^{\infty} \frac{Q_{t+1}(t+j)}{Q_{t}(t+j)} \times \frac{Q_{t}(t+j) B_{t}(t+j)}{\sum_{k=1}^{\infty} Q_{t}(t+k) B_{t}(t+k)}
\end{aligned}
$$

If we write the real value of the debt

$v_{t}=\frac{\sum_{j=0}^{\infty} Q_{t}(t+j) B_{t-1}(t+j)}{p_{t}}$

then our earlier identities (5) and (6) still hold:

$$
\begin{aligned}
& v_{t}=\frac{1}{r_{t+1}^{b}} v_{t+1}+s_{t \prime} \\
& v_{t}=\sum_{j=0}^{\infty}\left(\prod_{k=1}^{j} \frac{1}{r_{t+k}^{b}}\right) s_{t+j} .
\end{aligned}
$$

It is again often convenient to assume that the real rate of interest is a constant $r$ both across time and bonds. Then, again using $Q_{t}(t+j)=1 / r^{i} \times$ $E_{t}\left[p_{t} / p_{t+j}\right]$, the identities simplify to, first, (value of maturing bonds) (revenue from new bond sales) = surplus, 
$\frac{B_{t-1}(t)}{p_{t}}-\sum_{j=1}^{\infty} \frac{1}{r^{j}} E_{t}\left(\frac{1}{p_{t+j}}\right)\left[B_{t}(t+j)-B_{t-1}(t+j)\right]=\mathbf{s}_{t}$

and second, (value of outstanding debt) = (present value of surpluses),

$v_{t}=\frac{B_{t-1}(t)}{p_{t}}+\sum_{j=1}^{\infty} \frac{1}{r^{j}} E_{t}\left(\frac{1}{p_{t+j}}\right) B_{t-1}(t+j)=E_{t} \sum_{j=0}^{\infty} \frac{1}{r^{j}} \mathrm{~s}_{t+j}$.

2.5.2 Solving for Prices in Terms of Debt Policy and Surplus With only oneperiod debt, equation (20) expressed the price level at $t$ in terms of the present value of future surpluses. It was also a solution for the equilibrium price-level sequence $\left\{p_{t}\right\}$ in terms of exogenous debt and surplus paths $\left\{B_{t}(t+j), \mathrm{s}_{t}\right\}$. With long-term debt, future $p_{t+j}$ enter into the equation on the left-hand side, not just $p_{i}$. Therefore, we have to work more to get an expression with $p_{t}$ on the left and other variables on the right.

Cochrane (1998) derives the general solution for the price-level sequence $\left\{p_{t}\right\}$ given any surplus and debt path. The general formula is rather cumbersome. To get a flavor of some of the possibilities, we can directly solve three special cases, generated by three special types of debt policy:

1. One-period debt. If the government follows a policy of always rolling over one-period debt, $B_{t}(t+j)=0$ for $j>1$, then equation (20) reduces to

$$
\frac{B_{t-1}(t)}{p_{t}}=E_{t} \sum_{j=0}^{\infty} \frac{1}{r^{j}} s_{i+j}
$$

2. No new debt. Suppose the government does not issue new debt, but pays off existing debt (perhaps a perpetuity) as it matures. Then we have $B_{t}(t+j)-B_{t-1}(t+j)=0$, and equation (19) becomes

$$
\frac{B_{t-1}(t)}{p_{t}}=\mathbf{s}_{t}
$$

The price level is now set only by debt that comes due each day and that day's surplus.

3. Geometric maturity structure. Suppose the government commits to a maturity structure

$$
B_{t-1}(t+j)=\phi^{j} B_{t+j-1}(t+j) .
$$


Then (19) or (20) implies

$$
\frac{B_{t-1}(t)}{p_{t}}=s_{t}+(1-\phi) \sum_{j=1}^{\infty} \frac{1}{r^{j}} E_{t}\left(s_{t+j}\right),
$$

which nicely nests (21) and (22).

We have spent so much time looking at equations like (21) that these examples are worth examining closely: It is not generally true that each period's price level is determined by the value of all debt relative to the present value of surpluses. The latter conclusion is a very special case that comes entirely from the restriction that short-term debt is continuously rolled over.

2.5.3 Reaction to News of Surpluses To understand the effects of longterm debt, let us ask how the price level reacts if there is bad news about future surpluses. With one-period debt, the answer is simple: the price level must rise today, and we have

$$
\frac{B_{t-1}(t)}{p_{t}}=E_{t} \sum_{j=1}^{\infty} \frac{1}{r} s_{t+j}
$$

so if $E_{t} s_{t+j}$ declines, $p_{t}$ must rise.

With long-term debt, the equation (value of debt) $=($ present value of surpluses) is instead, from (20),

$$
\frac{B_{t-1}(t)}{p_{t}}+\sum_{j=1}^{\infty} \frac{1}{r^{j}} E_{t}\left(\frac{1}{p_{t+j}}\right) B_{t-1}(t+j)=\sum_{j=0}^{\infty} \frac{1}{r^{j}} E_{t} s_{t+j} .
$$

Now when expected future surpluses decline, expected future prices $p_{t+j}$ can rise to reestablish the budget constraint. Equivalently, the real or relative price of long-term debt, $q_{t}(t+j)=\left(1 / r^{j}\right) E_{t}\left(1 / p_{t+j}\right)$, can decline.

Which of these possibilities happens? The answer depends on debt policy, $\left\{B_{t-1}(t+j)\right\}$. For example, in the extreme case that the government sells no new debt, equation (22) shows that a decline in surpluses at date $t+j$ has no effect on the price level at time $t$. It affects only the price level at $t+j$, and hence only the price of outstanding $t+j$ bonds at time $t$. The geometric case gives an intermediate result. 
2.5.4 Reaction to Debt Sales What happens if at period $t$, the government issues more debt, with no change in surpluses? If no long-term debt is outstanding, again, the price level at $t$ is set by

$$
\frac{B_{t-1}(t)}{p_{t}}=E_{t} \sum_{j=1}^{\infty} \frac{1}{r^{j}} s_{t+j}
$$

Hence, a change in $B_{t}(t+1)$ has no effect on the price level at period $t$. It does affect the price level at $t+1$ :

$\frac{B_{t}(t+1)}{p_{t+1}}=E_{t+1} \sum_{j=1}^{\infty} \frac{1}{r^{j}} s_{t+1+j}$

so every $1 \%$ increase in debt sold at $t$ translates into a $1 \%$ increase in the price level at $t+1$.

We can describe this result as a unit-elastic demand curve for nominal debt at each date: extra debt sales simply drive down the price of debt, and the real revenue raised by bond sales is independent of the number sold. To see this, write the real value of debt at the end of time $t$ as

$q_{t}(t+1) B_{t}(t+1)=\frac{1}{r} E_{t}\left(\frac{1}{p_{t+1}}\right) B_{t}(t+1)$.

From (26), the quantity $B_{l}(t+1) / p_{t+1}$ is the same no matter what the level of debt sales $B_{t}(t+1)$, if surpluses do not change.

With long-term debt outstanding, unexpected long-term bond sales with constant surpluses can raise revenue and thus lower the price level. Unexpected debt sales dilute the claims of existing long-term debt to the real resources that will be available to redeem debt on the maturity date. This is an attractive story for the association of declining inflation and rising long-term debt in the early 1980s, or for the fact that inflation often moderates in recessions when long-term debt sales are particularly high.

\subsection{MONETARY FRICTIONS}

2.6.1 Money Demand in the Fiscal Theory The essence of the fiscal theory does not involve money or monetary frictions. Since we have spent so much time thinking about money, however, it is important to verify that adding money back in to a fiscal regime does not alter the basic story of price-level determination.

We have already considered how money can be added to a fiscal and frictionless regime. Here, we consider how monetary frictions affect a fiscal regime. Above, people could use money for transactions during 
the day, but nobody held non-interest-paying money overnight. Now assume they may; the security market may not always be open, so money for the next day's purchases must be held overnight, or real (overnight) money balances may enter the utility function.

The summary is simple: If monetary considerations can determine the price level, they do. If $M v=p y$ holds, with constant $v$ and wellcontrolled $M$, and if the Treasury adapts fiscal policy to the moneydetermined price level, the fiscal theory has little to say. However, in most monetary models that describe anything like modern institutions, monetary considerations alone do not determine the price level. In this case, the fiscal theory determines the price level, leaving monetary frictions at best to determine quantities or interest-rate spreads for liquid assets. As monetary considerations get weaker, fiscal considerations get stronger. This is the central point of Woodford (1995), and much of this section is a simplified version of Woodford's analysis.

Introduce money, and let $M_{t}$ denote money balances held overnight from time $t$ to time $t+1$. For simplicity, revert to one-period debt. The flow budget constraint now reads

$B_{t-1}(t)-\frac{B_{t}(t+1)}{R_{t}}+M_{t-1}-M_{t}=p_{t} s_{t}$

where $R_{t}=1 / Q_{t}(t+1)$ denotes the nominal interest rate. A useful form of the present-value budget constraint is

$\frac{B_{t-1}(t)}{p_{\imath}}=E_{t} \sum_{j=0}^{\infty} \frac{1}{r^{j}}\left(s_{i+j}+\frac{M_{t+j}-M_{t+j-1}}{p_{t+j}}\right)$.

In this form we see how money can introduce potential seignorage revenues. Consider a simple money demand function,

$M_{t} v\left(R_{t}\right)=p_{t} y_{t}$.

Now, why doesn't control of the money supply, plus the money demand equation (29), determine the price level?

CONSTANT VELOCITY In the most simplified quantity-theoretic tradition, it does. If the money supply is controlled, and if velocity is independent of interest rates, $M v=p y$ determines the price level $p$. If this price level agrees with the government budget constraint, fine. If it does not, one of the two determinants of the price level must give way. As we have seen, 
most users of this model specify that the government chooses a $\mathrm{Ri}$ cardian fiscal policy in which the budget adapts.

VARYING VELOCITY Truly constant velocity, in the face of arbitrarily large interest differentials, is an extreme and unlikely assumption. With an interest-elastic demand and fixed supply, money demand can still determine the expected rate of inflation or expected price level, but it does not determine the (ex post) price level. The government budget constraint then determines the price level.

For example, write money demand

$\ln M_{t}=\ln p_{t}+\ln y-b\left(\ln r+E_{t} \ln p_{t+1}-\ln p_{t}\right)$.

Assume constant output and real interest rate, and fixed money supply. Now, (money demand) $=$ (money supply) gives a log-linear difference equation for the price level, and hence pins down the rate of inflation at each date,

$E_{t} \ln p_{t+1}=\frac{1+b}{b} \ln p_{t}+\frac{1}{b}\left(\ln y-\ln M_{t}\right)-\ln r$.

Depending on the initial price level $p_{t}$, there are an infinite number of paths that satisfy this difference equation. It is conventional to pin down the price level as the nonexplosive solution,

$\ln p_{t}=\sum_{j=0}^{\infty}\left(\frac{b}{1+b}\right)^{j} \frac{1}{1+b}\left(E_{t} \ln M_{t+j}-\ln y-b \ln r\right)$.

But this choice is an extra condition, not derived from money demand, optimization, or any other principle. We may be able to rule out real quantities that grow faster than the real rate of interest, but nominal quantities may happily explode.

With a non-Ricardian fiscal regime, the budget constraint pins down the (ex post) price level at each date. If that choice implies an explosive expected future price level despite constant money supply, so be it. As Woodford (1995) notes, if we do not observe exploding price levels with constant money supply, that just means that governments do not follow constant-money-supply policies in the face of exploding price levels.

VARYING VELOCITY; MONEY PAYS INTEREST (Money demand) $=$ (money supply) really determines the interest differential between monetary and nonmonetary assets. In the above example, the convention that money 
pays no interest then means that (money demand) $=$ (money supply) must determine the inflation rate. If monetary assets pay interest $R_{t}^{m}$, however, as more and more monetary assets do, then the money demand equation becomes

$M_{t} v\left(R_{t}-R_{t}^{m}\right)=p_{t} y_{t}$

Now the price level at each date can be entirely determined by the fiscal condition (28). (Money demand) = (money supply) only affects the interest differential between money and other assets.

INTEREST-RATE TARGETS The money-supply regime matters as well as money demand. For example, even with $M v=p y$, monetary considerations alone do not determine the price level if money supply is sufficiently accommodative. Then, the government budget constraint can do so. A nominal-interest-rate target is the classic example. If the government provides whatever quantity of money is necessary for the nominal interest rate to equal $R$, then $M v(R)=p y$ determines $M / p$ but not the level of either $M$ or $p$.

2.6.2 Why Abandon Frictions for Studying Inflation? I use the fiscal theory to avoid monetary frictions altogether in the study of the price level, rather than follow the above style of analysis and the bulk of the fiscaltheory literature including Woodford (1995, 1996, 1997), Leeper (1991), Sims (1994), Dupour (1997), and Schmitt-Grohé and Uribe (1997), by including standard theoretical devices for generating monetary frictions. I argued in the introduction that these frictions have at best secondorder implications for the price level, as we have seen, and that they are not a realistic or empirically successful description of the U.S. economy. Here, I document the latter claims. Of course, monetary and other frictions will be important to financial economists and practitioners who want to study interest-rate spreads among liquid assets. Similarly, one will have to specify some frictions in order to be precise about why we care about inflation.

NO EXPLANATION FOR INFLATION Figure 1 presents the history of CPI inflation together with growth in the popular monetary aggregates. The history of business-cycle and even decade-long variation in inflation has essentially nothing to do with the history of monetary aggregates. The swings of inflation in the 1970s and especially the dramatic end of inflation in the early 1980s occurred without any obvious corresponding changes in monetary growth. If anything, M1 and M2 growth are negatively correlated with inflation in the 1970s, requiring artfully specified 
Figure 1 INFLATION AND GROWTH IN MONETARY AGGREGATES

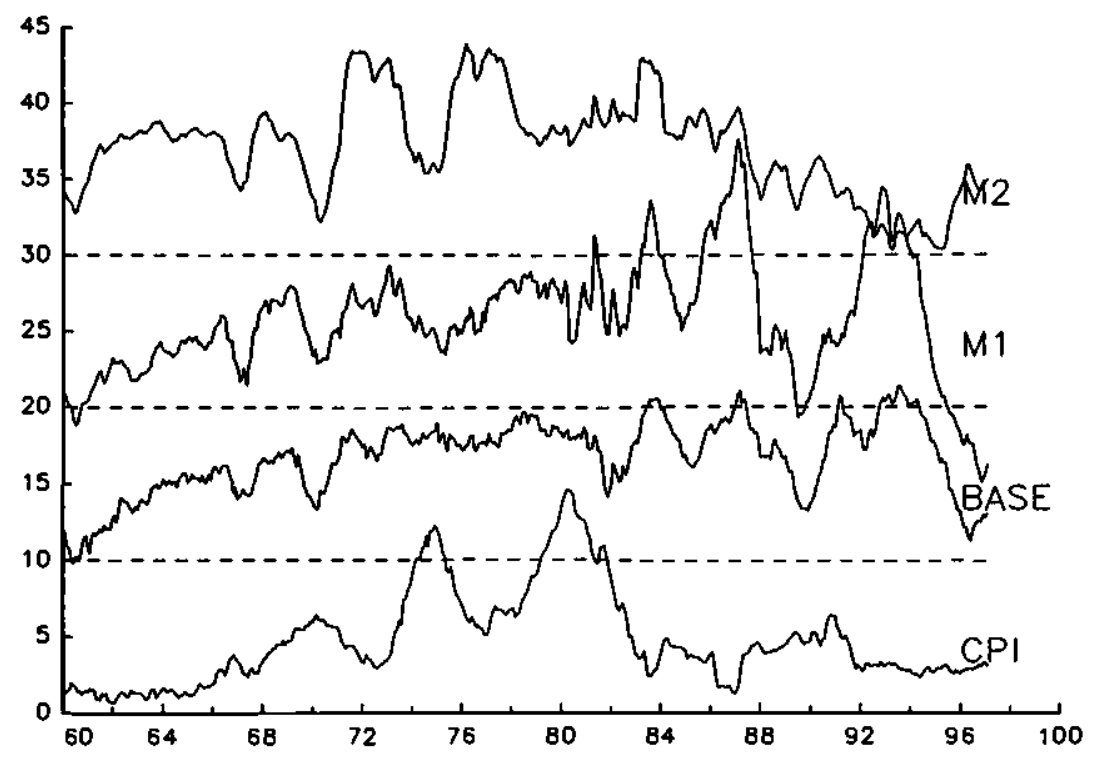

All series are monthly observations of annual growth rates. Base, M1, M2 are shifted up for clarity.

long and variable lags if one is going to insist that money growth caused the inflation. Base and M1 growth were much more volatile in the 1980s and 1990 s with stable inflation than they were when inflation was more volatile in the 1970s.

Monetary VARs provide a more formal accounting of variation. Despite a wide range of monetary policy indicators, identification schemes, and specifications, such VARs regularly assign trivial fractions of pricelevel variance to monetary shocks, and almost all to "price shocks." Cochrane (1994b) surveys this literature. As a specific example, Table 1 is an abridged version of Tables 3 and 4 from Christiano, Eichenbaum, and Evans's (1998) survey. Note in particular that federal-funds-rate shocks in the top left quadrant explain essentially no price variation. Therefore, the VARs refute the standard analysis that price variation results from unusually "tight" or "loose" interest-rate policy.

Since the total quantity of nominal debt appears on the left-hand side of the budget constraint, the irrelevance of open-market operations to the price level is an obvious fiscal proposition. Of course, exact irrelevance is a special case. Open-market operations do slightly alter the maturity structure of the debt, which can affect the timing of inflation; 
open-market operations can change the rate of return on government debt; open-market operations result in tiny but nonzero seignorage; and open-market operations may forecast changes in surpluses and so inherit a noncausal association with inflation.

To check whether monetary shocks forecast surpluses, Table 2 presents regressions of the surplus data described below on Christiano, Eichenbaum, and Evans's federal funds shock. With negative $R^{2}$ and most $t$-statistics below one, there is not a shred of statistical evidence that federal-funds shocks forecast surpluses. The point estimates in the first three rows are large: a 1-percentage-point federal-funds shock results in a roughly 1-percentage-point rise in the surplus/consumption ratio for as much as 2 years. Since the real debt/consumption ratio is about 0.5 , such an estimate implies as much as a $4 \%$ decline in the price level, roughly consistent with the VAR point estimates. However, as one expects from the $t$-values and $\bar{R}^{2}$, the coefficients are driven by two outliers $(1969,1975)$ in an otherwise symmetrical scatterplot. The negative point estimates in the last row add up to an economically as well as statistically insignificant effect.

MONEY DEMAND AND VELOCITY SHOCKS Money demand functions explain some of the fluctuations in money growth rates documented in Figure 1 via income and interest elasticities (endogenous velocity), but not

Table 1 PERCENTAGE OF $k$-QUARTER-AHEAD FORECAST ERROR VARIANCE DUE TO POLICY SHOCKS

\begin{tabular}{lrrlcrrr}
\hline Policy Shock & $k$ & $Y$ & $P$ & Policy Shock & $k$ & $Y$ & $P$ \\
\hline FF & 2 & 0.4 & 0.5 & MB & 2 & 0 & 0 \\
& 4 & 21 & 0.3 & & 4 & 5 & 3 \\
& 8 & 44 & 0.4 & & 8 & 5 & 4 \\
& 12 & 38 & 2.5 & & 12 & 3 & 2 \\
NBR & 2 & 0 & 0 & M1 & 2 & 0 & 0 \\
& 4 & 7 & 0 & & 4 & 0 & 0 \\
& 8 & 10 & 1 & & 8 & 3 & 0 \\
& 12 & 8 & 1 & & 12 & 6 & 0 \\
NBR/TR & 2 & 0 & 0 & M2 & 2 & 2 & 0 \\
& 4 & 17 & 0 & & 4 & 14 & 1 \\
& 8 & 30 & 0 & & 8 & 29 & 6 \\
& 12 & 22 & 1 & & 12 & 24 & 15 \\
\hline
\end{tabular}

Source: Christiano, Eichenbaum, and Evans (1998). $\Upsilon=$ industrial production; $p=$ price level; $k=$ horizon; $\mathrm{FF}=$ federal funds rate; $\mathrm{MB}=$ monetary base; $\mathrm{NBR}=$ nonborrowed reserves; $\mathrm{TR}=$ total reserves. 
Table 2 REGRESSIONS OF ANNUAL SURPLUS/CONSUMPTION RATIO ON ANNUAL AVERAGES OF CHRISTIANO, EICHENBAUM, AND EVANS'S (1998) FEDERAL-FUNDS SHOCKS.

\begin{tabular}{cccccccc}
\hline \multicolumn{7}{c}{ Coefficient } & $(t$-statistic) \\
\hline$\epsilon_{t}^{f f}$ & $\epsilon_{t-1}^{f f}$ & $\epsilon_{t-2}^{f f}$ & $\epsilon_{t-3}^{f f}$ & $\epsilon_{t-4}^{f f}$ & $\epsilon_{t-5}^{f f}$ & $R^{2}$ & $p$-Value \\
\hline & 1.11 & & & & -0.00 & 0.40 \\
& $(0.86)$ & & & & -0.006 & 0.41 \\
1.52 & 0.59 & & & & -0.07 & 0.69 \\
$(1.06)$ & $(0.42)$ & & & & & & \\
1.56 & 0.58 & -0.33 & & & & & \\
$(1.01)$ & $(1.55)$ & $(-0.23)$ & & -0.10 & 0.85 & -0.26 & 0.96 \\
1.23 & 0.14 & -1.52 & 0.09 & $-0.06)$ & $(0.05)$ & & \\
$(0.69)$ & $(0.08)$ & $(-0.82)$ & $(0.05)$ & $(-0.06)$ &
\end{tabular}

$p=$ value for test that all coefficients are zero.

much. To quote a recent review by Baba, Hendry, and Starr (1992), "Estimated U.S. M1 demand functions appear unstable, regularly breaking down . . (e.g., missing money, great velocity decline, M1-explosion)." Even the staunchest defenders of empirical money demand relations, such as Lucas (1988), can at best point to a stable income and interest elasticity over very long time scales, 50 years or more.

Suspiciously, "velocity shocks" are not traceable to changes in financial structure, and changes in financial structure do not seem to lead to velocity shocks. Velocity shocks also do not appear to be exogenous: Times such as 1980-1982 when the Fed pushes hard on the monetary lever are precisely the times when velocity becomes least predictable.

The following conceptual experiment offers one interpretation of elusive elasticities and velocity shocks. It is not surprising that the short-run interest elasticity of money demand is low, since changes in interest costs are trivially small. If you keep $\$ 1,000$ in cash and a non-interestbearing-checking account, a change from $5 \%$ to $6 \%$ in annual interest rates increases monthly interest costs by $\$ 0.83$. And since holding extra cash has benefits that at the margin are equal to marginal costs, the utility cost is another order of magnitude smaller than $\$ 0.83$, say $\$ 0.08$ per month. Consumers can be forgiven if they don't immediately change their cash management habits for 8 cents in monthly utility gains.

But suppose instead that the government moved $\$ 100$ from each person's savings account or mutual fund to their checking account overnight. A small interest elasticity implies that interest rates must jump dramatically in response to this change. For now, instead of looking at

$\ln M=\ln P+a \ln y-b r$ 
and noticing $b$ is small, we are looking at

$r=\frac{1}{b}(-\ln M+\ln P+a \ln y)$

and noticing that $1 / b$ is very large.

Intuition suggests the opposite reaction, however: people would just tolerate the suboptimal allocation of $\$ 100$, because, again, fine details of cash management don't matter that much. At a 5\% interest spread, an extra $\$ 100$ implies $\$ 0.42$ per month interest cost and an order of magnitude smaller utility cost, say $\$ 0.04$ per month. If consumers do not adjust immediately to gain the extra 4 cents, we see an endogenous velocity shock, associated with the open-market operation.

Obviously, if the elasticity depends on which variable is pushed, one would not want to impose a rigid money demand curve on any model. [This analysis owes a strong debt to Akerlof (1979) and Akerlof and Milbourne (1980). They show that $s-S$ money demand policies have similar mushy implications, since people must change the $s-S$ bounds before interest rates have any effect.]

THEORETICAL OBJECTIONS A generation of theorists have argued that the quantity theory is an increasingly implausible description of modern economies with competitive banking systems, including Black (1970), Fama (1980, 1983, 1985), Hall (1983), King (1983), White (1984), and Cowen and Kroszner (1994). Considering the vast number of liquid, nonreservable inside assets, as well as trade credit, credit cards, debit cards, and other means of financing transactions, and considering the flexibility and competitiveness of financial institutions, it is difficult to believe that an artificial scarcity of one liquid asset can have any systematic effect.

As these authors recognized, some sort of perfectly competitive, frictionless model is a more sensible first-order approximation to the U.S. financial system than is a rigid separation of assets into liquid "money" or "transactions-facilitating assets" and illiquid "investment assets." However, these authors could not get around the view that the price level had to be determined by an explicit commodity-based unit of account, or a special transactions demand for the monetary base together with a limited supply. The fiscal theory gives us a structure that can determine the price level within the natural perfectly competitive or frictionless approximation, while preserving the fact of apparently unbacked fiat money. 
One can of course study an infinite-velocity limit of the quantity theory, as advocated by Woodford (1997) and the "currency ghost" view of Cowen and Kroszner (1994). However, it does not seem productive to hinge the price level on whether U.S. transactions can be accomplished with fast-moving claims to one dollar bill, or whether two will be required. At some point, and especially as the interest costs of holding the remaining money become vanishingly small, velocity must become endogenous rather than rigidly linking money to transactions via an everlonger lever.

WHAT ABOUT OPEN MARKET OPERATIONS AND MONEY DEMAND? What about the common view and empirical evidence that monetary policy affects output? For example, Table 1 shows that federal-funds-rate shocks explain up to $40 \%$ of the variance of output, while explaining none of the variance of prices.

Choosing a fiscal and even frictionless description of the price level does not require that open-market operations have output-neutral effects. Open-market operations can still affect the interest-rate spreads of monetary assets, and interest-rate spreads can affect output. For example, Bernanke's (1983) nonmonetary view of the Great Depression stresses the disruption of credit arrangements following open-market operations. These output effects can occur while the fiscal constraint alone determines the price level. As Goodfriend (1988) reminds us, central banks pursued active interest-rate policy, with visible output effects, even under the classical gold standard. One can add sticky prices to a fiscal model with monetary frictions, as in Woodford (1997), to generate output variation related to inflation, but one need not tie output to inflation (counterfactually, I might add) in order to explain output effects of open-market operations.

Similarly, a fiscal theory of the price level is not inconsistent with the observation that money and nominal income often move together. Money is useful for transactions, and governments typically provide it elastically as needed, for example by following interest-rate policies. It does not follow from this observation that if the government exchanged bonds for money, there would be any effect on the price level.

\subsection{EPISODES}

Dramatic episodes of hyperinflation, stabilization, currency collapse, and so forth are perhaps the most natural place to start evaluating the fiscal theory. I focus instead on U.S. data below, in part because theories that are only good for extreme events in the unstable monetary arrangements of far-away (to admittedly parochial U.S. observers) lands will not 
in the end influence monetary analysis of the U.S. economy. However, a quick look at such episodes helps to illustrate the fiscal theory and make it plausible.

There is no tight relation between debt and the price level in many historical episodes. Wars offer the most dramatic example. Nominal debt increases substantially, often with relatively little change in the price level. Of course, such nominal-debt increases also come with the explicit or implicit promise that future taxes will be raised to retire the debt after the war. Hence both sides of the budget identity change, and the price level need not be affected. In fact, recall that (short-term) debt sales with no change in future surpluses produce no extra revenue. The whole point of selling extra nominal debt in a war is to raise revenue. If they raise revenue, such sales must have come with an implicit promise to raise future taxes.

The same lesson applies in peacetime: If the government raises revenue by selling additional (short-term) bonds, the debt sale must have come with an explicit or implicit promise to raise future surpluses. Both sides of the identity move at the same time, so we should not expect a tight relation between total nominal debt and the price level.

Hyperinflations are classic pieces of evidence for the quantity theory, since money and the price level both grow very quickly. However, hyperinflating countries issue little nominal debt other than money, so money and nominal debt are the same thing and the fiscal theory predicts the same hyperinflation as the quantity theory.

Hyperinflations are of course linked to government finances. In the standard quantity-theoretic analysis, an intractable budget shortfall forces the government to print money to pay its bills, and the money causes inflation. If a country tried to finance an intractable budget shortfall by rolling over explosive quantities of one-week interest-paying debt, while rigidly controlling the money stock, this would provide a nice experiment: the quantity theory predicts no inflation while the fiscal theory predicts hyperinflation. Alas, it hasn't happened. A country that had explosive inside money growth with no government budget problems would provide another nice experiment: The fiscal theory predicts no inflation and the quantity theory predicts hyperinflation. Unfortunately for economists, all the recorded hyperinflations resulted from explosive growth in nominal government debt.

Sargent's (1986) classic study of the ends of hyperinflations again points to a fiscal link, though his analysis is quantity-theoretic and Ricardian. The budget problem is solved; seignorage stops, so inflation stops. Again, the fiscal theory makes the identical prediction that inflation will stop once the budget problem is solved, though directly rather 
than via its inducements to seignorage. In fact, the fiscal theory nicely accommodates a troubling fact: money growth usually does not stop at the time of the fiscal announcement that ends the hyperinflation. This fact usually has to be explained by an increase in money demand at lower nominal interest rates.

Sargent's analysis and a fiscal theory can differ substantially over the effects of news about future surpluses or deficits. In a quantity-theoretic analysis, news about future deficits that will result in future seignorage primarily affects only future inflation. Cagan-style hyperinflation dynamics are the only way that future seignorage can affect today's price level, but such effects are weak, since future money growth is discounted at the interest elasticity of money demand [see equation (32)], which is on the order of 0.15 . In a fiscal model with short-term debt, future deficits are discounted at the much higher gross interest rate, producing discount factors on the order of 0.95 . Thus, the fiscal theory can predict a much stronger reaction of current prices to news of far-off deficits. This prediction depends on details in both cases: if news of future deficits causes the government to start printing money now, the quantity theory can also predict current inflation, and if there is a lot of long-term debt, the fiscal theory can predict no current inflation but instead a fall in longterm bond prices reflecting expected future inflation.

Along this line, the Asian currency plunges of late 1997 cry for a fiscal analysis. It seems much more plausible that the currencies plunged on bad fiscal news, induced by a wave of bank insolvencies, than on news that open-market purchases or seignorage would soon double the money supply. Bad fiscal news lowers the price-raises the interest rate-of longer-term debt, and high interest rates are characteristic of these crises. The fiscal story also makes sense of the fact, surprising to a standard analysis, that many governments had ample foreign exchange reserves (Burnside, Eichenbaum, and Rebelo 1998).

Similarly, Argentina suffered great stress on its currency board during the Mexican peso crisis, including very high interest rates. Reserves were high in this case as well-the currency was $100 \%$ backed. Again, this was a time of great fiscal stress for the government. The temptation to abrogate the board and devalue might well have turned into necessity. The high interest rates make sense again as high nominal rates that include this probability.

Brash (1996) unwittingly offers an essentially fiscal view of New Zealand's celebrated monetary reforms. Though he is the governor of the Reserve Bank of New Zealand, his description of that country's disinflation spends 40 pages on microeconomic reforms, tax reforms, and large and successful fiscal policy reforms before even talking about 
monetary policy. Then he describes only the political economy of an inflation contract, without once mentioning monetary restriction or open-market operations by which this contract is supposed to be implemented. A fiscal theorist sees direct causality from dramatically good fiscal news to the price level, with the actions of the central bank largely irrelevant.

As Woodford (1996) emphasizes, a fiscal analysis makes sense of the otherwise pointless deficit targets for entry into the European Monetary Union. If (say) Italian debt is to trade at par with (say) German debt, then either Italian surpluses must be sufficient to value that debt, or Germany must implicitly or explicitly stand ready to bail out the Italian budget. Of course, Italian debt may instead trade at a discount, reflecting a possibility of explicit default. Therefore, one must read the deficit targets as an attempt to avoid explicit default as well as subsidy.

\section{U.S. Debt and Inflation}

\subsection{DATA}

Easily available U.S. government deficit and debt data are potentially poor approximations to the economic concepts one wants. Above all, it is important to create a surplus series that corresponds to the revenue from debt operations. [Auerbach, Gokhale, and Kotlikoff (1994) stress the larger difficulties of deficit measurement.]

To produce more accurate data, I created annual data on privately held U.S. government debt from the CRSP government bond files, which in turn record data from the Treasury Bulletin. From these data, I created an annual series on the total real value of the debt, $v_{t}^{f}$, as the sum of December 31 price times quantity of all bonds outstanding, divided by the December CPI. I estimated the annual rate of return $r_{t+1}^{a}$ on the government bond portfolio from the Fama-Bliss (1987) zero-coupon bond return series multiplied by December 31 (year $t$ ) portfolio weights. Then, I estimated the annual surplus from the identity $s_{t+1}^{a}=v_{t}^{q} r_{t+1}^{a}-v_{t+1}^{a}$. (It is more natural in annual data to date December 31 year-t debt as $v_{t}^{f}$ rather than $v_{t+1}^{f}$, so this identity has slightly different timing than the discrete-time identities studied above, in which $v_{t}$ denotes the beginning of period debt.) I also created a zero-coupon equivalent maturity structure $B_{t}(t+j)$ by adding up the principal and all coupons of all bonds outstanding at December 31, year $t$, that come due in year $t+j$. I count the monetary base as zero-maturity debt. The data are described in detail in an appendix available on the author's Web site listed in the first footnote. 


\subsection{SURPLUS, DEBT, AND RETURNS}

Before addressing the fiscal theory directly, I characterize the new data on surplus, debt, and returns. I also develop the central patterns that we must try to match.

3.2.1 Surplus Figure 2 presents the primary surplus inferred from bond data described above, together with the conventionally measured surplus or deficit. The two series correlate well through the 1970s, when interest payments on the debt were small. In the 1980s, however, the primary surplus does become positive, while the deficit remains large, reflecting large interest payments on the outstanding debt.

One's first reaction to a view that the price level is set by the interaction of nominal debt and real surpluses might be to ask: what surpluses? Has not the federal government been in deficit continuously for the last 30 years? Of course, the theory refers to the primary surplus, correctly measured; the graph offers hope for the view that debt is eventually repaid with primary surpluses.

The surplus shows a clear cyclical pattern, dipping in the recessions of 1975,1982 , and 1990. Interestingly, the primary surplus suffers its big-

\section{Figure 2 REAL PRIMARY SURPLUS INFERRED FROM BOND DATA AND FEDERAL SURPLUS OR DEFICIT}

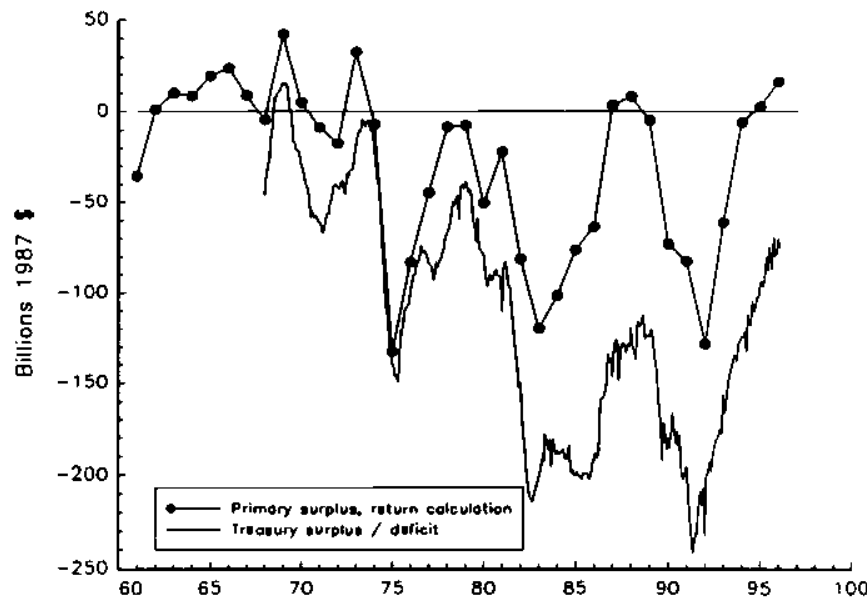

All series deflated by the consumer price index. The federal surplus or deficit is monthly observations of annual averages. 
Figure 3 REAL SURPLUS INFERRED FROM BOND DATA AND NET-OFINTEREST SURPLUS REPORTED BY THE TREASURY

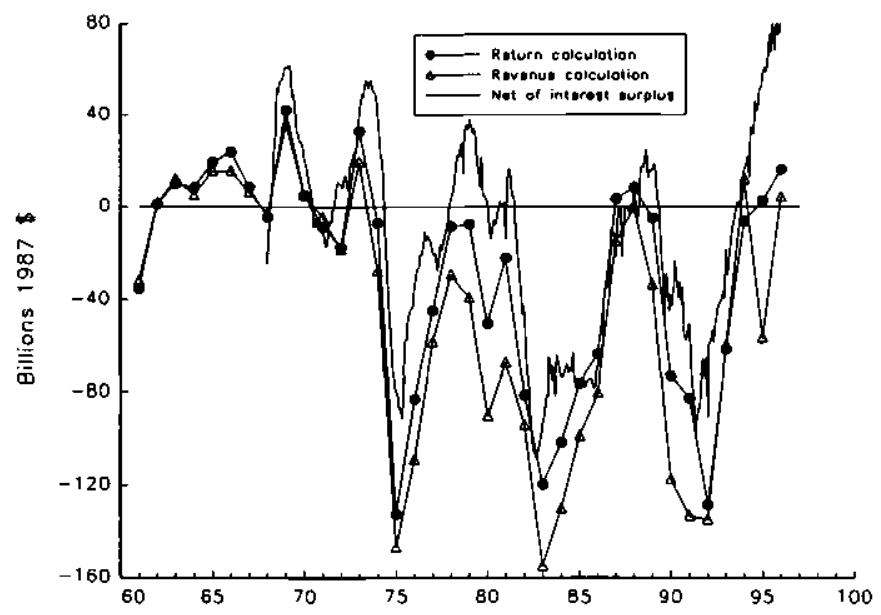

The return calculation starts by estimating the rate of return on government bonds, and then imputes the surplus from the rate of return and growth in total value. The revenue calculation is based on a direct estimate of revenue from debt transactions.

gest negative shock in 1975, with the onset of severe inflation, not during the Reagan deficits of the 1980 s.

Figure 3 contrasts three measures of the primary surplus. The preferred return calculation infers the surplus from growth in total debt and the estimated rate of return on government bonds, while the revenue calculation sums up revenue from bond transactions during the year, as described in the Appendix. The net-of-interest surplus is reported by the Treasury, and consists of the total surplus or deficit less interest payments, but not gains and losses incurred from bond sales or purchases.

The three series correlate well, but not perfectly. Unusually active debt policy in 1990-1991 and 1995 drove a wedge between the revenue and return calculations. Both measures are somewhat more pessimistic than the net-of-interest surplus series. The difference is substantial most recently: rather than a $\$ 80$ billion primary surplus, the bond data show almost no primary surplus or deficit.

Figure 4 presents the components of the revenue-based real surplus series. One can see that the cyclical variation in surplus (the negative of revenue) is driven by variation in new bond and bill sales. However, the need to pay coupons and redeem maturing bonds soon catches up with new sales. From 1983 to 1987, for example, new sales continue to rise, but 
revenue declines. Bond sales are spread over maturities, and thus the maturing bonds are much smoother than the bond sales. For example, with only one-period debt, maturing bonds would equal the previous period's sales. Lately, the Treasury has started to sell more of existing issues. Seignorage-change in the monetary base-is an insignificant fraction of government revenue.

3.2.2 Surplus and Output In order to focus on the cyclical properties of the surplus, Figure 5 contrasts the surplus/consumption ratio with the output/consumption ratio. Dividing by consumption allows us to scale variables with growth, producing plausibly stationary series. I divide the surplus by consumption rather than output to avoid putting businesscycle output variation in the surplus measure. The output/consumption ratio exploits the relative stability of consumption (permanent income) to produce a business-cycle indicator (see Cochrane, 1994a).

The graph emphasizes that most variation in the surplus is the predictable result of output variation. The dramatic deficit of 1975 is associated with a severe drop in output. The initial Reagan deficits also line up nicely with output. Only 1984 and 1985 are years with somewhat larger deficits than would be expected. The Reagan deficits resulted from large interest costs on a stock of debt built up over several recessions, not, as is

Figure 4 COMPONENTS OF REAL REVENUE FROM BOND SALES

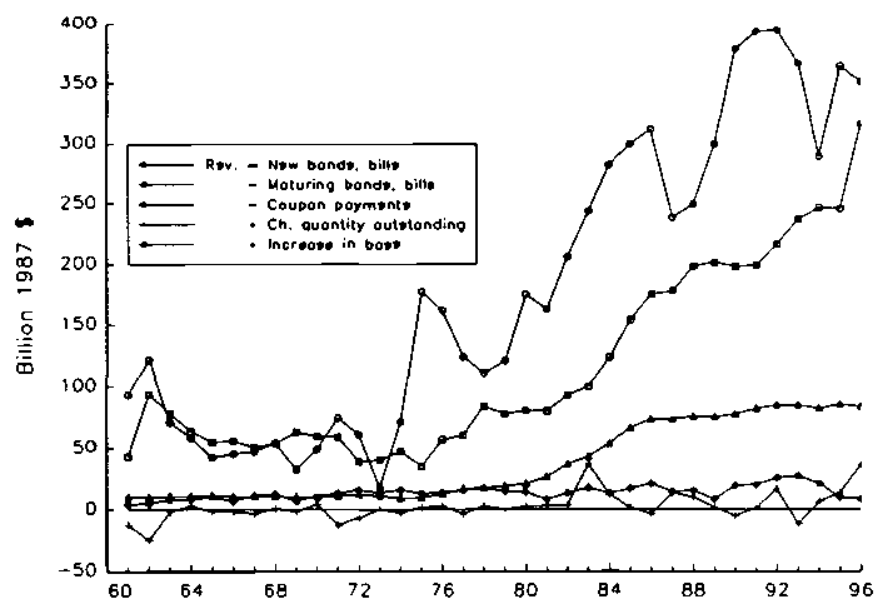

Revenue (negative surplus) is, by definition, equal to (new bond sales) + (change in quantity outstanding) + (change in base) - (maturing bonds) - (coupon payments). 
Figure 5 SURPLUS/CONSUMPTION AND OUTPUT/CONSUMPTION RATIO

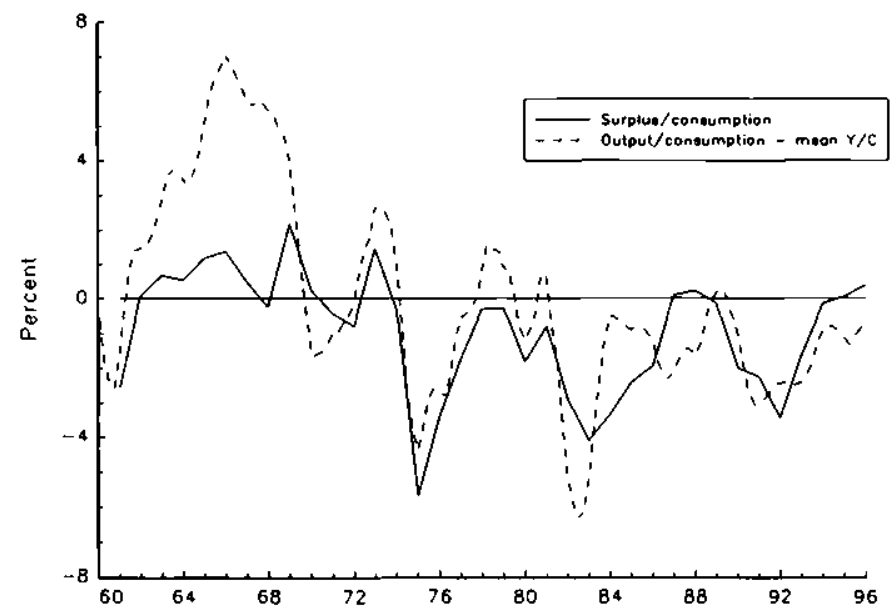

The output/consumption line graphs $y / c-E(y / c)$, so that the graphs fit on the same scale. Consumption is nondurable plus services consumption; output is GDP.

Figure 6 REAL PRIMARY SURPLUS DIVIDED BY NONDURABLES AND SERVICES CONSUMPTION, AND ANNUAL CPI INFLATION

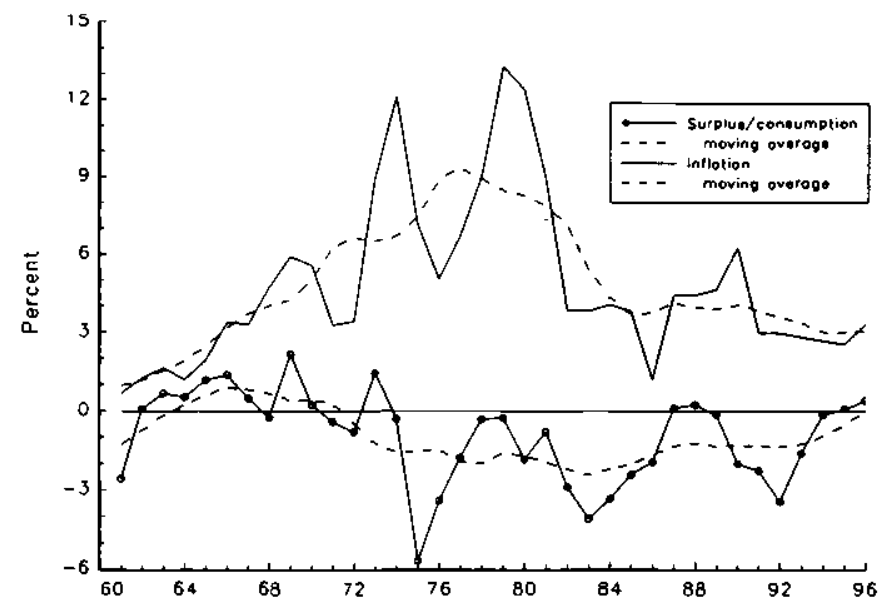

Moving averages use 3 years' data on each side. 
often claimed, from an unusually loose primary fiscal policy. The graph also points to a secular relation between surpluses and output. The output slowdown that started in about 1973, even relative to consumption, is associated with a similar secular decline in the surplus.

3.2.3 Surplus and Inflation Figure 6 presents the surplus/consumption ratio together with annual CPI inflation. Since inflation and the surplus are both procyclical, it is little surprise that business-cycle movements in the surplus are positively correlated with business-cycle movements in inflation through the $1970 \mathrm{~s}$. On the other hand, the longer-term variation in the surplus and inflation are negatively correlated, as shown by the moving averages.

3.2.4 Bond Returns and Debt Growth Figure 7 presents the real rate of return on the government bond portfolio, together with the three-month and five-year real rates of return which, along with other returns, are used to construct it.

Before about 1980, the average maturity structure is still quite short. Therefore, the government bond portfolio return tracks the three-month rate pretty well. In fact, since the monetary base, which pays no interest,

Figure 7 RETURN ON GOVERNMENT BOND PORTFOLIO, AND THREE-MONTH AND FIVE-YEAR ZERO-COUPON RETURNS

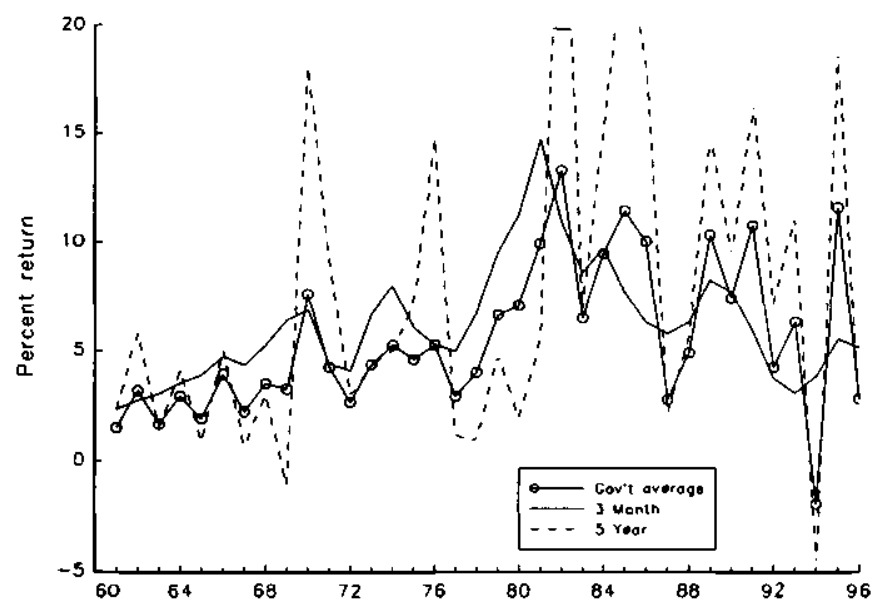

The government bond portfolio return is estimated as the average of all zero-coupon returns weighted by the zero-coupon maturity structure at the beginning of the year. 
Figure 8 REAL RETURN ON GOVERNMENT BOND PORTFOLIO, REAL DEBT GROWTH, AND SURPLUS/DEBT RATIO

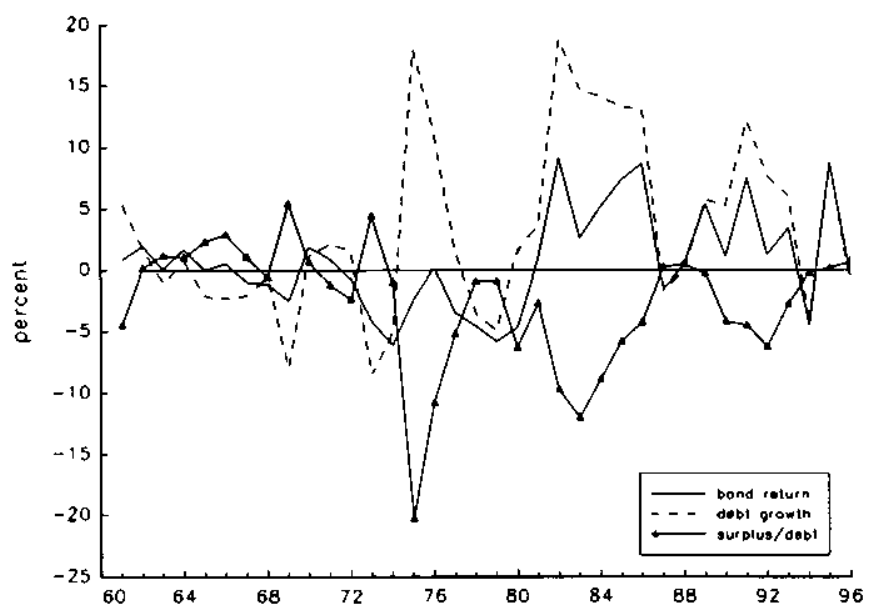

The real bond return is estimated from the returns on zero-coupon bonds weighted by the beginning-ofyear maturity structure. Real debt growth is the growth in total market value of the debt. The three series are related by the accounting identity $v_{t} / v_{t-1}=r_{t}-s_{t} / v_{t-1}$.

is such a large fraction of government debt in this period, the rate of return on government bonds is typically a few points less than the threemonth rate. In the 1980 s and 1990 s, the maturity structure lengthens. During this period the return on government debt behaves much more like a long-term rate, subject to large swings as long-term bond prices move around.

Figure 8 presents the real rate of return on government bonds and the real percentage increase in the value of the debt. The surplus (as a fraction of value) is the difference between the growth in total debt and the return on the government bond portfolio,

$\frac{s_{t+1}^{a}}{v_{t}^{a}}=r_{t+1}^{a}-\frac{v_{t+1}^{a}}{v_{t}^{a}}$

so this graph documents the sources of surplus variation.

In 1975 there was a large (25\%) increase in the total value of government debt. However, the rate of return on government bonds was not large at all, so we estimate a large primary deficit, as shown. Debt also grew very quickly in the early 1980 s, but around half of that growth was due to very high real returns on outstanding debt. This is why the 


\begin{tabular}{cccc} 
Table 3 & \multicolumn{2}{l}{$\begin{array}{l}\text { CORRELATION MATRIX OF } \\
\text { GOVERNMENT BOND RETURN, } \\
\\
\text { REAL DEBT GROWTH, AND } \\
\text { SURPLUS/DEBT RATIO }\end{array}$} \\
\hline & $r_{t+1}^{a}$ & $v_{t+1}^{a} / v_{t}^{a}$ & $s_{t+1}^{a} / v_{t}^{a}$ \\
\hline$r_{t+1}^{a}$ & 1 & 0.70 & -0.16 \\
$v_{t+1}^{a} / v_{t}^{a}$ & & 1 & -0.82 \\
$s_{t+1}^{a} / v_{t}^{a}$ & & & 1 \\
\hline
\end{tabular}

surplus measure above did not find extreme primary deficits, as one might have expected.

The graph also reminds us that the real rate of return on government debt increased dramatically in the early 1980 s and has stayed high and variable since. This is in part due to higher real returns on government bonds and in part due to the smaller proportion of monetary base in the debt.

Finally, the graph documents an important and interesting correlation pattern. The surplus is very well negatively correlated with debt growth; returns are positively correlated with debt growth, and the surplus is negatively, though weakly, correlated with returns. (See Table 3.)

3.2.5 Surplus, Value, and Inflation Figure 9 presents the real value of the debt value and the surplus, each scaled by consumption, and inflation. The surplus is positively associated with inflation, and negatively associated with changes in value; we will work hard to understand these correlations.

\subsection{EXPLAINING THE CORRELATIONS}

Our task is now to understand the pattern of correlations documented above. I start by viewing the surplus and nominal debt as policy choices. The price level is then determined by the government budget constraint. The central issue in matching the data this way is understanding the real value of the debt. If the government controls the nominal value, then the price level is trivially the ratio of nominal to real value of the debt.

A Ricardian or monetary story is backward-looking: the nominal value of the debt is determined by the accumulation of past deficits, the price level is determined by $M v=p y$, and these two variables determine the real value of the debt. Future surpluses must then adjust to pay off this debt. A fiscal story is forward-looking. The real value of the debt is determined by the present value of expected future surpluses, and the price 
Figure 9 VALUE/CONSUMPTION, SURPLUS/CONSUMPTION, AND INFLATION

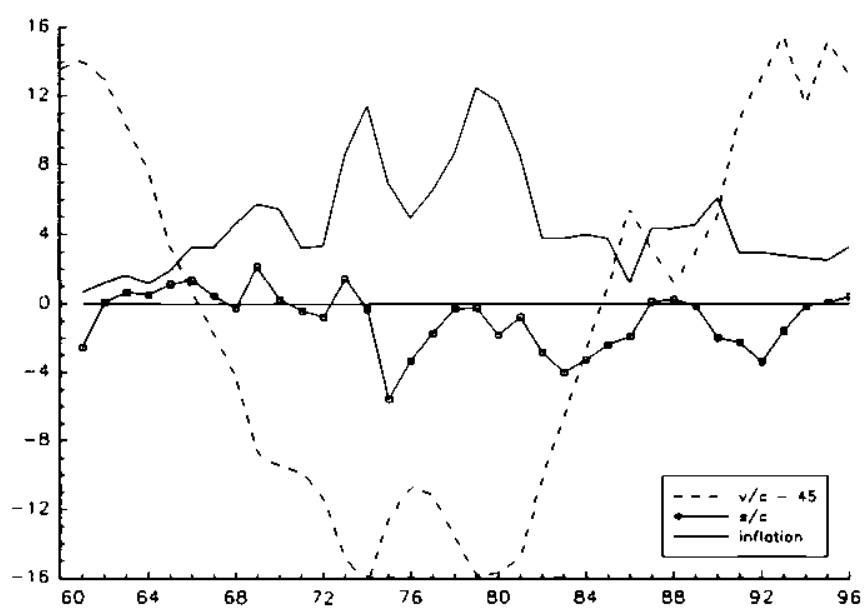

Value/consumption is shifted down by 45 percentage points to fit on the graph with the other two series.

level (and/or long-term bond prices) adjusts to equate that real value to the nominal value. Equivalently, the monetary and fiscal analyses tell different stories about growth in value. In either case, the accounting identity

$\frac{v_{t+1}^{a}}{v_{t}^{a}}=r_{t+1}^{a}-\frac{s_{t+1}^{a}}{v_{t}^{a}}$

holds. In a monetary story, the ex post real rate of return on government bonds is the predetermined nominal rate deflated by the monetarily determined price level. Therefore, this identity determines the new real value $v_{t+1}^{t}$ of the debt from current and past information. In a fiscal story, the value $v_{t+1}^{t}$ of the debt is determined first; this identity then determines the ex post rate of return on government bonds, $r_{t+1}^{a}$; the price level (or the prices of long-term bonds) adjust $r_{t+1}^{a}=r p_{t} / p_{t+1}$ so that the identity holds.

From this perspective, the central puzzles are that the level of the real value of the debt seems to have very little to do with surpluses, and, worse, high surpluses are associated with declines in the value of the 
debt. This pattern of correlations is what a backward-looking view with relatively stable money and hence prices might expect: high deficits mean growing real debt, and the current value of the debt is just cumulated past surpluses.

To see the puzzle from the perspective of a forward-looking view, consider an $\mathrm{AR}(1)$ model for the surplus, which the graphs suggest is reasonable. If we write $s_{t}^{a}=\rho s_{t-1}^{a}+\epsilon_{t}$ with constant expected returns, we obtain a perfect positive correlation between surpluses and debt:

$v_{t}^{a}=E_{t} \sum_{j=1}^{\infty} \beta^{i} s_{t+j}^{a}=\frac{\beta \rho}{1-\beta \rho} s_{t}$.

Currently high surpluses indicate high surpluses in the future, and thus should indicate a high real value of the debt. But this positive correlation between surpluses and the value of the debt is completely counterfactual; the value of the debt declines when surpluses are high. This is the basic idea of Canzoneri, Cumby, and Diba's (1997) rejection.

Of course, an AR(1) surplus process is obvious but perhaps too simple. If we model the surplus as an AR(2) or higher process, low current surpluses can come with news of higher future surpluses, so that the value of the debt rises. While appeal to such a model may seem contrived at first, on second thought it is in fact the most plausible view. Deficits go up-surpluses decline-when taxes decrease and spending increases in a recession. In this situation, the government sells more nominal debt precisely to raise revenue. As we have seen, the only way extra nominal debt sales can raise revenue is if they come with a promise to raise surpluses in the future. If a low surplus did not come with promises of increased surpluses in the future, the government would not raise any extra revenue with extra nominal debt sales.

To understand the issue, it is worth thinking about alternative policies that the government might follow. The extra revenue to cover the declining surplus must come from somewhere. If current surpluses decline in a recession and the government holds future surpluses constant, the price level must increase. This implies a low or negative (net) real return on government bonds; the "extra revenue" comes by inflating away the real value of outstanding debt. This policy-financing cyclical deficits by inflating away outstanding debt-would obviously lead to much more volatile and countercyclical inflation. Thus, the fact that the government follows the current policy, selling more debt in recessions while promising to raise surpluses in the following booms, smooths inflation and the value of government bonds, at least to some extent. 
3.3.1 An Exogenous-Surplus Model with Short-Term Debt To tell a quantitative version of this story, I specify an exogenous path for the surplus and debt. I find the real value of the debt as the present value of the surplus, and the price level as the ratio of real to nominal debt. I specify the processes to deliver the correlations in the data; surpluses are correlated with declining values of the debt, the debt moves much more slowly than the surplus, and its level is poorly correlated with the surplus; real and nominal debt growth track closely, and the surplus is negatively correlated with inflation.

MODELING SURPLUS AND VALUE To match the model with stationary time series, I examine the (real value)/consumption and surplus/consumption ratios and the inflation rate (rather than price level). As an accounting identity, the value/consumption and surplus/consumption ratios obey

$\frac{v_{t}^{a}}{c_{t}}=\frac{1}{r_{t+1}^{a}} \frac{c_{t+1}}{c_{t}}\left(\frac{s_{t+1}^{a}}{c_{t+1}}+\frac{v_{t+1}^{a}}{c_{t+1}}\right)$.

Define $\beta=E\left[c_{t+1} /\left(c_{t} r_{t+1}^{a}\right)\right]$. I start by assuming this discount factor is constant over time. Then, we can iterate (33) forward, take expectations, and write the value/consumption ratio as the present value of the surplus/ consumption ratio. Denote $v c_{t} \equiv v_{t}^{a} / c_{t}-E\left(v_{t}^{a} / c_{t}\right), s c_{t} \equiv s_{t}^{a} / c_{t}-E\left(s_{t}^{a} / c_{t}\right)$. Then the value/consumption ratio also obeys the familiar identity,

$v c_{t}=E_{t} \sum_{j=1}^{\infty} \beta^{i} s c_{t+j}$.

I model the surplus as the sum of a business-cycle component $a_{t}$ and a long-run component $z_{t}$ :

$s c_{t}=z_{t}+a_{t \prime}$

$z_{t}=\eta_{z} z_{t-1}+\epsilon_{z t}$

$a_{t}=\eta_{a} a_{t-1}+\epsilon_{a t}$.

We saw above how the surplus is highly correlated with output. Therefore, think of the business-cycle component $a_{t}$ as driven by varying output at constant tax and spending policies, and not controlled by the government. Think of the long-term component $z_{t}$ as reflecting tax rates, spending policies, and so forth, which the government does control. However, for optimal-taxation reasons, the government does not want to vary $z_{t}$ period by period to offset $a_{t}$, for example increasing tax rates in recessions in order to offset the loss of tax revenue. Thus, as in much of the tax-smoothing literature, write $z_{\mathfrak{k}}$ as a very persistent process, almost 
if not exactly a random walk, and assume that the government chooses $\epsilon_{z t}$ each period.

Given this surplus process, the real value of the debt is

$v c_{t}=E_{t} \sum_{j=1}^{\infty} \beta^{j} s c_{t+j}=\frac{\beta \eta_{z}}{1-\beta \eta_{z}} z_{t}+\frac{\beta \eta_{a}}{1-\beta \eta_{a}} a_{t}$.

Putting together (34) and (35), we can write the observable series $s, v$ in terms of the unobservable surplus components $z, a$ as

$\left[\begin{array}{l}s c_{t} \\ v c_{t}\end{array}\right]=\left[\begin{array}{cc}1 & 1 \\ \frac{\beta \eta_{z}}{1-\beta \eta_{z}} & \frac{\beta \eta_{a}}{1-\beta \eta_{a}}\end{array}\right]\left[\begin{array}{l}z_{t} \\ a_{t}\end{array}\right]=B\left[\begin{array}{l}z_{t} \\ a_{t}\end{array}\right]$.

PARAMETERS I pick parameters so that $s c, v c$ follow

$$
\begin{aligned}
& {\left[\begin{array}{l}
s c_{t} \\
v c_{t}
\end{array}\right]=\left[\begin{array}{rr}
0.55 & 0.06 \\
-0.55 & 0.96
\end{array}\right]\left[\begin{array}{l}
s c_{t-1} \\
v c_{t-1}
\end{array}\right]+\delta_{t},} \\
& {\left[\begin{array}{cc}
\sigma\left(\delta_{s}\right) & \rho_{s v} \\
& \sigma\left(\delta_{v}\right)
\end{array}\right]=\left[\begin{array}{rr}
0.013 & -0.55 \\
& 0.035
\end{array}\right]}
\end{aligned}
$$

This is the OLS estimate, except for the lower left coefficient -0.55 of $v c_{t}$ on $s c_{t-1}$. The OLS estimate is -0.75 (s.e. $=0.26$ ); I use -0.55 instead in order to satisfy the constraint that this coefficient must equal the negative of the coefficient of $s c_{t}$ on $v c_{t-1}$ implied by the structural model, or more generally by the fact that $v c$ is the present value of $s c$. The corresponding structural parameters are

$$
\begin{gathered}
{\left[\begin{array}{l}
a_{t} \\
z_{t}
\end{array}\right]=\left[\begin{array}{cc}
0.64 & 0 \\
0 & 0.87
\end{array}\right]\left[\begin{array}{l}
a_{t-1} \\
z_{t-1}
\end{array}\right]+\epsilon_{t \prime}} \\
{\left[\begin{array}{cc}
\sigma\left(\epsilon_{z}\right) & \rho_{a z} \\
\sigma\left(\epsilon_{a}\right)
\end{array}\right]=\left[\begin{array}{cc}
0.023 & -0.95 \\
& 0.011
\end{array}\right], \quad \beta=0.988 .}
\end{gathered}
$$

The difference between the structural representation (38) and the surplus value VAR (37) is very important. The surplus $s=a+z$ is exogenous; it does not respond to the real value of the debt or to prices. Yet the surplus seems to respond to the debt in the VAR representation, what Bohn (1998) interprets as "corrective action." In this case, the value of the debt reveals changing surplus forecasts.

As expected, the structural representation has one business-cycle component, $\eta_{a}=0.64$, and one slow-moving component with $\eta_{z}=0.87$. 
The negative correlation between surplus and value innovations in the data, -0.55 , induces an even stronger negative correlation between business-cycle and long-run surplus innovations in the structural model, -0.95 . As above, this is a central part of the story: when there is a negative business-cycle surplus shock, the government wants to raise revenue by nominal debt sales; to do so it must increase the present value of future surpluses by increasing the long-run component of the deficit.

INFLATION AND NOMINAL DEBT I consider only one-period debt, whose nominal value is $V_{\imath}^{a}$. Real and nominal debt are of course related by

$$
\frac{V_{t}^{a}}{p_{t}}=v_{t}^{a}
$$

In this simple model, inflation is controlled by the government via the decision of how much nominal debt to issue for a given real value of the surplus. Therefore, we can model either inflation or nominal debt and find the value of the other. I model inflation, and then calculate the supporting nominal debt policy later. (There is a small approximation in this procedure: The government can only affect next period's price level by changing nominal debt. If we think of the model operating at monthly or daily frequency, however, the government can control almost all of this year's price level with this year's debt.)

The government chooses debt so that inflation is a function of the two state variables $z, a$ :

$d p_{t} \equiv \Delta \ln p_{t}-\Delta \ln p=\left[\begin{array}{ll}\alpha_{z} & \alpha_{a}\end{array}\right]\left[\begin{array}{l}z_{t} \\ a_{t}\end{array}\right]$

where $\Delta \ln p=E\left(\Delta \ln p_{t}\right)$ is the steady state. I chose the parameters $\alpha$ so that

$d p_{t}=\left[\begin{array}{ll}1 & -0.21\end{array}\right]\left[\begin{array}{l}s c_{t} \\ v c_{t}\end{array}\right]$

One can recover the underlying nominal debt policy by differencing (39). Clearly, this model will only capture the parts of inflation that are correlated with surplus and value. This is in some sense the interesting part: we want to understand the puzzling positive correlation of surplus and inflation. To fully capture the inflation time series, we can add an additional inflation or nominal debt shock. 
Figure 10 ARTIFICIAL DATA ON SURPLUS/CONSUMPTION, VALUE/CONSUMPTION, AND INFLATION.

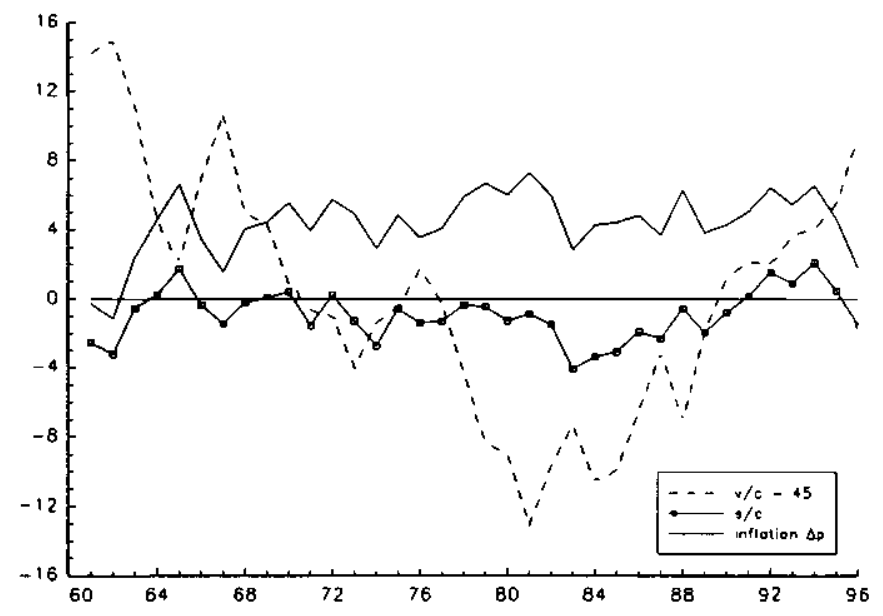

Shocks are drawn from a random number generator.

ARTIFICIAL TIME SERIES Figure 10 presents artificial time series from this system. The shocks are generated by a random number generator. Comparing artificial to actual data on the same series in Figure 9, we see that the system replicates the initially puzzling features of the data: The value of the debt is poorly correlated with the surplus and moves more slowly than the surplus; the short-run correlations between value and surplus are negative-the surplus is highly negatively correlated with growth in the value of the debt, and business-cycle movements in inflation are positively correlated with the surplus.

If we use the sample residuals from the $s c, v c$ VAR representation rather than draw residuals from a random number generator, the sample and artificial $s c, v c$ series match by construction. However, since we do not have an inflation shock, inflation does not match exactly. Figure 11 shows actual and simulated inflation, using the parameters (40). The figure shows that the model does a good job of matching both the secular and cyclical fluctuations in inflation.

The parameters relating inflation to $s c, v c$ are ad hoc. I tried picking parameters to replicate the OLS regression $d p_{t}=0.08 s c_{t}-0.21 v c_{t}+\epsilon_{t}$. This simulation tracks the level of inflation more closely but misses the cyclical fluctuations. Since we cannot statistically fit a three-series model with two shocks, one cannot argue between the two parametrizations on statistical grounds; I stick with the former parametrization, 
since it produces a subjectively more convincing story at the businesscycle frequencies.

DEBT POLICY AND INFLATION SMOOTHING We think of the government as picking the nominal debt $V_{t}$ along with the long-run surplus shock $\epsilon_{z t}$ each period. For convenience, I have characterized this policy by its inflation outcome, but we should look at the actual nominal debt policy. The actual and simulated real debt growth $\left(v c_{t+1} / v c_{t}\right)$ are exactly the same. Hence, I calculate the nominal debt growth that generates simulated price level $p^{\text {sim }}$ by $V_{t}=p_{t}^{\text {sim }} v_{t}^{f}$. Actual nominal debt growth similarly generates actual inflation. Figure 12 presents real and nominal debt growth; inflation is of course the difference between them.

Figure 12 emphasizes that fluctuations in debt growth are far larger than fluctuations of inflation. Furthermore, fluctuations in nominal debt growth closely mirror fluctuations in real debt growth.

What policy for nominal debt growth would have resulted in zero inflation? The answer is one way of getting at the question, what caused inflation? One answer in this case is easy: if nominal debt growth had been the same as real debt growth, inflation would have been zero. However, the character of such a policy is quite surprising, since real debt growth and inflation are so strongly negatively correlated. Nominal debt growth should have been more volatile. It should have declined even more sharply than it already did in 1973 and 1979, for example.

Figure 11 ACTUAL AND SIMULATED INFLATION

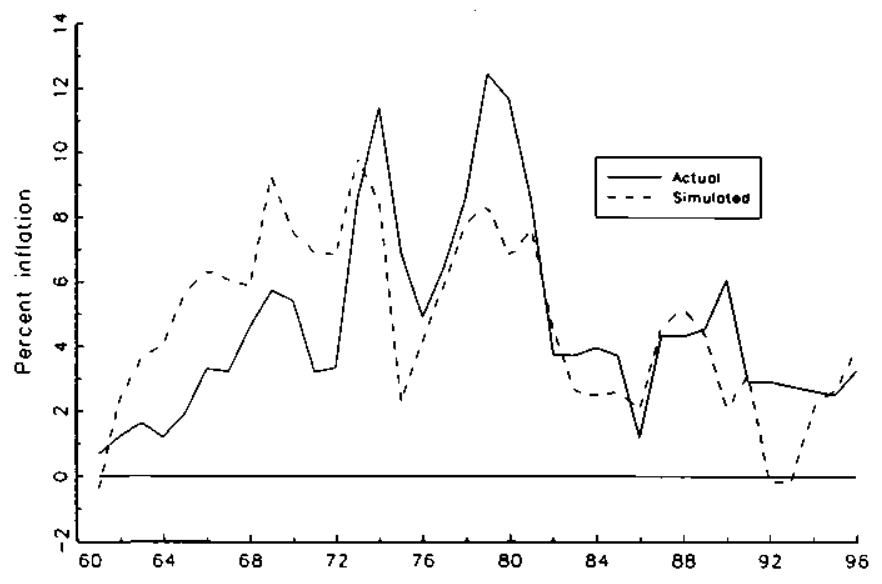


Figure 12 REAL AND NOMINAL DEBT GROWTH, AND SIMULATED

NOMINAL DEBT GROWTH $=($ REAL DEBT GROWTH $) \times$ (SIMULATED INFLATION)

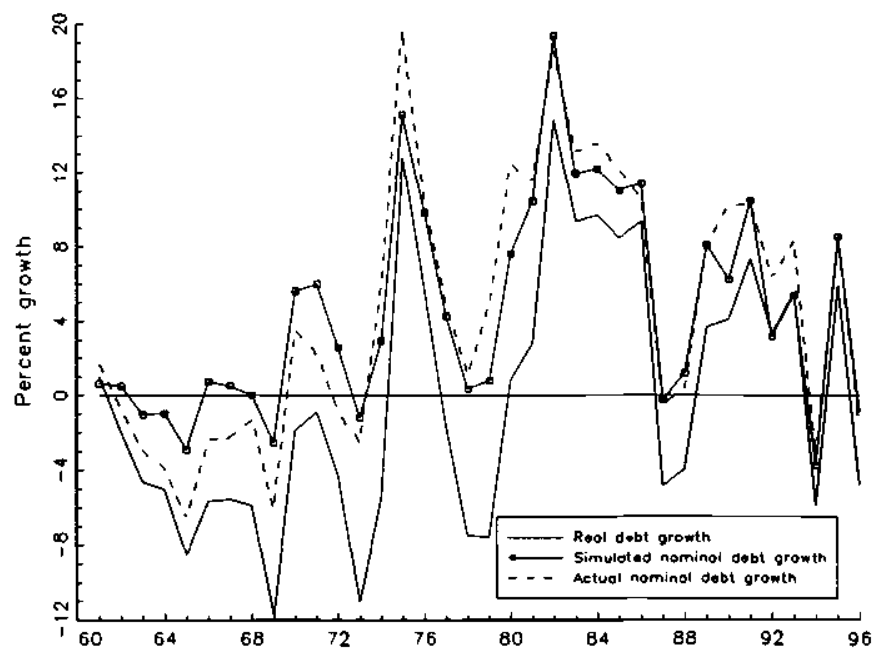

We are used to the monetarist claim that bad inflation outcomes have come from excessively volatile monetary policy; that stable $(k \%)$ money growth rules would have led to stable inflation. The exact opposite is the case here. Growth in the real value of the debt is so volatile that steady $(k \%)$ nominal debt growth would have resulted in wildly fluctuating inflation. Wild swings in nominal debt growth in fact did a great deal to stabilize inflation.

Real debt growth could also have been different. Of course, constant surplus along with constant nominal debt would have given a constant price level, but it is more convincing to think about alternative surplus policies within the constraint that the cyclical component $a_{t}$ is beyond the government's control, and that the persistence of the long-run component $z_{t}$ must be respected, leaving the government only the choice of its innovation $\epsilon_{z t}$. To have a constant price level in this way, the government must choose positive long-run shocks to exactly offset bad cyclical shocks. From the identity (33), with $\Delta \equiv E_{t}-E_{t-1}$, no innovation in the rate of return implies

$-\Delta s c_{t}=\Delta v c_{t}=\Delta \sum \beta^{j} s c_{t+j}$.

The model implies 


$$
\begin{aligned}
\Delta \sum \beta^{j} s c_{t+j} & =\frac{1}{1-\beta \eta_{z}} \epsilon_{z t}+\frac{1}{1-\beta \eta_{a}} \epsilon_{a t}, \\
\Delta s c_{t} & =\epsilon_{z t}+\epsilon_{a t} .
\end{aligned}
$$

Solving for $\epsilon_{z t}$, we have

$$
\epsilon_{z t}=-\frac{1+\frac{1}{1-\eta a \beta}}{1+\frac{1}{1-\eta z \beta}} \epsilon_{a t} .
$$

Only this choice for $\epsilon_{z t}$ will leave no innovation in the price level.

Evaluating this expression using the above persistence parameters $\eta_{a}$ $\eta_{z}$, the government could have eliminated inflation with a $z$-process that had -1.00 correlation with the $a$-process, rather than the actual -0.95 correlation, and with a standard deviation of 0.105 rather than 0.11 . Again, we see how much inflation smoothing is already in debt policy. The orthogonal component of the surplus process that "caused" inflation is quite small.

This example also shows quantitatively how the initially puzzling features of the data flow naturally from a government that is trying to smooth inflation despite large cyclical surplus shocks. In order to smooth inflation, long-term surpluses must rise when short-term surpluses decline, and low surpluses must be associated with declining value of the debt.

This logic and Figure 12 also suggest how we could have missed a fiscal determination of inflation all along. If we had lived in an economy with stable nominal debt, fluctuating real values, and correspondingly fluctuating inflation, or if we had lived in an economy with stable real values of the debt but fluctuating nominal values causing inflation, we would have noticed. In fact, we lived in an economy with wildly fluctuating real values of the debt, and with nominal values that almost-but not quite-smoothed inflation. Equivalently, there is so little independent variation in real and nominal values of the debt that we never see time series corresponding to classic experiments, in which one of surplus and debt is varied and the other is held constant.

The idea that the government can separately determine nominal debt and surpluses is strained, however. In fact, nominal debt sales are the most likely signal of future surpluses. If the government simply sold less debt in the late $70 \mathrm{~s}$, consumers may have misread this to mean that future surpluses were also going to be lower, so revenue from bond sales would have been less. The next step in this kind of modeling therefore should be to recognize a regime. Consumers rationally infer expected 
future surpluses from nominal debt sales. Then, the government can really only choose one quantity at each date. To change inflation, the government must change regimes to one in which nominal debt sales do and are understood to carry larger changes in future real surpluses.

Over the long run of decades, nominal debt growth and inflation are positively rather than negatively correlated. Hence, at very low frequencies we can understand inflation as the consequence of excessive nominal debt growth with relatively constant surpluses rather than require changing expectations of future surpluses to do the work.

\subsection{BOND RETURNS}

So far, I have assumed that the expected government bond return is constant. Variation in the expected rate of return at which future surpluses are discounted may account for substantial variation in the real value of the debt. Suggestively, the government-bond return varies by about as much as the surplus/consumption ratio, so variation in bond returns is at least a plausibly important source of variation in the real value of the debt. Also, fluctuations in government bond returns are clearly associated with cyclical movements in inflation, and the disinflation of the early 1980s was associated with a large increase in bond returns.

In this section, I give a preliminary assessment of whether expected return variation is an important part of the story. I apply the methodology used by Campbell and Shiller (1988) and Cochrane (1992) to decompose the variation in stock-market prices into expected dividend growth, expected return, and bubble components. They find that almost all variation in stock-market values is due to varying expected returns and almost none due to variation in expected future dividend growth, so perhaps the same is true here.

LINEARIZING THE PRESENT-VALUE RELATION To separate the present-value identity into additive return and surplus components, I Taylorapproximate the one-period identity (33) around its steady state and iterate forward, following Campbell and Shiller (1988). Table 4 summarizes steady-state values and deviations from steady state.

The linearized version of the iterated identity is

$v c_{t} \approx-\sum_{j=1}^{k} \rho^{j-1} \tilde{r}_{t+j}^{a}+\sum_{j=1}^{k} \rho^{j-1} d c_{t+j}+\frac{1}{v c} \sum_{j=1}^{k} \rho^{j} s c_{t+j}+\rho^{k} v c_{t+k}$.

$s_{t}^{t} / c_{t}$ can be negative, so I do not approximate it in logs. I verified the accuracy of the approximation by graphing $\mathrm{vc}_{t}$ constructed back from the last date in the sample according to (41) against the actual value, and it is 
Table 4 VARIABLE DEFINITIONS AND VALUES FOR APPROXIMATE PRESENT-VALUE IDENTITY

\begin{tabular}{|c|c|c|c|c|}
\hline \multirow[b]{2}{*}{ Variable } & \multicolumn{2}{|r|}{ Notation } & \multirow[b]{2}{*}{$\begin{array}{l}\text { Sample } \\
\text { Mean }^{4}\end{array}$} & \multirow{2}{*}{$\begin{array}{c}\text { Steady-State } \\
\text { Value in } \\
\text { Calculation }\end{array}$} \\
\hline & $\begin{array}{l}\text { Steady } \\
\text { State }\end{array}$ & $\begin{array}{c}\text { Deviation from } \\
\text { Steady State }\end{array}$ & & \\
\hline$v_{f}^{f} / c_{t}$ & $v c$ & $v c_{t}=\ln \left(v_{t}^{e} / c_{t}\right)-v c$ & $43 \%$ & $43 \%$ \\
\hline$s_{t}^{a} / c_{t}$ & $s c$ & $s c_{t}=s_{t}^{a} / c_{t}-s c$ & $-0.9 \%$ & $+0.4 \%$ \\
\hline$c_{t+1} / c_{t}$ & $\frac{\Delta c}{r^{a}}$ & $\begin{array}{l}d c_{t}=\ln \left(c_{t+1} / c_{t}\right)-\Delta c \\
\tilde{r}^{a}\end{array}=\ln \left(r^{a}\right)-\ln \left(r^{a}\right)$ & $3.2 \%$ & \\
\hline$\left(1 / r_{t+1}^{a}\right) c_{t+1} / c_{t}$ & $\rho$ & $r_{t+1}=\operatorname{In}\left(r_{t+1}\right)-\operatorname{In}(r)$ & $\begin{array}{l}0.04 \% \\
1.025\end{array}$ & 0.99 \\
\hline
\end{tabular}

"Geometric mean where appropriate, e.g. $v c=\exp \left\{E\left[\ln \left(v_{t} / c_{i}\right)\right]\right\}$.

quite accurate. Letting the horizon go to infinity and taking expectations yields a linearized version of the present-value formula:

$v c_{t} \approx-E_{t} \sum_{j=1}^{\infty} \rho^{j-1} \tilde{r}_{t+j}^{a}+E_{t} \sum_{j=1}^{\infty} \rho^{j-1} d c_{t+j}+\frac{1}{v c} E_{t} \sum_{j=1}^{\infty} \rho^{j} s c_{t+j}$

Real debt/consumption is high if the effective discount rate is low, or if future surpluses are high. This identity holds for any information set that includes $v_{t}^{a} / c_{t}$.

The steady state is defined by $(1-\rho) v c=\rho s c$ and $\rho \equiv d c / r^{a}$. We may rightly worry that the steady state and the fiscal theory in general require consistently positive and high surpluses. However, since $\rho$ is quite near one-the average real bond return is close to the average consumption growth rate-a very small steady-state surplus can service a large real debt.

The sample mean surplus/consumption ratio is in fact negative, and the sample mean real bond return in Table 4 is less than the sample mean consumption growth, implying that $\rho>1$ and that all the sums explode. However, as Figure 8 shows, the low returns are driven by the 1970 s and the low average surplus is driven by the 1980 s. One might reasonably regard these experiences as unusual. For this reason I impose $\rho=0.99$ rather than use sample means. The implied steady-state surplus/consumption ratio is $0.4 \%$, which is positive but not unbelievably high, given the sample experience that has ranged from $+2 \%$ to $-6 \%$ (see Figure 5).

PERFECT FORESIGHT The next question is, how much information should we consider when evaluating the identity? First, let us assume perfect foresight. Suppose people knew exactly what the path of future real gov- 
ernment bond returns and future surpluses was going to be. Does variation in surpluses or variation in ex-post returns account for variation in the real value of the debt?

To answer this question, I calculate at each date $t$ the terms in (41), iterated to the end of the sample. For example, at date $t$, the component due to future returns is

return component $t_{t}=-\sum_{j=t+1}^{T} \rho^{j-t-1} \tilde{r}_{j}^{a}$.

Figure 13 presents the results. The sloping dashed line is the mean or steady state plus the present value of the endpoint, $\rho^{T-t} v_{T}^{\alpha} / c_{T}$. The solid and dashed variable lines add the return component and the return plus surplus components to the endpoint component. As we move back through time, these variable components explain variation of the $v^{\prime \prime} / c$ ratio through time. The difference between end + return + surplus and the actual $v^{a} / c$ ratio is due to the consumption component and approximation error, both of which are small.

Starting in the mid-1960s, the value of the debt falls dramatically. Since the end+return line is fairly steady but the end+return+surplus line tracks the decline, the decline is attributed to changing surpluses: The large deficits of 1975 and the early 1980s were starting to appear on the horizon, driving down the value of the debt. Starting in 1972, however, the end + return + surplus line is fairly steady, while the end+return line drops rapidly. Now the high returns of the 1980 s are starting to matter. By 1980, future budgets moved back into surplus, but the value of the

\section{Figure 13 COMPONENTS OF VALUE/CONSUMPTION RATIO}

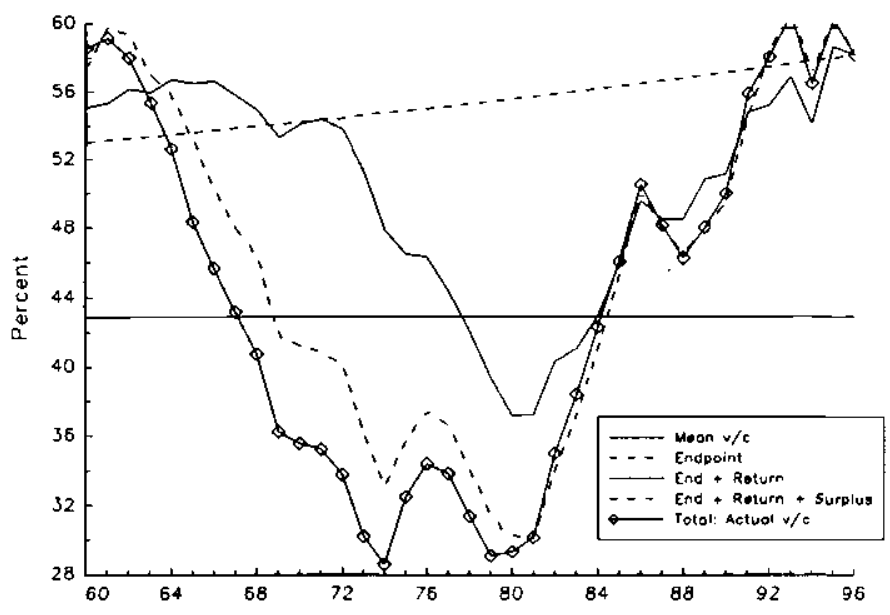


debt is still low because interest (discount) rates are so high. As we move to the present, good surpluses are discounted with fewer and fewer high interest rates, raising the value of the debt.

With perfect foresight, then, both surplus and return variation are important in understanding the real value of the debt.

A SIMPLE VAR Perfect foresight is of course an extreme assumption. What story can we tell based on documentable patterns of forecastability in the variables? To address this question, I form the expectations in (42) with simple VARs. Denoting the VAR by

$x_{t}=A x_{t-1}+\epsilon_{t}$

we measure terms in (42) by, for example,

$E\left[\sum_{j=1}^{\infty} \rho^{j-1} \Delta \ln r_{t+j}^{a} \mid x_{t}\right]=e_{r}^{\prime}\left[A(I-\rho A)^{-1} x_{t}\right]$,

where $e_{r}$ is a vector of zeros and ones that picks off the return element of the VAR.

I form the VAR with a single lag of the debt/consumption ratio, real bond return, surplus/consumption ratio, and consumption growth. Table 5 presents the estimated VAR equations. The important points: The real debt/consumption ratio is very persistent $(0.96)$, as we expect. Higher surpluses forecast lower debt $(-0.73)$. Again, we must think that high surpluses forecast low future surpluses to account for this fact. The

Table 5 OLS REGRESSIONS, 1960-1996

\begin{tabular}{lccccc}
\hline & \multicolumn{5}{c}{ Right-hand variable } \\
\cline { 2 - 6 } $\begin{array}{l}\text { Left-hand } \\
\text { variable }\end{array}$ & $\ln \left(\frac{v}{c}\right)_{t-1}$ & $\left(\frac{1}{v c} \frac{s}{c}\right)_{t-1}$ & $\ln r_{t-1}^{b}$ & $\ln \frac{c_{t-1}}{c_{t-2}}$ & $R^{2}$ \\
\hline $\ln \left(\frac{v}{c}\right)_{1}$ & 0.96 & -0.73 & 0.18 & -2.31 & 0.95 \\
$\left(\frac{1}{v c} \frac{s}{c}\right)_{1}$ & $(21)$ & $(-3.1)$ & $(0.6)$ & $(-3.7)$ & \\
$\ln r_{t}^{b}$ & 0.067 & 0.46 & -0.19 & 1.23 & 0.58 \\
$\ln \frac{c_{t}}{c_{t-1}}$ & $(2.9)$ & $(3.9)$ & $(-1.4)$ & $(4.0)$ & \\
\hline
\end{tabular}

t-statistics in parentheses. 
surplus is also persistent (0.46). Higher debt forecasts slightly higher (0.067) surpluses. The last is a key coefficient, and its statistical significance is encouraging. Higher debt also forecasts higher bond returns (0.046), though this is less significant. Overall, bond returns and consumption growth seem nearly unforecastable.

Figure 14 presents the contributions of return, surplus, and consumption growth terms to explaining the debt/consumption ratio, along with the actual ratio. For example, the line marked Return graphs the time series $e_{r}^{\prime} A(I-\rho A)^{-1} x_{t}$.

In contrast to the ex post decomposition, the forecastable components of the surplus now almost exactly account for all variation in the value of the debt. The central facts behind this result is that higher value forecasts higher future surpluses, as seen in the coefficient of surplus on value in the VAR, and surpluses are persistent. Though a higher value also forecasts a lower bond return, bond returns are much less persistent.

We can make the same point quantitatively with a variance decomposition. From (42),

$$
\begin{aligned}
\operatorname{var}\left[v c_{t}\right] \approx & -\sum_{j=1}^{\infty} \rho^{j-1} \operatorname{cov}\left(v c_{t}, \tilde{r}_{t+j}^{a}\right)+\sum_{j=1}^{\infty} \rho^{j-1} \operatorname{cov}\left(v c_{t}, d c_{t+j}\right) \\
& +\frac{1}{v c} \sum_{j=1}^{\infty} \rho^{j} \operatorname{cov}\left(v c_{t}, s c_{t+j}\right) .
\end{aligned}
$$

The debt/consumption ratio can vary only if it forecasts returns, surpluses, or consumption growth. The question is, which components account for fluctuations in value? To answer this question, I estimate the above moments from the VAR representation. For example,

$$
\sum_{j=1}^{\infty} \rho^{j} \operatorname{cov}\left(v c_{t}, s c_{t+j}\right)=e_{v}^{\prime} E\left(x x^{\prime}\right) \rho A(I-\rho A)^{-1} e_{s}, \quad E\left(x x^{\prime}\right)=\sum_{j=0}^{\infty} A^{j} \Sigma A^{\prime \prime}
$$

Table 6 presents the fractions of debt value variance so explained. Again, we see that forecasts of future surpluses account for the vast majority of

Table 6 FRACTIONS OF (DEBT VALUE)/CONSUMPTION EXPLAINED BY VAR FORECASTS OF SURPLUS/ CONSUMPTION, GOVERNMENT BOND RETURNS, AND CONSUMPTION GROWTH

\begin{tabular}{llc}
\hline Surplus & Retum & Consumption \\
\hline $84.7 \%$ & $13.6 \%$ & $2.6 \%$ \\
\hline
\end{tabular}

Each term is $100 \times \operatorname{cov}\left(v c_{i}, \Sigma_{j} \rho^{j} x_{t+j}\right) / v a r\left(v c_{i}\right)$, as estimated from the VAR representation. 
fluctuations in debt value. Furthermore, almost all variation is accounted for; we do not have to rely on bubble terms.

We are left with an unsettling picture. Based on perfect foresight, expected return variation is an important determinant of the value of the debt. Based on a simple VAR, expected return variation is unimportant. The latter result depends on the VAR: Variables such as yield spreads that forecast more long-run interest-rate variation could raise the contribution of bond returns.

\subsection{MATURITY}

The maturity structure is also potentially significant in our attempt to make sense of fiscal price determination. Bad fiscal news might be met by declines in long-term bond prices rather than a rise in the price level. Long-term debt sales can raise revenue with no change in future surpluses, by diluting the claims of existing long-term bonds. The inflation of the 1970s came down sharply along with large sales of long-term debt in the early 1980s, and inflation comes down with large debt sales in recessions. This mechanism may provide part of the explanation. Here I present some facts about the maturity structure that help us to see whether this is an important route to follow.

Figure 15 presents measures of the maturity structure, on a zerocoupon-equivalent basis as always. Overall, the maturity structure is surprisingly short: 40 to $70 \%$ of the debt has maturity one year or less,

Figure 14 COMPONENTS OF VALUE, AS MEASURED BY VAR

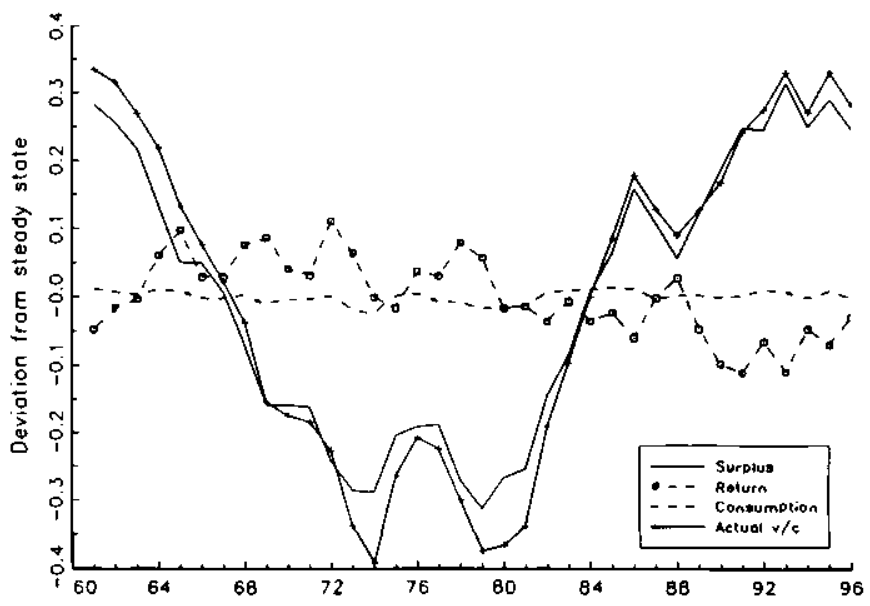


Figure 15 MATURITY STRUCTURE OF DEBT, ON A ZERO-COUPON EQUIVALENT BASIS

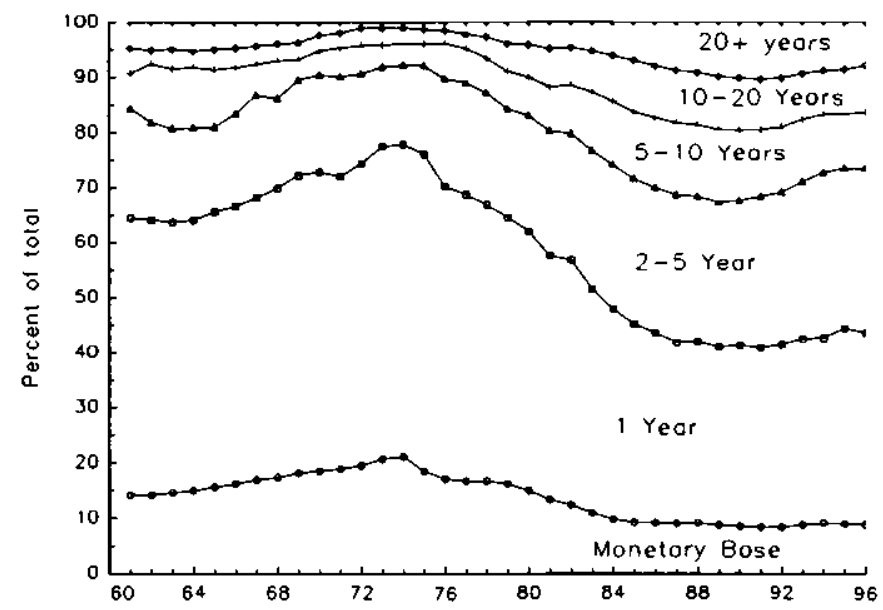

For example, debt between one and two years includes debt with one- and two-year maturity, plus all coupon payments that come due between one and two years.

Figure 16 MATURITY STRUCTURE OF DEBT, ON A ZERO-COUPON BASIS

Moturity structure, debt greoter thon 1 yeor moturity

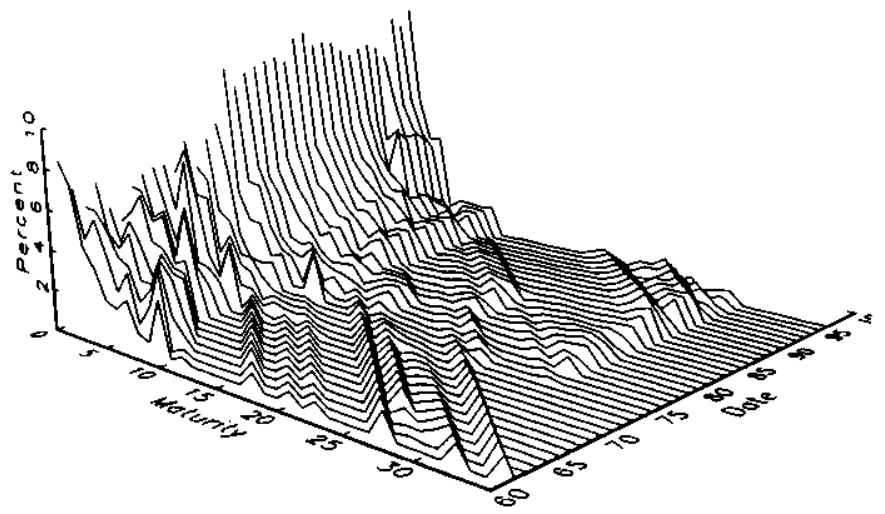

Each curve is the face value of outstanding debt divided by the face value of all debt. 
and is rolled over every year. These are face values; the market values of long-term debt are even smaller. As is well known from simpler measures, the maturity structure was quite short until about 1975 . Then longer-term debt gradually became more and more important. The buildup in long-term debt has been gradual, peaking about 1988.

Figure 16 presents the maturity structure of debt with more than oneyear maturity. (One-year and less maturity is such a large fraction of the debt that one cannot see the rest if it is included.) Starting in 1960, a few very long-term, low-coupon bonds are outstanding. The spikes in the maturity structure are the principal amounts of these bonds. As the bonds age, the spikes move in towards the zero-maturity point. The government sold very little long-term debt, so the major feature of the term structure, and the root cause of the shortening maturity structure seen in Figure 15, is the aging of this long-term debt.

Starting about 1975, along with the first big primary deficit, we can see the effect of new, regular long-term debt sales. Initially, these sales also leave lumps in the maturity structure, but soon the coupons of the accumulated long-term bonds smooth the maturity structure. A few large sales in the mid-1980s show up as lumps that then age. One can also see increased sales of 10-year debt and 2-year debt in the eventual height of the lines on the left-hand side.

\section{Conclusion}

Two main themes recur through this article. First, one can use the fiscal theory to understand why money is valued in modern economies with apparently unbacked fiat money. In systems in which money is explicitly backed, such as a gold standard or currency board, it turns out that the backing in terms of overall government resources is all that really matters: The fiscal theory points out that this backing continues to matter when explicit backing disappears. When money is valued because it is backed, the fact that certain assets have a liquidity value in exchange has at best second-order effects on the price level, and the value of money will therefore not be affected by financial innovation.

Second, in order to understand U.S. data from this fiscal perspective, we must view the primary surplus as following a process in which a negative shock today induces a positive change in the long run. While not immediately obvious, this is a natural specification. The government is faced with cyclical surplus shocks about which it can do little, yet it does not want wildly fluctuating and countercyclical inflation. Therefore, it sells extra debt in recessions, raising revenue by so doing because it implicitly promises to raise subsequent surpluses. 
Akerlof, G. A. (1979). Irving Fisher on his head: The consequences of constant threshold-target monitoring of money holdings. Quarterly Journal of Economics 93:169-189.

—, and R. D. Milbourne. (1980). Irving Fisher on his head II: The consequences of the timing of payments for the demand for money. Quarterly Journal of Economics 95:145-157.

Auerbach, A. J., J. Gokhale, and L. J. Kotlikoff. (1994). Generational accounting: A meaningful way to evaluate fiscal policy. Journal of Economic Perspectives 8:73-94.

Baba, Y., Hendry, D. F, and Starr, R. M. (1992). The demand for M1 in the U.S.A., 1960-1988. Review of Economic Studies 59:25-61.

Bernanke, B. S. (1983). Nonmonetary effects of the financial crisis in the propagation of the Great Depression. American Economic Review 73:257-276.

Black, F. (1970). Banking and interest rates in a world without money. Journal of Bank Research, Autumn, 9-20.

Bohn, H. (1998). The behavior of U.S. public debt and deficits. University of California at Santa Barbara. Working Paper.

Brash, D. T. (1996). New Zealand's remarkable reforms. Institute for Economic Affairs. Fifth IEA Annual Hayek Memorial Lecture, Occasional Paper 100.

Burnside, C., M. Eichenbaum, and S. Rebelo. (1998). Prospective deficits and the Asian currency crisis. Northwestern University. Working paper.

Campbell, J. Y., and R. J. Shiller. (1988). Stock prices, earnings, and expected dividends. Journal of Finance 43:661-676.

Canzoneri, M. B., R. E. Cumby, and B. T. Diba. (1997). Is the price level determined by the needs of fiscal solvency? Georgetown University. Working Paper.

Christiano, L. J., M. Eichenbaum, and C. L. Evans. (1998). Monetary policy shocks: What have we learned and to what end? Northwestern University and Federal Reserve Bank of Chicago. Manuscript.

Cochrane, J. H. (1992). Explaining the variance of price-dividend ratios. Review of Financial Studies 5, 243-280.

- (1994a). Permanent and transitory components of GNP and stock prices. Quarterly Journal of Economics CIX:241-266.

\section{1:295-364.}

- (1998). Long-term debt and optimal policy in the fiscal theory of the price level. Cambridge, MA: National Bureau of Economic Research. NBER Working Paper.

Cowen, T., and R. Kroszner. (1994). Explorations in the New Monetary Economics. Cambridge, MA: Blackwell.

Dupor, B. (1997). Exchange rates and bank notes: The fiscal theory of the price level. University of Pennsylvania. Manuscript.

Fama, E. F. (1980). Banking in a theory of finance. Journal of Monetary Economics 6:39-57.

- (1983). Financial intermediation and price level control. Journal of Monetary Economics 12:7-28.

- (1985). What's different about banks? Journal of Monetary Economics 15:29-39.

- and R. R. Bliss. (1987). The information in long-maturity forward rates. American Economic Review 77:680-692. 
Goodfriend, M. (1998). Central banking under the gold standard. CarnegieRochester Conference Series on Public Policy 29:85-124.

Hall, R. E. (1983). Optimal fiduciary monetary systems. Journal of Monetary Economics 12:33-50.

Hamilton, J. D., and M. A. Flavin. (1986). On the limitations of government borrowing: A framework for empirical testing. American Economic Review 76:808-819.

King, R. G. (1983). On the economics of private money. Journal of Monetary Economics 12:127-158.

Leeper, E. (1991). Equilibria under "active" and "passive" monetary policies. Journal of Monetary Economics 27:129-147.

Lucas, R. E., Jr. (1980). Equilibrium in a pure currency economy. Economic Inquiry 18:203-220.

Carnegie-Rochester Conference Series on Public Policy 29:137-167.

Sargent, T. J. (1986). Rational Expectations and Inflation. New York: Harper \& Row.

. (1987). Dynamic Macroeconomic Theory. Cambridge, MA: Harvard University Press.

Schmitt-Grohé, S., and M. Uribe. (1997). Price level determinacy and monetary policy under a balanced-budget requirement. Federal Reserve Board. Manuscript.

Sims, C. A. (1994). A simple model for the determination of the price level and the interaction of monetary and fiscal policy. Economic Theory 4:381-399.

(1997). Fiscal foundations of price stability in open economies. Yale University. Working Paper.

White, L. H. (1984). Competitive payments systems and the unit of account. American Economic Review 74:699-712.

Woodford, M. (1994). Monetary policy and price level determinacy in a cash-inadvance economy. Economic Theory 4:345-389.

- (1995). Price level determinacy without control of a monetary aggregate. Carnegie-Rochester Conference Series on Public Policy 43:1-46.

. (1996). Control of the public debt: A requirement for price stability? Cambridge, MA: National Bureau of Economic Research. NBER Working Paper 5684 .

(1997). Doing without money: Controlling inflation in a post-monetary world. Cambridge, MA: National Bureau of Economic Research. NBER Working Paper 6188.

\section{Comment}

HENNING BOHN

University of Califomla, Santa Barbara

\section{Introduction}

John Cochrane provides a provocative and quite radical perspective on U.S. inflation: Money and monetary frictions are irrelevant. Money need 
not even exist for the price level to be determinate, but nominal bonds are essential. The price level is obtained by equating the present value of exogenous budget surpluses with the real value of nominal debt. After explaining the general idea of the fiscal theory and acknowledging that the basic model has problems explaining U.S. data, the paper offers a more complicated model with long-term bonds and goes on to attack competing theories.

The paper's scathing critique of traditional monetary theory invites a somewhat critical response. Since my comments will indeed be mostly critical, let me emphasize that I am quite sympathetic towards fiscal theory in principle, e.g., towards Woodford's (1997) cashless limit version. Cochrane's version is more extreme, however, in abstracting from all monetary frictions; and he claims to explain U.S. history.

My comments will focus on three questions. How promising is the cashless view of U.S. history? Is it theoretically coherent? And how can we distinguish empirically between a fiscal and a monetary price determination?

\section{How Promising Is the Cashless View of U.S. History?}

John's attacks on the quantity theory should not distract from the real question: Does the cashless view provide a good (better?) explanation of postwar U.S. inflation? There are good reasons to be skeptical.

First, the basic model is counterfactual. In Cochrane's words: "The 1970s were a decade of low deficits and high inflation, while the 1980 s saw a dramatic increase in government debt with low inflation." In the model, high deficits should be inflationary. Should we really credit Ronald Reagan with defeating inflation? Because his actions signaled future budget surpluses? And Paul Volcker had nothing to do with it? At the end, Cochrane hints that adding long-term bonds (adding degrees of freedom?) might improve the model's fit, but that remains a conjecture.

Second, Cochrane applies a rather low plausibility standard. The best evidence in favor is a graph showing roughly parallel movements of actual and simulated inflation (Figure 11). The simulated inflation is, however, based on parameters chosen ad hoc to produce a "subjectively . . . convincing story." Moreover, "the model will only capture the parts of inflation that are correlated with surplus and value." How much is that? Since Cochrane criticizes quantity theory for not explaining all of inflation within a simple model, his model should be held to the same standard.

Finally, note that transactions balances show no signs of decline. Since 1980 , the downward drift in the M1/GDP ratio has stopped. The currency/ GDP ratio has actually risen by about $25 \%$. Though financial innovation 
has produced new means of payment and plausibly destabilized the demand for specific monetary aggregates, the U.S. economy is not moving in a cashless direction.

\section{Is the Cashless View Theoretically Coherent?}

My most serious concerns are about the political economy of John's model. The notion that bondholders are residual claimants on the government is a dangerous and misguided idea. Over the past 20 years, economists have tried hard to convince politicians that money and nominal bonds raise serious time-consistency problems and that politicians should commit to a noninflationary policy. This policy advice presumescorrectly I believe-that inflation and inflation uncertainty have some real cost. The entire literature on central-bank independence is, for example, based on this presumption.

In a frictionless economy, why should we advise politicians to maintain stable prices? Why should we expect a politician ever to enact a budget surplus? Nominal debt could be inflated away instantly and painlessly. If inflation has no cost while other taxes are distortionary, this would be efficient. In the time-consistency literature, it is well established that monetary frictions are essential to explain why a government can issue nominal bonds in the first place (Calvo, 1978; Bohn, 1988). Cochrane avoids this issue by assuming that nominal bonds are outstanding from the start. When it comes to new debt issues, he mentions "implicit promises to increase subsequent surpluses." It is unclear how and by whom these "promises" are made and how they are enforced. Moreover, if debt sales require a promise of future surpluses, isn't that making future surpluses endogenous, a function of debt? In Section 3.3 .1 , the $z_{t}$-component of the primary surplus is described as an exogenous stochastic process on one page and as being controlled by the government on another page. Overall, there is no coherent story of how budget surpluses are determined.

A nonmonetary example (to avoid misleading monetary intuition) may help to clarify why nominal debt is difficult to imagine in a frictionless economy. Consider a real economy with a homogeneous good, say, apples. The harvest is 100 apples. The government has 10 employees that each need to consume 1 apple. One feasible policy is to impose a tax of 10 apples. Alternatively, the government may try to borrow 1 apple and impose a tax of 9 apples. If individuals have a $100 \%$ time preference, the government can borrow 1 apple in period 1 if and only if it can credibly promise to repay 2 apples in period 2 , i.e., it promises to impose a tax of 12 apples. 
Now suppose the government decides to offer bonds denominated in "widgets." What's a widget? No one knows, but fortunately, no one cares. Individuals will trade 1 apple for a 1-widget government bond if and only if the government can credibly promise that a widget will be worth 2 apples in period 2 . Uncertainty could be added easily, say, a value of 1 or 3 apples conditional on a coin toss. The key point is that a credible commitment about the value of widgets is required before any borrowing can take place. The same logic applies to dollar-denominated debt. In Cochrane's frictionless model, a dollar is just a label like "widget." The government must make promises about the future purchasing power of dollars before it can issue dollar-denominated bonds. When the repayment period arrives, the budget surplus is constrained by these prior commitments. Since John's model is silent about such commitments, it is an incomplete theory. Either the government is constrained or there is a time-consistency problem.

The widgets story highlights another issue, the difference between default and inflation. Suppose the government reneges on its promises and declares a widget to be worth 1 apple instead of 2 . If only the government issues widget-denominated bonds, a cut in the purchasing power of widgets (inflation) is equivalent to a partial default. If widgets are used as unit of account by the private sector, however, an outright default leaves private claims unaffected while inflation devalues private loans, too. To persuade individuals to use widgets (dollars) as numeraire, the government will have to make credible promises about their value.

The private use of dollars raises further questions about the dynamics of consumer prices. Empirically, consumer prices move quite sluggishly as compared to speculative asset prices. This is a long-standing puzzle, e.g., in the purchasing-power parity literature. The frictionless view treats $1 / p_{t}$ as the price of a speculative asset, as a claim on stochastic future budget surpluses. This does not look promising. For example, suppose there is a news announcement that all future primary budget surpluses are cut in half: Do we really expect all stores to immediately change their price tags to double all nominal prices?

This question is analogous to the old question of what would happen if the Fed doubled the money supply. Realistically, prices would rise, but much more slowly than the quantity theory predicts. The question about halving the budget surplus should have the same answer. The failure to account for sluggish price adjustment is a major reason for the quantity theory's empirical problems. It seems unfair to denounce the quantity theory without acknowledging that the fiscal theory faces similar problems. Basic versions of both theories falsely predict that consumer prices should jump around in response to news announcements. 
Overall, Cochrane is creating unnecessary controversy by assuming away monetary frictions. Monetary and fiscal theories of inflation have actually much in common. Monetary theorists have long accepted that the government budget constraint matters for inflation because budget deficits can be monetized. When fiat money is held as medium of exchange, nominal bonds are not required in the basic monetization story (e.g., in Sargent, 1986). Nominal bonds are quantitatively important, however, because they magnify the government's financial gains from inflation. On the fiscal side, Woodford (1997) has shown that the fiscal theory can be derived as a "cashless limit" within the same conceptual framework. The more relevant question is which theory fits better for a certain country over a certain period.

\section{How Can We Identity an Economy with Fiscal Price Determination?}

The question if inflation is better explained by monetary ("Ricardian") or by fiscal ("non-Ricardian") considerations is at heart a political-economy question. If fiscal policymakers control the central bank, budget deficits are likely important for inflation. If the money supply is determined independently, fiscal authorities must either satisfy the intertemporal budget constraint or face default. Cochrane stacks the deck against the Ricardian case by ignoring the possibility of outright defaults, making the Ricardian case look special.

The political-economy perspective provides considerable guidance for empirical analysis. Of course, nothing is testable without auxiliary assumptions, which Cochrane refuses to make. Common sense suggests, however, that a positive regression response of the money supply to budget deficits would provide prima facie evidence for monetization. Similarly, a positive regression response of budget surpluses to debt accumulation provides prima facie evidence for fiscal adjustment. For the U.S., there is no convincing evidence for monetization, but Bohn (1998) and Canzoneri, Cumby, and Diba (1997) have found clear evidence for a surplus-to-debt linkage.

Cochrane's rebuttal is that one can create an observationally equivalent statistical model that interprets this linkage as a signaling effect. This is unconvincing, however, because the statistical model is ad hoc, whereas the evidence for fiscal adjustment is based on a coherent economic model. [Bohn (1998) examines an optimizing, tax-smoothing government.] The challenge for fiscal theory is to explain the data within a 
convincing model of government behavior. Exogenous policy rules don't qualify in this context, because they beg the question of who makes and enforces them.

Alternatively, one may try to find other statistical tests, though that seems easier in principle than in practice. For example, suppose there are shocks to the real interest rate. In a Ricardian model, increased debt service will force the fiscal authority to raise the primary surplus or face a default. In a fiscal-theory model, a higher discount rate on future real surpluses should trigger an immediate increase in prices. Thus, the fiscal theory has testable implications. Real interest rates are unfortunately difficult to measure, so that this particular test is likely inconclusive. A search for a better test is an important issue for future research. For now, an insistence on theory-based regressions is perhaps the best defense against arbitrary statistical modeling.

\section{A Technical Complaint}

Finally, in a paper about budget constraints, an incorrect intertemporal budget constraint should not be left unchallenged. Equation (7) is wrong. In a stochastic economy, budget surpluses must be discounted at a risk-adjusted interest rate that depends on the stochastic process for the primary surplus and on the economy's pricing kernel (Bohn, 1995). Except in special cases, the discount rate differs from the ex post return on government debt. Contrary to Cochrane's claims, assumptions about the rest of the economy do matter in this context.

\section{REFERENCES}

Bohn, H. 1988, Why do we have nominal government debt? Journal of Monetary Economics 21:127-140.

- (1995). The sustainability of budget deficits in a stochastic economy. Journal of Money, Credit, and Banking 27:257-271.

- (1998). The behavior of U.S. public debt and deficits. Quarterly Journal of Economics 113:949-964.

Calvo, G. A. (1978). On the dynamic consistency of optimal policy in a monetary economy. Econometrica 46:1411-1428.

Canzoneri, M., R. Cumby, and B. Diba. (1997). ls the price level determined by the needs of fiscal solvency? Georgetown University. Working Paper.

Sargent, T. (1986). Rational Expectations and Inflation. New York: Harper \& Row. Woodford, M. (1997). Doing without money: Controlling inflation in a postmonetary world. Cambridge, MA: National Bureau of Economic Research. NBER Working Paper 6188. 


\section{Comment}

\section{MICHAEL WOODFORD}

Princeton University

\section{Introduction}

John Cochrane has written a fascinating and provocative paper that is certain to stimulate a great deal of further discussion and research. The paper ranges over quite a broad territory and throws out far too many new ideas for me to comment on all of them here. I do think, however, that it is important to mention several of the paper's broad themes, in order to distinguish among them. This is necessary in order for my subsequent remarks, which mainly concern one particular strand in the paper's analysis, to be properly understood.

\section{Broad Themes of the Paper}

The paper argues for (and illustrates) several heterodox views about the explanation of inflation. Each is interesting and worth discussion, but I think it is important to realize that they are distinct theses, and need not be accepted or rejected as a package. I would distinguish at least three distinct themes, each of which would be quite controversial in many quarters:

1. Abstraction from monetary frictions, even when modeling inflation.

2. A fiscal theory of price-level determination.

3. Monetary-policy ineffectiveness, especially in the sense of having no effect upon inflation.

None of these provocative theses necessarily implies the others. For example, a "cashless" account of U.S. inflation [in the sense defined in Woodford (1998a)] may nonetheless (a) ascribe no role to fiscal policy, and (b) imply that monetary policy matters a great deal, for the evolution of inflation among other things. An example is the model of post-1979 U.S. monetary policy presented in Rotemberg and Woodford (1997). The theoretical model underlying that work is a neo-Wicksellian model of inflation determination, in which the key elements are a specification of monetary policy in terms of an interest-rate feedback rule (which links nominal interest rates to the behavior of inflation), and a theory of the

I would like to thank Michael Bordo, Matt Canzoneri, and Eduardo Loyo for helpfuI discussions, and Loyo for collaboration on the empirical work reported here. 
determinants of the equilibrium real rate of interest (which is affected by inflation as a result of nominal rigidities). The model abstracts entirely from monetary frictions in its account of the economic determinants of the equilibrium real rate of return, and since monetary policy is formulated directly in terms of an interest-rate rule, it is not necessary to explicitly model the sources of the demand for the monetary base that allow the central bank to achieve the interest-rate changes that it seeks. In such a model it is not essential that one abstract from the existence of monetary frictions, but it is possible to do so, and since they are not central to the model, and likely to be quantitatively small in any event, exposition and analysis of the model is simpler when they are dispensed with.

But the price level may be determined in such a model without any reference to the government's budget or to the size of the public debt. [See the discussion in Woodford (1998a) of "Wicksellian" policy regimes.] In Rotemberg and Woodford (1997), fiscal policy is assumed to be Ricardian, in the sense discussed by Cochrane. This implies that Ricardian equivalence obtains in that model, and fiscal variables are irrelevant to the determination of both output and inflation.

Furthermore, monetary policy matters in that model, for the equilibrium behavior of both inflation and output. Here it is important to distinguish between "cashless" models in the sense of Woodford (1998a)-in which the money supply is not an important state variable, because the amount of cash needed for transactions is small enough to result in only negligible distortions - and models in which the central bank has no lever with which to affect equilibrium, because it is too small a player in financial markets, and government-supplied financial claims have no special features. In the cashless limit as I define it, the central bank can still control nominal interest rates through open-market operations between money and bonds, due to the existence of a residual demand for the government-monopolized monetary base. But once one models the way in which the bank sets its interest-rate instrument, the details of the associated changes in the money supply are unimportant; and even the level of nominal interest rates only matters through its implication for the level of short-term real interest rates, given inflation expectations. The Fed's assumed control of the federal funds rate is an important element of the reconstruction of U.S. time series given in Rotemberg and Woodford (1997), as is the assumption that other short-term nominal rates move with it in equilibrium; and the model used there implies that alternative monetary policy regimes would lead to very different inflation performance, as shown by the counterfactual policy simulations reported in the paper. 
Similarly, a "fiscal theory of the price level" of the kind proposed in Woodford (1995) need not abstract from monetary frictions, and may well assign an important role to monetary policy. As Cochrane notes, many previous presentations of fiscalist models incorporate a conventional specification of money demand. ${ }^{1}$ Cochrane is right that liquidity preference plays no central role in a fiscalist account of price-level determination, and so there are expository advantages to dispensing with it [as I do in much of the analysis in Woodford (1998b)]. But it is also useful to remember that the fiscalist view does not depend upon any unconventional view about the substitutability of money and other assets-a point that I was concerned to make in discussions such as Woodford (1995), exactly because of the importance of questions about the existence of a clear distinction between monetary and nonmonetary assets in previous (but very different) criticisms of the quantity theory of money.

And whether one assumes a cashless limiting economy or not, fiscalist accounts of inflation determination generally imply that the specification of both monetary and fiscal policy matters. For central-bank interest-rate policy will affect the evolution of nominal government liabilities, a crucial state variable in a fiscal theory of the price level, even if one ignores the effects of monetary distortions in private-sector behavioral relations. For example, in Loyo's (1997) explanation of Brazilian inflation in the early 1980 s, the crucial event that triggers the inflationary spiral is a change in the monetary policy rule, from a "passive" rule to an "active" one in Leeper's (1991) sense. Loyo expounds his theory in a cashless model, and assumes a non-Ricardian fiscal policy (that does not substantially change between the late 1970 s and early 1980 s); equilibrium inflation is then determined by price-level adjustment at each date to equate the value of existing public debt with the present value of expected future budget surpluses. Still, the specification of monetary policy matters for his model, and indeed the change in monetary policy is crucial to his story.

Thus Cochrane's three themes deserve separate consideration. My own view is that the consideration of "cashless" models is quite appropriate and often useful, at least as a first approximation; there are surely some economies and some issues for which modeling the demand for monetary assets does matter, but it is often a second-order issue, even when analyzing monetary policy and the determinants of inflation.

The fiscalist view of price-level determination is probably of more restricted applicability, for its application depends upon what kind of fiscal policy, Ricardian or non-Ricardian, a government is expected to

1. See, e.g., Leeper (1991), Sims (1994), or Woodford $(1995,1996)$. 
follow. The non-Ricardian alternative seems to me a perfectly logical possibility [and one can even think of reasons for a non-Ricardian regime to be deliberately chosen, as part of an optimal policy regime, as discussed in Woodford (1998b)], but the frequency with which actual fiscal policies are or have been of that kind remains an open question at present. The interest of the theory does not require an assertion that all or even most policy regimes are of that kind; it would still be of interest to consider its normative properties even if no actual governments had ever behaved in such a way. And as I discuss below, there are certainly reasons to doubt that U.S. fiscal policy is non-Ricardian, at least as things stand at present. But I am less sure about U.S. policy during the late 1960 s and in the 1970s, as discussed below. And I find it quite plausible that the regime in effect prior to the 1951 Federal ReserveTreasury accord should be described as non-Ricardian. [That period would represent a historical example of the kind of interest-rate pegging regime for which the theory was developed, in Woodford (1995).]

The thesis of Cochrane's which I find least plausible is the last one: his assertions that open-market operations have actually been ineffective in the U.S. over the period that he studies, and that monetary policy is unimportant for an explanation of inflation history. As noted above, the assumption that the Fed can control short-term nominal interest rates is central to the account of recent U.S. time series given in Rotemberg and Woodford (1997). I also believe that an attempt to interpret recent U.S. inflation history along fiscalist lines would be most plausible if it incorporated such a view, and allowed for feedback from inflation to the level of nominal interest rates as a result of Fed policy. (I illustrate how such an account might proceed below.)

The VAR evidence discussed in Section 2.6.2 is no real reason to doubt the importance of monetary policy. It simply implies that the unsystematic component of monetary policy has not been a very important source of disturbances to the economy. That finding might be disquieting to some monetarists, though I actually suspect that it would be cheerfully accepted by Friedman and Schwartz. It in no way implies that the nature of systematic monetary policy does not greatly matter for the effects (upon both inflation and output) of other kinds of economic disturbances. For example, the Rotemberg-Woodford (1997) reconstruction of the U.S. data attributes less than $2 \%$ of inflation variation since 1979 to the effects of exogenous monetary policy shocks (see Figure 3 of that paper), while at the same time implying that alternative coefficients in the interest-rate rule followed by the Fed should lead to radically different inflation outcomes (see Table 2 of that paper).

It is not entirely clear which of these themes Cochrane means to em- 
phasize more. The paper's title stresses the "frictionless" aspect of his account, which might be a reference either to his neglect of monetary frictions, or to his view that monetary policy has been irrelevant. In fact, it seems to me that the paper spends the most time on, and has the greatest number of new results about, the second thesis-the fiscal theory of the price level. Accordingly, I shall direct my remaining remarks solely to that aspect of the paper. And since the most ambitious aspect of Cochrane's discussion of the fiscal theory is his discussion of its empirical implications, I shall direct my attention there. ${ }^{2}$

\section{Can One Distinguish Ricardian from Non-Ricardian Policy Regimes?}

The most important contribution of the paper is surely its discussion of whether the record of U.S. fiscal policy and inflation since 1960 can be squared with a fiscalist view of inflation determination. ${ }^{3}$ Probably few readers will feel that Cochrane's proposed interpretation of the U.S. data conclusively settles this issue. However, his illustration of how a fiscalist interpretation of those data is possible makes an important advance, in that it shows that it is not nearly so easy to reject the fiscalist view out of hand as might have been supposed. Many have supposed that the simple fact that U.S. deficits (and the size of the public debt) increased in the early 1980s, while inflation dramatically declined at almost the same time, was in itself a clear demonstration that the variations in U.S. inflation in this period could not be explained in fiscalist terms. Cochrane shows that this is not so. The data can be reconciled with a fiscalist account, in which U.S. real primary deficits have evolved exogenously and in turn determined the inflation rate; and this is because they can be reconciled with a statistical model of the deficit process according to which expectations of future fiscal surpluses improved sharply over the first half of the 1980s. This demonstration will surely spark further discussion of the merits of alternative possible interpretations. Cochrane's construction of a useful annual data set for the changing value of U.S. public debt and for the associated primary deficits should also help to stimulate further work of this kind.

2. For a recent attempt of my own to clarify some of the theoretical issues, see Woodford (1998b).

3. Despite the amount of recent theoretical analysis in this vein, few attempts at empirical applications have yet been made. Two noteworthy early efforts were Shim (1984) and Leeper (1989). Leeper stresses the importance for empirical testing of recognition that the private sector is likely to have information about future government budgets that is not revealed by the recent evolution of the government budget itself, an important theme of Cochrane's work here as well. 
Cochrane resists the idea that one should try to "test" the validity of a fiscalist interpretation by seeking to test whether or not U.S. fiscal policy has been Ricardian; instead, he simply proposes to construct a fiscalist interpretation of the data, to see if one can, and to see how implausibly complicated such an interpretation of the data would have to be. $\mathrm{He}$ is right, I think, not to organize his investigation around a formal hypothesis test. This is not because the hypothesis of a non-Ricardian fiscal regime has no testable implications. The problem is simply that it is a hypothesis not about what has happened (say, whether inflation has been correlated with changes in the value of the public debt) but about why it has happened, about the causal connections between the changes in various variables. Such hypotheses about causality can never be confirmed or rejected on the basis of a series of observations without the help of identifying assumptions of one sort or another, and these identifying assumptions are seldom implied by the hypothesis itself, in its most general form. Thus it is often not possible to test a hypothesis (which is nonetheless of considerable import) except jointly with a number of other maintained assumptions, the validity of which may be debatable to a greater or lesser extent. Careful thought about the source of convincing identifying assumptions is always crucial in applied work, and in the absence of them, it is better to admit that one is not engaged in hypothesis testing.

It does not seem easy to test in a convincing way for the existence of a Ricardian or non-Ricardian fiscal regime simply on the basis of the observed evolution of government budget deficits and the value of the public debt. For example, it is a mistake to suppose that tests of the "sustainability" of fiscal policy, in the sense of asking whether the value of the public debt would satisfy a transversality condition of the form

$$
\lim _{j \rightarrow \infty} E_{t} \frac{1}{r^{j}} v_{t+j}=0
$$

in the absence of a change in the law of motion associated with current policy, show whether current fiscal policy is Ricardian or not. The reason, as Cochrane notes, is that under a non-Ricardian regime, (1) is predicted to hold in equilibrium. It is simply not guaranteed to hold as a result of the way that government budgets are determined, regardless of the path of goods and asset prices, and as a result it can help to determine equilibrium prices.

In fact, if anything, it is under a regime of fiscal determination of the price level that one should least expect to see, in a finite sample, a path of 
the public debt apparently inconsistent with the transversality condition. The reason is that the fiscal theory of the price level implies that even if government fiscal policy does not guarantee a bounded debt/GDP ratio, any disturbances (fiscal or otherwise) that lead to an expectation of an explosive public debt, in the absence of any change in the price level, will stimulate aggregate demand and so drive up prices enough to restore the expectation that (1) will be satisfied. In a Ricardian world, by contrast, where people do not regard government debt as net wealth because they are confident that fiscal policy will eventually have to adjust to satisfy (1), a transitory period of failure of government budgets to adjust so as to maintain the debt/GDP within normal bounds might well result in explosive debt growth for a time-exactly because the private sector's confidence that fiscal policy will eventually adjust would prevent adjustment from occurring through inflation. ${ }^{4}$ Thus evidence of the stationarity of the U.S. debt/GDP ratio is actually more compatible with a fiscalist account of U.S. inflation determination than a contrary finding would be.

Tests based upon estimation of specific feedback rules for the determination of government budget surpluses, as in Bohn (1998), are more to the point. In principle, estimation of such a fiscal policy rule is exactly what should determine whether policy is Ricardian or not. However, it is important to realize that valid inference depends upon being able to treat the estimated relation as truly structural; hence the usual problems with simultaneous-equations bias and other sorts of potential specification error must be attended to. For example, if fiscal policy were known to be described by a linear feedback rule like

$s_{t}=\alpha \frac{B_{t-1}(t)}{p_{t}}+\epsilon_{t}$

where $\epsilon_{t}$ is an exogenous fiscal policy disturbance, then estimation of the coefficient $\alpha$ would indeed settle the question of whether policy is

4. Woodford (1998b) analyzes the possible equilibria under a fiscal regime in which the real primary surplus is exogenously fixed unless the real public debt reaches the government's "debt limit," at which point financial markets force the government's budget to adjust due to inability to borrow more. If the private sector has Ricardian expectations, the resulting equilibrium is one in which a shock can give rise to a debt explosion which eventually results in the debt limit being reached and a forced adjustment of the government's budget, confirming the Ricardian expectations. An econometrician observing such an equilibrium prior to the debt crisis would correctly infer that fiscal policy was "unsustainable." On the other hand, under the same government policy, if the private sector has fiscalist expectations, the same sort of shock results in a price-level adjustment, as a result of which the debt limit is never hit, and the government never deviates from its desired exogenous path for the real primary surplus, confirming these expectations as well. 
Ricardian. On the other hand, even granting the correctness of this specification, an OLS estimate of $\alpha$ could be expected to be unbiased only if one were sure that the disturbance $\epsilon_{t}$ should be uncorrelated with the regressor $B_{t-1}(t) / p_{t}$. In the case of a fiscalist equilibrium, one would not expect this to be true, and indeed the likely bias in the estimate of $\alpha$ would be positive. The same kind of fiscal disturbances that would increase the current surplus (in the absence of any change in the market value of the public debt) would also be likely to cause an endogenous increase in the market value of existing government debt, as Cochrane discusses.

The obvious way to deal with this problem is by looking for instrumental variables that are associated with some nontrivial degree of variation in the market value of the public debt, but are believed to be uncorrelated with exogenous fiscal policy shifts. The most likely source of such variables would involve identifying one or more structural disturbances not related to fiscal policy. Of course, even if one could agree upon those, there would remain the question of the correctness of the specification of the fiscal rule (2). If $\epsilon_{t}$ actually includes omitted endogenous variables to which fiscal policy responds, and the nonfiscal shock affects those variables, the assumption that $\epsilon_{t}$ should be uncorrelated with the identified nonfiscal shock might well be wrong. Still, future work along these lines is likely to be fruitful. But it is important to realize that it will have to involve looking at more than just the evolution of the budget surplus and the market value of the debt alone. Not only would such estimation require the use of one or more other instruments, but the construction of the instrumental variables is likely to require the specification and estimation of additional structural equations, such as a feedback rule for monetary policy that would allow identification of a monetary policy shock, that could then be used as an instrument in the estimation of the fiscal policy rule.

In fact, the most fruitful approach to the problem may well involve estimation of joint specifications of monetary and fiscal policy. For the predicted consequences of alternative monetary policy rules depend a great deal on whether fiscal policy is Ricardian or not; this is one of the main reasons why the question of whether a given country's fiscal regime should be modeled as Ricardian is of such importance. Exactly because the predictions are dramatic, they are an appealing basis for inference about the character of fiscal policy (and of private-sector expectations regarding it). For example, Leeper (1991) shows, in the context of parametric families of monetary and fiscal policy rules, that a certain type of monetary policy rule (his "active" monetary policy) implies a unique stationary rational expectations equilibrium, associated with sta- 
tionary fluctuations in both inflation and the real public debt, in the case of a (locally) Ricardian fiscal policy5; but the same kind of monetary policy is inconsistent with the existence of a stationary equilibrium in the case of (locally) non-Ricardian fiscal policy. [In the case of the latter policy configuration, the only possible equilibrium may involve explosive inflation dynamics, as in Loyo's (1997) analysis of Brazilian inflation in the early 1980s.] Similarly, an alternative type of monetary policy rule (Leeper's "passive" monetary policy) implies a unique stationary equilibrium in the case of a (locally) non-Ricardian fiscal policy, but makes rational expectations equilibrium indeterminate in the case of a (locally) Ricardian policy, so that the economy might in the latter case be subject to inflation variations due purely to self-fulfilling expectations. ${ }^{6}$

Results of this kind make possible inferences about the nature of fiscal policy on the basis of estimates of monetary policy rules. Thus, for example, Loyo (1997) argues that Brazilian fiscal policy in the late 1970s and early 1980 s was non-Ricardian, not on the basis of an estimated feedback rule for fiscal policy, but on the ground that the shift around 1980 from "passive" to "active" monetary policy (according to his estimated monetary policy rules) coincided with a transition from a period of stable inflation to one of ever-accelerating inflation. Similarly, given the stability of U.S. inflation, and assuming that one prefers an explanation under which this represents a determinate equilibrium prediction rather than simply one among a vast set of possible outcomes, one might suppose that recent U.S. experience could only plausibly be attributed to a combination of "active" monetary policy and Ricardian fiscal policy, or to a combination of "passive" monetary policy and non-Ricardian fiscal policy. Under such reasoning, convincing estimates of the U.S. monetary policy rule would tell one a great deal about this aspect of fiscal policy.

In fact, much recent literature follows Taylor (1993) in characterizing recent U.S. monetary policy by an interest-rate feedback rule of the form

$R_{t}=R^{*}+\phi_{p}\left(\pi_{t}-\pi^{*}\right)+\phi_{y} y_{t}$

5. Technically, Leeper's distinction between "passive" and "active" fiscal policies- $\alpha$ greater or less than $r-1$ in (2)-corresponds to policies that are "locally Ricardian" and "locally non-Ricardian," respectively, in the sense defined in Woodford (1998b). A locally nonRicardian rule may nonetheless be globally Ricardian, and in fact, when $0<\alpha<r-1$, the fiscal policy rule allows the value of the public debt to explode, though not at a rate as high as the interest rate. The local criterion is the relevant one if, as Leeper is, one is interested in equilibria in which fluctuations in inflation and in the debt/GDP ratio are stationary.

6. For further discussion of how the determinacy of equilibrium is affected by the joint properties of monetary and fiscal policy rules, see Benhablb, Schmitt-Grohé, and Uribe (1998). 
or a generalization of this allowing for lags, forecasts, and a stochastic disturbance term. Here $R_{t}$ represents the federal funds rate, $\pi_{t}$ the inflation rate, $\pi^{*}$ the implicit inflation target, $R^{*}$ the steady-state funds rate consistent with stationary inflation at the target rate, and $y_{t}$ the log of real GDP relative to trend; Taylor argues that desirable coefficients, and empirically realistic ones for the U.S., at least since the late 1980s, involve $\phi_{p}>1, \phi_{y}>0.7$ In the context of Leeper's model, which assumes an exogenous level of real GDP (because prices are flexible), the coefficient $\phi_{y}$ is irrelevant to the issue of stability and determinacy of equilibrium, and a policy of the form (3) corresponds to what he calls "active" monetary policy if and only if $\phi_{p}>0$. Thus if Taylor's characterization of U.S. monetary policy is correct, it suggests that U.S. fiscal policy must be expected to be Ricardian, given that we do not observe signs either of a Brazilian-style debt explosion and inflationary spiral, or of a Japanesestyle deflationary trap.

Of course, the conditions for stability and determinacy of equilibrium depend upon the specification of one's model's other structural equations, and not simply upon the form of the monetary policy rule, and so a conclusive judgment cannot be reached without consideration of alternative, more realistic specifications-both of the monetary policy rule (3) and of the model's structural equations. Still, such alternative analyses as have been undertaken to date tend to confirm that $\phi_{p}>1, \phi_{y}>0$ are sufficient conditions for determinacy under a Ricardian fiscal policy and instability under a non-Ricardian policy, ${ }^{8}$ and also to confirm that U.S. monetary policy since the 1980 s is of a form that implies these results, even when the specification (3) is generalized. ${ }^{9}$ This is why the account given in Rotemberg and Woodford (1997) of U.S. inflation since 1980 assumes a Ricardian fiscal policy-not because of any evidence about the nature of fiscal policy, but because our estimated monetary policy rule is only consistent with a stationary equilibrium (given our structural equations) under that hypothesis. Furthermore, our model is able to account quite well for the estimated effects of monetary policy shocks during this period under the hypothesis of Ricardian fiscal policy,

7. Taylor's (1993) description of recent U.S. monetary policy assumes $\pi^{*}=0.02$ per year, $R^{*}=0.04$ per year, $\phi_{p}=1.5$, and $\phi_{y}=0.5$.

8. For example, Woodford (1996) generalizes Leeper's model to allow for sticky prices and endogenous supply, and finds that in that case $\phi_{y}>0$ only lowers the threshold value of $\phi_{p}$ needed to get Leeper's results. Rotemberg and Woodford (1998) demonstrate this as well, in the context of a more complicated sticky-price model, and also show that partial adjustment of the funds rate toward a time-varying target defined by (3) does not change this threshold. See, however, Benhabib, Schmitt-Grohé, and Uribe (1998) for results with a contrary flavor.

9. See, e.g., Clarida, Gali, and Gertler (1998). 
whereas the predicted effects would be different in the case of a different type of fiscal policy, such as the exogenous process for the real primary surplus assumed by Cochrane in his account of U.S. inflation here.

On the other hand, these results, even if taken to imply that current U.S. fiscal policy is best modeled as Ricardian, do not imply that all government policies are always best modeled that way, or even that U.S. policy has always been of that kind. Indeed, attempts to extend the characterization of U.S. monetary policy in terms of a "Taylor rule" to the period prior to 1979 have typically estimated a coefficient $\phi_{p}$ well below one for the earlier period..$^{10}$ In the context of Leeper's model, and other simple models with a similar structure, this would imply that inflation should have been subject to fluctuations due purely to self-fulfilling expectations in this period, and that is indeed the interpretation suggested by Clarida, Galí, and Gertler (1998). That is perhaps one possible interpretation of the instability of the 1970s. But such estimates of the monetary policy rule are also quite consistent with the view that fiscal policy was non-Ricardian during that period, and that there was a determinate stationary equilibrium inflation process-determined by variations in fiscal expectations. Indeed, the latter interpretation would have the advantage (apart from explaining how equilibrium is determined) of offering a potential explanation of why monetary policy was conducted in the way that it was in that period, namely, that "passive" monetary policy was made necessary by the determination of the fiscal authorities to follow a non-Ricardian policy. Similarly, attempts to estimate "Taylor rules" for other countries sometimes result in estimated rules that would imply indeterminacy of equilibrium in the case of a Ricardian fiscal policy. ${ }^{11}$ Possibly these results imply that the assumed form of feedback rule for monetary policy is mis-specified, but an interpretation in terms of a non-Ricardian policy regime would also seem to be worth pursuing.

\section{A Fiscalist Interpretation of U.S. Inflation History}

I turn now to Cochrane's proposed interpretation of U.S. time series in terms of a fiscal regime under which the evolution of the real primary budget surplus has been completely exogenous. Such a characterization, if correct, would represent a classic example of a non-Ricardian fiscal policy rule. If the policy were correctly understood by the private sector, fiscal shocks ought to have wealth effects and affect aggregate demand, and, in the simple model assumed here (in which prices are perfectly

10. See, e.g., Clarida, Galí, and Gertler (1998) and Taylor (1998).

il. See, e.g., Kutter (1998). 
flexible and equilibrium real activity and real rates of return accordingly exogenous), equilibrium would have to be restored by price-level adjustments. The primary achievement of this analysis is to show that the fiscal series themselves are not inconsistent with the non-Ricardian hypothesis. In particular, a model of the debt and surplus series is presented that is fully consistent with the evidence that Bohn (1998) and Canzoneri, Cumby, and Diba (1998) offer as support for Ricardian policy in the U.S., but that contradicts their Ricardian interpretations of these facts. This illustrates concretely how difficult it is to distinguish between Ricardian and non-Ricardian regimes on the basis of these series alone.

The explanation of inflation variations under such a regime is given somewhat less thorough attention, although an illustration is given (in his Figure 11) of the extent to which the assumption that inflation is a linear function of the current surplus and the current value of the public debt (each deflated by a consumption-based measure of "permanent income") with suitable coefficients could account for both low-frequency and cyclical fluctuations in inflation over the period. This does not seem to quite represent a complete model of how inflation is determined..$^{12}$ In particular, there is no discussion of how the particular coefficients in his equation (40) relate to the mechanism stressed in the fiscal theory of the price level, according to which inflation variations occur insofar as they are necessary to make the real value of the public debt consistent with expectations regarding future surpluses. The results of the exercise do show that an explanation of inflation variations as largely due to exogenous fiscal developments is not absurd on its face, as would be the case if the inflation series were completely independent of the fiscal series. Instead, Figure 11 shows that if one could explain why variations in the fiscal series should affect inflation in the hypothesized way, one might potentially explain a good bit of the variation in annual inflation rates along such lines.

A more interesting version of such an exercise, in my view, would

12. The inflation equation (40) is described as resulting from rules by which the government picks the long-run surplus shock $\epsilon_{2 t}$ and the nominal government debt $V_{t}$ each period. But this seems to allow too many independent dimensions of variation in fiscal policy. The government can control the growth of the public debt by varying the size of its budget surplus, and it has many instruments through which it can affect the size of the surplus. But it can't use its control of its budget to simultaneously achieve target levels of the real public debt and of the nominal public debt, which is essentially what this discussion assumes. What is missing is the specification of a monetary policy rule. This is presumably left out because, under Cochrane's view that open-market operations are irrelevant, monetary policy should not be able to affect market rates of return. But in that case, the missing equation would still be a specification of the short-term nominal interest rate-as an exogenous process, if monetary policy cannot affect it. See the treatment of a regime with elastic supply of private money in Woodford (1995). 
involve specifying a monetary policy rule as well as the stochastic process for the primary budget surplus, and then asking what endogenous inflation variations would be implied by the fiscal theory of the price level. Such a variation is interesting for several reasons. First, it allows us to ask whether we can account for the history of U.S. inflation in terms of the variations required to ensure a value for the U.S. public debt commensurate with expected future budget surpluses. I shall not claim that the possibility of such a reconstruction of the data proves that the explanation is correct; but, in the spirit of Cochrane's exercise, it is certainly worth seeing if any story of that kind can be told at all, and what it would involve.

Second, an estimated monetary policy rule may or may not even be consistent with the existence of a stationary equilibrium under the proposed model of fiscal policy, as discussed above. This means that we can go beyond simply saying that Cochrane's structural interpretation of his VAR model of the debt and surplus series is another possible structural interpretation, no better and no worse than the Ricardian interpretation favored by Bohn (1998) and by Canzoneri, Cumby, and Diba (1998); we can instead test the consistency of this interpretation with an estimated monetary policy rule, and one of the interpretations of the fiscal VAR will necessarily fit better with that rule. And finally, given an estimated monetary policy rule, we can ask not only about the conformity of overall inflation variations predicted by the model with those observed, but about how the model predicts inflation should respond to each of the different shocks in the VAR model of fiscal policy; for example, we can ask how inflation should respond both to Cochrane's "cyclical" surplus innovation and to his "long-run" surplus innovation, and compare these predictions with historical experience, given the identification of those shocks under his interpretation of the VAR.

I shall illustrate how this could be done without pretending to have carried out a complete or conclusive analysis, which would be beyond the scope of this discussion. I first estimate a VAR model of the debt and surplus processes, intermediate in size between the VARs reported by Cochrane in his equations (37) and his Table 5. My VAR is of the form

$x_{t}=A x_{t-1}+\epsilon_{t}$

where $x_{t}$ is the transpose of the vector $\left[v c_{t} s c_{t} d c_{t}\right] .{ }^{13}$ Under the proposed non-Ricardian interpretation, these three series are all (at leastjointly) exo-

13. I use Cochrane's notation, and also his data, kindly supplied. 
genous, and the estimated VAR equations are interpreted as structural. I include the $d c$ series, interpreted as indicating the exogenous evolution of "permanent income," because that process, along with the two series included in Cochrane's equation (37), is needed for a complete statistical model of the evolution of the primary budget surplus. On the other hand, I do not include the $\tilde{r}_{t}^{a}$ series, included in Cochrane's Table 5 VAR, because this series (the ex post real return on the public debt) should be implied by the evolution of the three elements of $x$. Note that log-linear approximation of the government budget accounting identity ${ }^{14}$ yields

$\tilde{r}_{t}^{a}=\rho\left(v c_{t}+s c_{t}\right)+d c_{t}-v c_{t-1}$

Thus a statistical model of the form (4), combined with the identity (5), represents a complete model of the evolution of these four series.

Note that the VAR (4) will imply, in general, a time-varying expected return process. Because I allow for this, there is no need to adjust the coefficients of the VAR to make them compatible with the present-value relation, as Cochrane does with the numbers reported in equation (37). These expected real returns, like "permanent income" expectations, are assumed to evolve exogenously with respect to the nominal variables, as would make sense under the assumption of perfectly flexible prices. Finally, I do not assume that the evolution of either "permanent income" or expected real returns is necessarily exogenous with respect to the fiscal disturbances. The same real disturbances that determine the path of the real primary budget surplus (e.g., variations in military spending needs) may well affect real activity and investment demand, and hence equilibrium consumption and real rates of return. So I simply assume jointly exogenous processes for the real primary surplus, consumption, and the expected real rate of return, the evolution of which can be described in terms of a state vector with three elements each period. The present-value relation then implies that $v c_{t}$ will also be a linear combination of these three states, and so we can use $v c_{t}, s c_{t}$, and $d c_{t}$ as proxies for the three states (given that expected returns are not directly observed). Under this interpretation, there are no a priori restrictions upon the elements of $A$.

The coefficients of the OLS regressions used to estimate the VAR are presented in Table 1. (Constants are neglected in the table, though included in the regressions.) These regressions are reasonably similar to the corresponding equations in Cochrane's Table 5. In particular, the coefficient of 0.067 on $v c_{t-1}$ in the $s c_{t}$ equation is consistent with the evidence that Bohn (1998) interprets as showing that surpluses are ad- 
Table 1 VAR COEFFICIENTS

\begin{tabular}{lcccc}
\hline & \multicolumn{4}{c}{ Regressor } \\
\cline { 2 - 4 } Equation & $v c_{t-1}$ & $s c_{t-1}$ & $d c_{t-1}$ & $R^{2}$ \\
\hline$v c_{t}$ & 1.000 & -0.634 & -2.508 & .95 \\
(s.e.) & $(.041)$ & $(.198)$ & $(.641)$ & \\
$s c_{t}$ & 0.067 & 0.455 & 1.662 & .67 \\
(s.e.) & $(.022)$ & $(.109)$ & $(.352)$ & \\
$d c_{t}$ & 0.007 & -0.041 & 0.355 & .15 \\
(s.e.) & $(.011)$ & $(.052)$ & $(.169)$ & \\
\hline
\end{tabular}

justed in response to variations in the size of the public debt; and the pattern of positive and negative coefficients on $s c_{t-1}$ in the $s c_{t}$ and $v c_{t}$ equations respectively is consistent with the evidence that Canzoneri, Cumby, and Diba (1998) interpret as showing that positive disturbances to government budget surpluses imply further high surpluses in the future, while reducing the size of the government debt. Nonetheless, one can interpret all of these coefficients as being consistent with an exogenous surplus process, as just discussed. Using the identity (5), the estimated coefficients imply a real-return equation of the form

$$
E_{t-1} \tilde{r}_{t}^{a}=0.064 v c_{t-1}-0.219 s c_{t-1}-0.483 d c_{t-1} \text {, }
$$

which is also similar to the corresponding equation in Cochrane's Table 5.

I now adjoin to this model of the fiscal variables a monetary policy rule of the form

$R_{t}=\phi_{p} \pi_{t}+z_{t}$

where $z_{t}$ is an exogenous time-varying intercept, that may be thought of as reflecting a time-varying implicit inflation target. This would coincide with the Taylor specification (3) if one were to assume that $z_{t}$ varies linearly with detrended $\log$ GDP. Instead I shall assume that $z_{t}$ varies as some function of the same real state vector $x_{t}$ as contains all available information about current and future expected real returns, permanent income growth, and real government budget surpluses, and write

$z_{t}=\alpha^{\prime} x_{t}$

where $\alpha$ is a vector of constant coefficients, and the constant term is omitted as in (4). (Note that this assumption implies that monetary pol- 
Table 2 INFLATION FORECASTING REGRESSION

\begin{tabular}{lccccc}
\hline \multicolumn{5}{c}{ Regressor } \\
\cline { 2 - 6 } & $\pi_{t-1}$ & $v c_{t-1}$ & $s c_{t-1}$ & $d c_{t-1}$ & $R^{2}$ \\
\hline$\pi_{t}$ & 0.677 & -0.027 & 0.088 & 0.524 & .66 \\
$($ s.e.) & $(.231)$ & $(.026)$ & $(.066)$ & $(.275)$ & \\
\hline
\end{tabular}

icy does not introduce any additional source of randomness beyond those already reflected in the state vector $x_{t}$.) This equation is in turn connected to the rest of the equation system by the assumption that in equilibrium, expected holding returns on the public debt and on the riskless short-term nominal instrument whose return is controlled by the Fed must be equal (or at least equal up to a constant premium). Thus an additional equilibrium condition is

$E_{t} \tilde{r}_{t+1}^{a}=R_{t}-E_{t} \pi_{t+1}$

Under this assumption about the form of the monetary policy rule, one may estimate the coefficients $\phi_{p}$ and $\alpha$ for Cochrane's sample period in the following way. Equations (6) through (9) imply that expected inflation at any point in time may be written

$E_{t} \pi_{t+1}=\lambda \pi_{t}+\gamma^{\prime} x_{t}$

where $\lambda=\phi_{p}, \gamma=\alpha-\xi$, and $\xi$ is the vector of coefficients multiplying the vector $x_{t-1}$ in (6). Given (10), we can construct a time series for expected inflation by regressing $\pi_{t}$ on $\pi_{t-1}$ and the vector $x_{t-1}$, and using the fitted values as our series for expected inflation. The coefficients of this regression are given in Table $2 .{ }^{15}$ Combining the implied expected inflation series with the expected real return series implied by (6) allows us to construct a series for expected nominal returns on public debt. According to (9), this should coincide with the nominal interest rate $R_{t}$ controlled by the Fed.

Since the constructed series is a linear combination of $\pi_{t}$ and the elements of $x_{t}$, one immediately has a representation of monetary policy of the form (7)-(8). The coefficient values we thus obtain are $\phi_{p}=0.677$ and

$z_{t}=0.037 v c_{t}-0.131 s c_{t}+0.041 d c_{t}$.

15. Here the inflation variable $\pi_{t}$ is the annualized first difference of the log of the GDP deflator, denoted $\mathrm{dp}$, by Cochrane. 
Note that these values do not necessarily imply that the central bank responds to fiscal variables as such. Representation (11) of the timevarying intercept in the monetary policy rule is almost identical to a specification of the form

$z_{t}=0.588 E_{t} \tilde{r}_{t+1}^{a}+0.325 d c_{t}$.

This last specification involves no explicit dependence upon fiscal variables, and makes a certain degree of intuitive sense: the Fed raises interest rates, for any given level of inflation, when expected real returns are high, or when growth is strong. [Consumption growth is probably not the best proxy for this last concern, but a representation of the form (8) allows us to model the inflation dynamics implied by the monetaryfiscal policy regime without introducing laws of motion for any additional real variables.]

One further aspect of government policy remains to be specified, and that is the composition of the public debt, which matters for the response of inflation to shocks for reasons that are well explained by Cochrane. I shall simplify the analysis, as in Woodford (1998b), by assuming that the public debt is at all times made up of a single type of government bond, a claim to a perpetual stream of riskless nominal coupons that decay geometrically with time. In Cochrane's notation, this implies that at all times $B_{t}(t+j)=\theta^{j-1} B_{t}(t+1)$ for all $j \geqslant 1$, where $\theta$ is a constant factor satisfying $0 \leqslant \theta<r \pi$, and $\pi$ is the steady-state inflation rate. (In fact, this structure of the aggregate stream of coupons is all that matters for our analysis, and not the actual existence of any perpetuities with geometrically decaying coupons.)

Now let $Q_{t}$ denote the price of such a perpetuity in period $t$, after payment of the period $t$ coupon, where a unit of the perpetuity pays a coupon of one dollar the next period, and let $q_{t} \equiv \log \left(Q_{t} / Q\right)$ indicate percentage deviations in this price from its steady-state value. Then the return on government debt satisfies

$r_{t}^{a}=\frac{1+\theta Q_{t}}{Q_{t-1}} \frac{p_{t-1}}{p_{t}}$

Log-linearization of this yields

$\tilde{r}_{t}^{a}=\omega q_{t}-q_{t-1}-\pi_{t}$

where the duration parameter $\omega \equiv \theta / r \pi$ is necessarily less than one. (The parameter $\omega$ indicates the steady-state fraction of the value of the public 
debt that may be attributed to coupon payments more than one year in the future.)

The expectations theory of the term structure [i.e., combining (6) with (13) and integrating forward] implies furthermore that

$q_{t}=-\sum_{j=0}^{\infty} \omega^{j} E_{t} R_{t+j}$.

Equations (13) and (14) then indicate how inflation and expected Fed policy must be related to the ex post real returns on government debt. However, these real returns must also satisfy the identity (5); under our assumed non-Ricardian fiscal regime, the evolution of $\tilde{r}_{t}^{a}$ is thus completely determined by the evolutions of the exogenous states $x_{t}$. In this case, the fiscal theory of the price level implies that inflation is endogenously determined each year to satisfy (13). Thus equations (5), (13), and (14) determine equilibrium inflation as a function of the exogenous real states and expected Fed policy. These equations, together with law of motion (4) for the exogenous real states and monetary policy rule (7)-(8), constitute a complete system to determine the rational expectations equilibrium paths of $x_{t}, \tilde{r}_{t}^{a}, \pi_{t}, R_{t}$, and $q_{t}$.

A first question about this equation system is whether monetary and fiscal policy rules of this kind imply a determinate rational expectations equilibrium. Here the answer, as in Leeper's (1991) analysis, is that there exists a unique stationary equilibrium inflation process if and only if $\left|\phi_{p}\right|<1$, so that monetary policy is "passive" in Leeper's sense. Our estimated monetary policy rule need not have this property, but it happens that it does $\left(\phi_{p}=0.677\right)$. As I have argued above, this is an important check upon the coherence of the proposed structural interpretation of the VAR in terms of an exogenous surplus process.

In the case that $\left|\phi_{p}\right|<1$, the unique stationary equilibrium involves inflation evolving according to a law of motion

$\pi_{t}=\phi_{p} \pi_{t-1}+\left(\alpha^{\prime}-\xi^{\prime}\right) x_{t}+f^{\prime} \epsilon_{t \prime}$

where

$f^{\prime}=\left[\phi_{p} \omega\left(\delta_{0}^{\prime}+\omega \delta_{1}^{\prime}\right)-\omega \alpha^{\prime}\right] \cdot(I-\omega A)^{-1}-\delta_{0}^{\prime}$

and $\delta_{0}^{\prime} \equiv\left(\begin{array}{lll}\rho & \rho & 1\end{array}\right)$ and $\delta_{1}^{\prime} \equiv\left(\begin{array}{lll}-1 & 0 & 0\end{array}\right)$ are the vectors of coefficients on $x_{t}$ and $x_{t-1}$ respectively in (5), and where $\epsilon_{t}$ is again the vector of exogenous disturbances in (4). This equation, together with (4), completely describes the evolution of inflation and the real states, as a function of the history of disturbances $\epsilon_{i}$. It will be apparent from (15) why the bound on 
$\left|\phi_{p}\right|$ is required for existence of a stationary inflation process. It will also be obvious that this inflation process satisfies (10). Thus our method of estimation of the monetary policy rule necessarily delivers a rule that-if it is consistent with the existence of a stationary equilibrium at all-will imply an evolution of expected inflation that is consistent with our regression forecasts. What are not automatically granted are correct predictions about the surprise component of inflation, the part of each year's inflation that is not explained by the regression reported in Table 2. It is thus of particular interest to test these predictions.

Equation (15) implies that

$\pi_{t}-E_{t-1} \pi_{t}=f^{\prime} \epsilon_{t}$

and our estimated coefficients imply numerical values for the vector of coefficients $f$, for any given value of the duration parameter $\omega$. The predicted values for the elements of $f$ thus represent a testable crossequation restriction implied by the theory. These three coefficients are each plotted, as a function of $\omega$, in Figure 1 . We can then compare these predictions with the coefficients of a regression of the residuals from our inflation regression [interpreted as an OLS estimate of equation (15)] upon the residuals from the VAR (4). These estimated coefficients $\hat{f}$ are also shown in Figure 1, by the dashed horizontal line in each panel. The dotted horizontal lines in each panel indicate a plus and minus twostandard-error confidence interval for each estimated coefficient. ${ }^{16}$

One observes that the signs of the point estimates are consistent with the fiscal theory of the price level in each case: positive innovations in any of the three series $(v c, s c$, or $d c)$ are predicted to result in an unexpected reduction in inflation, and in the U.S. data that is what occurs. ${ }^{17}$ The quantitative magnitudes of these effects are also roughly what the theory predicts, especially if one takes into account the fact that U.S. government debt is not of extremely short duration. Cochrane's Figure 15 shows that about $50 \%$ (on average) of the present value of coupons due on U.S. government liabilities has been due within a year; this suggests $\omega=0.5$ as a reasonable calibration of the duration parameter.

16. These standard errors are computed treating the residuals from the inflation forecasting regression in Table 2 as data, and so do not take into account the uncertainty of our estimates of the residuals themselves. Hence they exaggerate the precision of these estimated effects.

17. According to the crude standard-error measure used in producing the figure, the estimated decline is significant at nearly the $5 \%$ level in the case of an sc innovation, and much more significant in the other two cases. 
Figure 1 THEORETICAL AND ESTIMATED RESPONSES OF INFLATION TO VAR INNOVATIONS
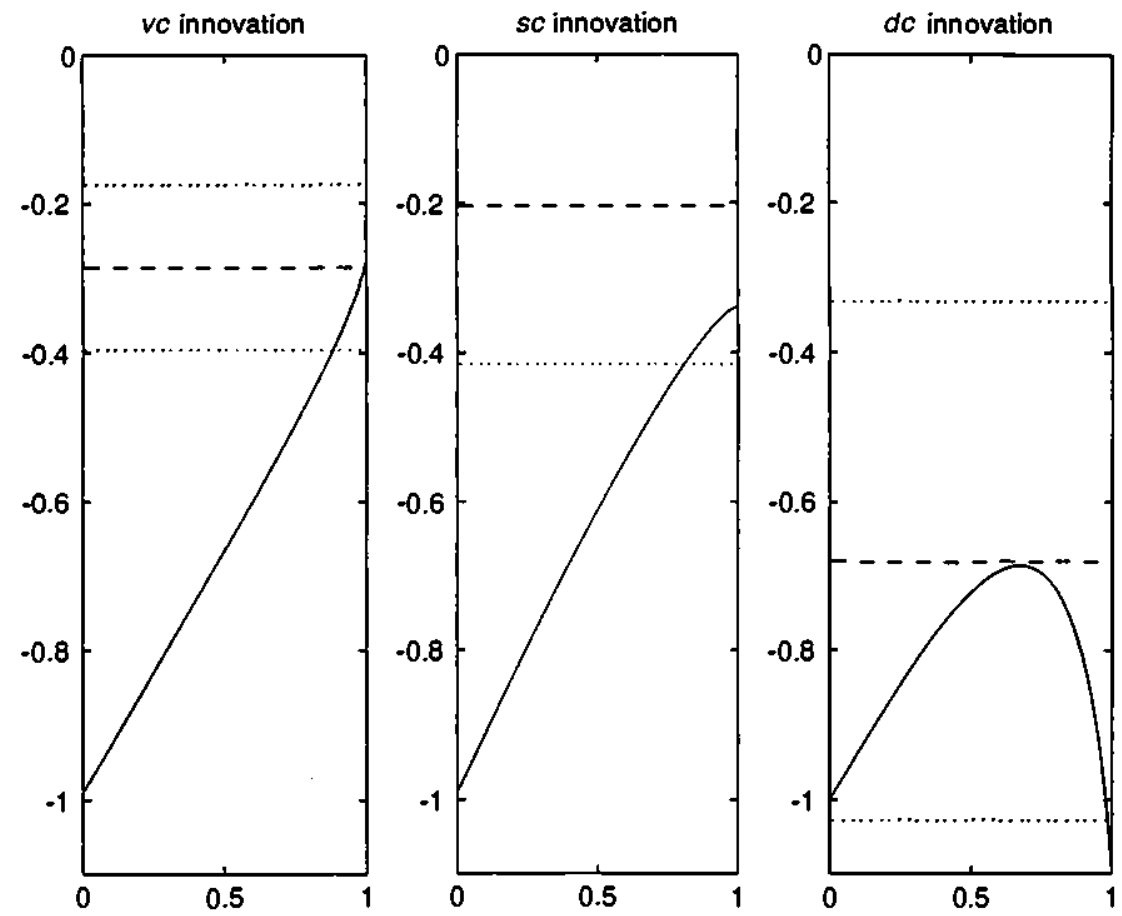

In each panel, horizontal axis indicates the value of $\omega$. Theory: solid curve; estimate: dashed line.

Increasing $\omega$ to this extent decreases the predicted response of inflation to each of the innovations, as more adjustment occurs through unexpected changes in bond prices rather than in inflation, 18 and in each case this moves the prediction closer to the point estimate. Nonetheless, the point estimates indicate smaller responses, especially to the $v c$ and $s c$ innovations, than are predicted by the fiscal theory. In the case of the $v c$ and $s c$ innovations, the predicted response lies outside the $95 \%$ confidence intervals plotted in the figure (though these are probably too narrow). This problem could be solved by assuming a value of $\omega$ on the order of 0.9 , but this would seem to be inconsistent with the actual average duration of U.S. government liabilities.

Another problem is that the theory predicts that unexpected inflation should be entirely explained by the three VAR innovations, and it is not;

18. See Woodford (1998b) for further analysis of this effect. 
Figure 2(a). ACTUAL AND THEORETICAL INFLATION SERIES,

CASE $\omega=0$.

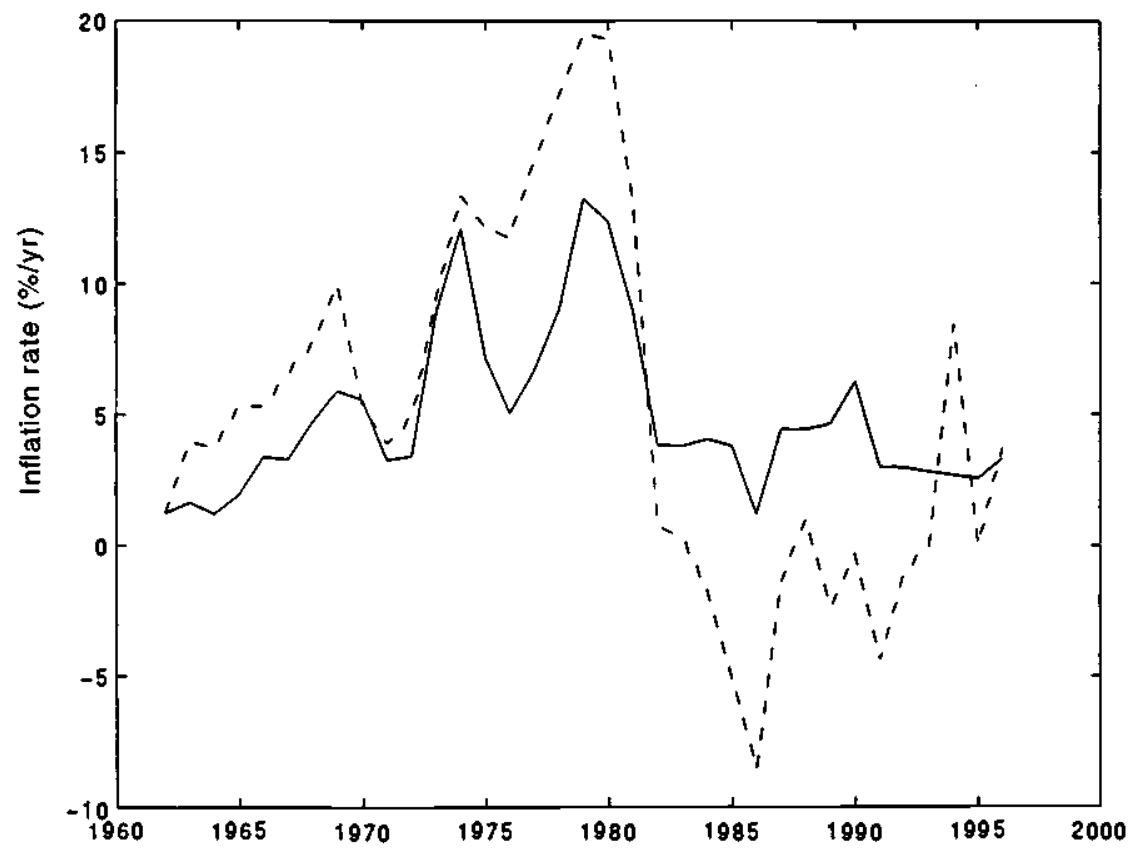

Solid curve: actual; dashed curve: theoretical.

in fact, these innovations explain only $57 \%$ of the variation in the inflation residuals. Of course, the prediction that unexpected inflation should depend only upon the disturbances $\epsilon_{t}$ depends upon our assumption that the $z_{t}$-intercept in the monetary policy rule is a function of the variables $x_{t ;}$ if we allow $z_{t}$ to depend upon some other random state as well (representing exogenous disturbances to monetary policy, or simply another state variable to which the Fed responds), then unexpected inflation should depend upon that state too. This generalization would, however, complicate the previous discussion, especially our consideration of how the parameters of the monetary policy rule can be inferred from the coefficients of the inflation forecasting regression (10), and so I do not pursue it here.

I turn now to the extent to which this theory of inflation determination can explain the U.S. inflation time series. Figures $2 a-c$ compare the actual inflation time series with the prediction of the model, obtained by simulating (15) given the historical evolution of the state vector $x_{t}$ under 
Figure 2(b). ACTUAL AND THEORETICAL INFLATION SERIES, CASE $\omega=.5$.

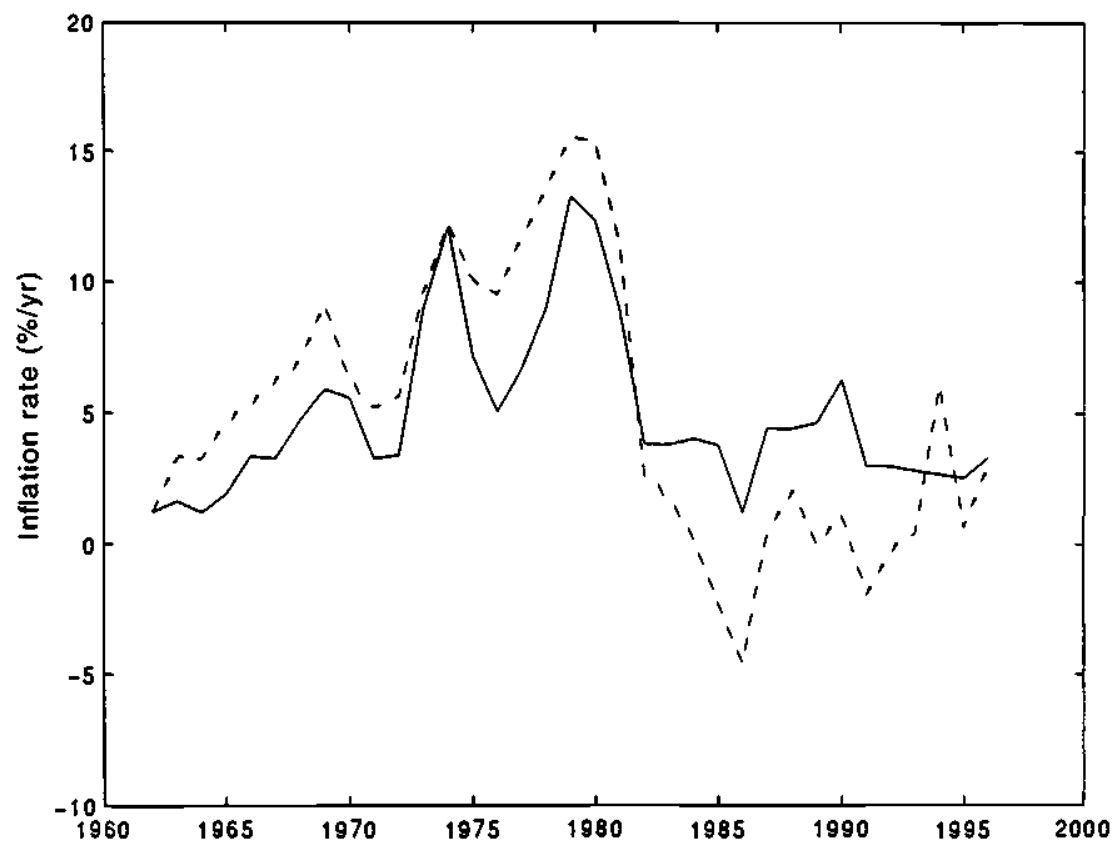

Solid curve: actual; dashed curve: theoretical.

three different assumed values for $\omega$. The simulation assuming $\omega=0$ (all government debt matures within a year) correctly predicts the great inflation of the 1970s and the sharp disinflation of the early 1980s; so these gross facts are clearly not problematic for a fiscalist account, as Cochrane emphasizes. But this simple model greatly overpredicts the volatility of inflation variations. Its failure demonstrates that simply choosing coefficients consistent with the inflation-forecasting regression (10) is hardly a guarantee that the model will do well at explaining overall inflation variations; it is clearly crucial to correctly predict the unforecastable movements in inflation, which (at the annual frequency) are no small part of the story.

Figures $2 b$ and $c$ show that allowing for longer-duration government debt greatly improves the model's ability to account for the historical inflation dynamics. In fact, the simulation assuming $\omega=0.99$ (essentially, the entire government debt made up of consols) does quite a good job of accounting for both the magnitude and timing of all the main 
Figure 2(c). ACTUAL AND THEORETICAL INFLATION SERIES, CASE $\omega=.99$.

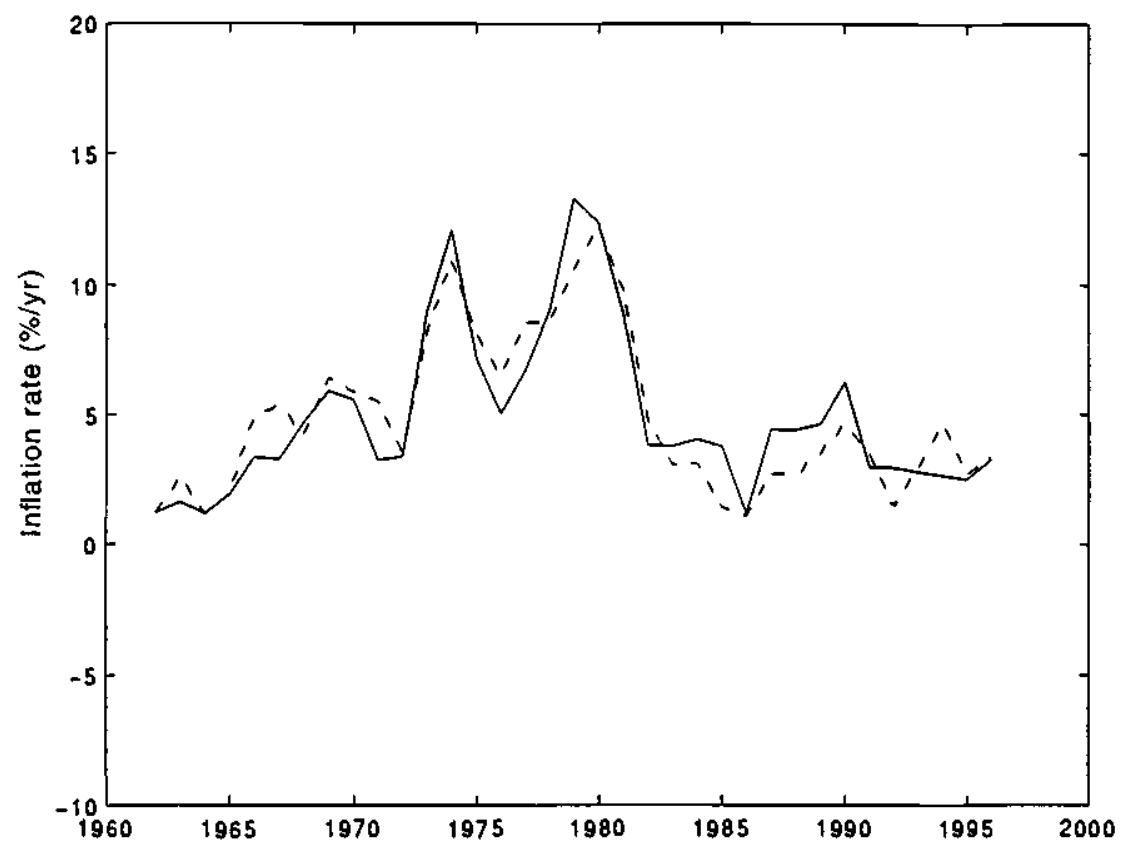

Solid curve: actual; dashed curve: theoretical.

variations in the U.S. inflation rate over this 35-year period. This indicates that even though more than $40 \%$ of the variation in unexpected inflation is uncorrelated with any of the disturbances $\epsilon_{t}$ a model that neglects other sources of unexpected inflation variation can still do quite well at accounting for medium-frequency inflation variation. Thus this particular prediction of our simple model is not such an embarrassment as it might have seemed. ${ }^{19}$

However, the assumption that U.S. government liabilities consist entirely of consols is plainly incorrect. Under the more realistic assumption that $\omega=0.5$, the model's predictions are still quite inaccurate-for example, it implies that the fiscal consolidation of the mid-1980s should have led to actual deflation, at rates as high as $5 \%$ in a single year, something

19. A variance decomposition of the VAR obtained by adjoining an unrestricted inflation equation to the equations in (4) shows that while the inflation innovation orthogonal to the other three innovations accounts for $43 \%$ of the variance of unexpected inflation variation at a 1-year horizon, it accounts for only $23 \%$ of the variance at a 10 -year horizon. 
that was certainly not seen. The reason that the model does better under the assumption of a higher $\omega$ would seem to be that longer-duration debt implies that more of the adjustment should occur through unexpected changes in bond prices instead of unexpected variations in inflation, and that better matches what has happened, even though much of U.S. government liabilities are of relatively short duration.

The reason for this failure of the model may be its assumption of perfectly flexible prices, and hence exogenous expected real rates of return. This implies that inflation surprises affect bond prices only through their effect on expectations of future inflation, and not through any possible effect upon expected real rates of return; then, given evidence on the degree to which inflation surprises change forecasts of future inflation, inflation surprises can only be associated with larger bond-price movements by increasing the duration of the bonds. Consideration of whether a sticky-price model like the one used in Woodford (1996), in which fiscal shocks affect both inflation and real rates of return, can better account for the data is an obvious topic for further study.

This brief treatment should suffice to illustrate how assuming a particular form of monetary policy rule allows us to increase the number of testable restrictions implied by a proposed structural interpretation of fiscal-variable VARs such as Cochrane's. We have seen that in the case of the kind of monetary policy rule proposed above, the interpretation in terms of an exogenous process for the primary budget surplus passes some of these tests, though it is less consistent with others.

\section{Ricardian and Non-Ricardian Interpretations Compared}

A Ricardian interpretation of the VAR reported in Table 1 is also possible, but is less consistent with the monetary policy rule estimated above. It would be possible to treat the $s c_{t}$ equation of the VAR,

$s c_{t}=a_{21} v c_{t-1}+a_{22} s c_{t-1}+a_{23} d c_{t-1}+\epsilon_{2 t \prime}$

as an estimate of a feedback rule for the government budget surplus, as in Bohn's (1998) interpretation of his surplus regressions. Under this interpretation, the joint evolution of the primary surplus and of the real value of the government debt would be determined by the fiscal rule (16) and the accounting identity (5), given an exogenous process for "permanent income" growth $d c_{t}$, and the endogenous evolution of the ex post returns $\tilde{r}_{t}^{a}$ on government debt.

Substituting equation (13) for this last variable, these two equations can be written in matrix form as 
$\tilde{x}_{t}=B \tilde{x}_{t-1}+C e_{t}+D y_{t}$

where $\tilde{x}_{t}$ is the vector of fiscal variables $\left[v c_{t} s c_{t}\right]^{\prime}, e_{t}$ is a vector of exogenous variables including $e_{2 t} d c_{t^{\prime}}$ and $d c_{t-1}$, and $y_{t}$ is a vector of nominal endogenous variables $\left[\begin{array}{lll}q_{t} & q_{t-1} & \pi_{t}\end{array}\right]^{\prime}$. Here the matrix $B$ is given by

$B=\left[\begin{array}{lr}\rho^{-1}-a_{21} & -a_{22} \\ a_{21} & a_{22}\end{array}\right]$.

The estimates in Table 1 imply that the eigenvalues of $B$ are 0.87 and 0.53 , both inside the unit circle. It follows that (17) implies bounded fluctuations in $\tilde{x}_{t}$ in the case of any bounded fluctuations in the variables $e_{t}$ and $y_{t}$. Thus avoidance of unbounded growth in the value of the public debt does not place any restriction at all upon the paths of inflation and bond prices, apart from requiring that those variables themselves fluctuate within bounds, and such a fiscal policy rule is (at least locally) Ricardian. Thus the VAR itself does not exclude a Ricardian interpretation.

But suppose that we again assume a monetary policy rule given by (7) and (12), ${ }^{20}$ where $\phi_{p}$ is estimated in the way explained above, and also again assume that $r_{t} \equiv E_{t} \tilde{r}_{t+1}^{a}$ is an exogenous stochastic process, determined by factors unaffected by the evolution of the nominal variables $y_{t}$. Then substitution of (7) and (12) into (6) to eliminate $R_{t}$ yields an expectational stochastic difference equation for $\pi_{t}$. Eliminating $R_{t}$ in the same way from the quasidifferenced form of (14),

$q_{t}=-R_{t}+\omega E_{t} q_{t+1}$

similarly yields a stochastic expectational difference equation for $q_{r}$. These two difference equations, together with (17), then constitute a system that can be written in matrix form as

$\left[\begin{array}{c}E_{t} y_{t+1} \\ \tilde{x}_{t}\end{array}\right]=\left[\begin{array}{cc}H & 0 \\ D & B\end{array}\right]\left[\begin{array}{c}y_{t} \\ \tilde{x}_{t-1}\end{array}\right]+\left[\begin{array}{c}G \\ C\end{array}\right] e_{t \prime}$

where the vector of exogenous state variables $e_{t}$ is now augmented to also include $r_{t}$. The system of equations (18) then includes all of the restrictions upon the evolution of the endogenous variables imposed by

20. Note that under the present specification of the fiscal rule, (11) and (12) are no longer equivalent monetary policy specifications, as $v c_{l}$ and $s c_{k}$ are no longer exogenous with respect to the nominal variables. Hence it is necessary to specify that the assumed form of monetary policy rule is given by (7) and (12). 
the model; any stationary solution of this system represents a stationary rational expectations equilibrium.

Given that the vector $y_{t}$ includes two state variables $\left(q_{t}\right.$ and $\left.\pi_{t}\right)$ that are not predetermined, the system (18) has a unique stationary solution if and only if the square matrix has exactly three eigenvalues inside the unit circle and two outside. ${ }^{21}$ The block-triangular form of the matrix implies that the eigenvalues are just the eigenvalues of $B$ together with those of $H$. As just discussed, the VAR point estimates imply that both eigenvalues of $B$ lie within the unit circle. The matrix $H$ is given by

$H=\left[\begin{array}{ccc}\omega^{-1} & 0 & \omega^{-1} \phi_{p} \\ 1 & 0 & 0 \\ 0 & 0 & \phi_{p}\end{array}\right]$,

so that its eigenvalues are $0, \omega^{-1}$, and $\phi_{p}$. Since we necessarily have $\omega^{-1}>1$, there is a determinate equilibrium inflation process, under this policy regime, if and only if $\left|\phi_{p}\right|>1$, as in Leeper's analysis.

Our point estimate for $\phi_{p}$, however, is well below the critical value of one. If we take that estimate as correctly identifying U.S. monetary policy, it would imply that rational expectations equilibrium should have been indeterminate, under the Ricardian interpretation of the VAR. One possible equilibnum would be exactly the equilibrium associated with the exogenous primary surplus process, ${ }^{22}$ but there would also be a vast set of additional stationary equilibria, involving alternative responses of inflation and bond prices to the real disturbances, and also involving responses of the nominal variables to "sunspot" shocks. This richness of possibilities might be regarded as a virtue-for some other member of the set might fit the U.S. time series better than does the unique equilibnum consistent with an exogenous surplus process. But we would be left with no explanation of why that particular equilibrium should have been realized rather than some very different one, and in this respect our understanding of U.S. inflation history would have to be judged less complete.

Of course, one might argue that the data do not clearly reject the hypothesis that $\left|\phi_{p}\right|>1$; the standard error of the estimate of the coefficient on $\pi_{t-1}$ in Table 2 is large enough to allow this. And perhaps more

21. Here I assume stationarity of the exogenous disturbances $e_{1}$, and ignore certain nongeneric cases that can be shown not to apply here.

22. Note that system (18) has three exogenous disturbance processes, $d c_{t}, r_{t}$, and the fiscal shocks $\epsilon_{21}$, just like our prevlous non-Ricardian model, and if the jolnt law of motion of these processes is as assumed in that model, the equilibrlum under the non-Ricardian regime is also an equilibrium under the Ricardian regime. 
to the point, our estimates depend upon an assumed specification of the monetary policy rule, (7)-(8), that may well be incorrect. Future work will surely need to consider alternative specifications. As noted above, much work does find support for specifications consistent with determinacy of equilibrium under a Ricardian fiscal regime, at least for post-1979 U.S. monetary policy. Future work will surely want to consider the possibility that the Ricardian or non-Ricardian character of U.S. fiscal policy may also have changed over time.

Narrative evidence about the nature of shocks can also help to distinguish among alternative possible interpretations of the time series; here, too, there are important reasons to prefer a Ricardian interpretation, at least of U.S. experience since 1980. The non-Ricardian interpretation of the U.S. data offered by Cochrane, and in the above account, attributes the disinflation of the early 1980 s to a large increase in the equilibrium value of the public debt, resulting from fiscal developments that increased expected future budget surpluses. Cochrane shows that the increase in the value of the public debt occurred, and according to his VAR forecasts, the increase in expected budget surpluses occurred as well.

However, a Ricardian interpretation of these facts remains possible, which is that an exogenous change in monetary policy caused the disinflation, which resulted in a windfall to bondholders, which in turn required at least a prospective increase in the size of primary surpluses, in order to allow the increased real debt service to be paid. The two views of the causal connection between events are equally coherent, but the Ricardian story has the advantage that considerable narrative evidence also exists of a deliberate change in U.S. monetary policy in the period 1979-1982, intended to bring down inflation. Furthermore, the political efforts to reduce government budget deficits in the U.S., beginning in the mid-1980s, seem to have a great deal to do with concern about the size of the public debt and about the size of the associated debt service. It is less easy to identify the exogenous fiscal changes that might have increases expectations of future surpluses for independent reasons, as the non-Ricardian story would require.

On the other hand, the Ricardian interpretation is less clearly applicable to the inflation of the 1970s. There is little narrative evidence to indicate that the losses suffered by bondholders in that period resulted from a deliberate decision at the Fed to increase the U.S. inflation rate. And on the other hand, at least some of the exogenous fiscal shocks can be identified. For example, the large primary deficit in 1975 can be attributed to a one-time tax rebate, a deliberate change in fiscal policy in- 
tended to stimulate the economy. ${ }^{23}$ Furthermore, there is little evidence in discussions of fiscal policy in the period 1965-1979 (by contrast with the 1980s and 1990s) to suggest a concern with budget balance as either a goal or a constraint. To the contrary, influential policy advisors celebrated the liberation of fiscal policy from the fetish of balanced budgets ${ }^{24}$; and while mainstream economists always supposed that deficits in times of recession would have to be offset by surpluses during booms, this advice was not formulated in a way that would ensure a Ricardian regime, and may in any event have had little effect upon the way fiscal policy was conducted in practice or understood by the public. Hence a non-Ricardian interpretation of this period may well prove fruitful. ${ }^{25}$

\section{REFERENCES}

Benhabib, J., S. Schmitt-Grohé, and M. Uribe. (1998). Monetary policy and multiple equilibria, Federal Reserve Board. FEDS Paper 1998-29. June.

Blinder, A. S. (1981). Temporary income taxes and consumer spending. Journal of Political Economy 89:26-53.

Bohn, H. (1998). The behavior of U.S. public debt and deficits. Quarterly Journal of Economics 113:949-964.

Canzoneri, M. B., R. E. Cumby, and B. T. Diba. (1998). Is the price level determined by the needs of fiscal solvency? CEPR Discussion Paper no. 1772. January.

Clarida, R., J. Gall, and M. Gertler. (1998). Monetary policy rules and macroeconomic stability: Evidence and some theory. Cambridge, MA: National Bureau of Economic Research. NBER Working Paper 6442. March.

Heller, W. (1966). New Dimensions of Political Economy. New York: W. W. Norton.

Kutter, M. (1998). Application of an optimization-based econometric framework for the evaluation of monetary policy: German monetary policy 1973-1989. Department of Economics, London School of Economics. Unpublished. May.

Leeper, E. (1989). Policy rules, information and fiscal effects in a "Ricardian" Model. Federal Reserve Board. International Finance Discussion Paper 360. August.

__ (1991). Equilibria under "active" and "passive" monetary and fiscal policies. Journal of Monetary Economics 27:129-147 (1991).

Loyo, E. (1997). The wealth effects of monetary policy and Brazilian inflation. Department of Economics, Princeton University. Unpublished. November.

Rotemberg, J. J., and M. Woodford (1997). An optimization-based econometric framework for the evaluation of monetary policy. NBER Macroeconomics Annual

23. For details, see, e.g., Blinder (1981).

24. See, e.g., Heller (1966) and Stein (1969).

25. The suggestion of Canzoneri, Cumby, and Diba (1998), that if U.S. fiscal policy had ever been non-Ricardian, it would surely have been in the period since 1980, is thus exactly the opposite of what I would propose. Note that Shim (1984) finds an important role for fiscal shocks in explaining U.S. inflation in the period prior to 1980 . In private communication, Shim reports that his estimates proved unstable when he attempted to update his work, adding data from the early 1980 s. 
1997. (Expanded version: Cambridge, MA: National Bureau of Economic Research. NBER Technical Working Paper 233. May 1988.)

. (1998). Interest-rate rules in an estimated sticky-price model. $\ln$ Monetary

Policy Rules, J. B. Taylor, (ed.). Chicago: University of Chicago Press.

Shim, S. D. (1984). Inflation and the government budget constraint: International evidence. Department of Economics, University of Minnesota. Unpublished Ph.D. Dissertation. August.

Sims, C. A. (1994). A simple model for the study of the determination of the price level and the interaction of monetary and fiscal policy. Economic Theory 4:381-399.

Stein, H. (1969). The Fiscal Revolution in America: Policy in Pursuit of Reality. Chicago: University of Chicago Press, 1969.

Taylor, J. B. (1993). Discretion versus policy rules in practice. Carnegie-Rochester Conference Series on Public Policy 39:195-214.

- (1998). An historical analysis of monetary policy rules. In Monetary Policy Rules, J. B. Taylor (ed.). Chicago: University of Chicago Press.

Woodford, M. (1995). Price-level determinacy without control of a monetary aggregate. Carnegie-Rochester Conference Series on Public Policy 43:1-46 (1995).

- (1996). Control of the public debt: A requirement for price stability? Cambridge, MA: National Bureau of Economic Research. NBER Working Paper 5684. July.

. (1998a). Doing without money: Controlling inflation in a post-monetary world. Review of Economic Dynamics 1:173-219.

_ (1998b). Public debt and the price level. Department of Economics, Princeton University. Unpublished. July.

\section{Discussion}

Benjamin Friedman expressed puzzlement at Cochrane's claim that the fiscal theory of the price level is untestable. He argued that an empirical test is certainly possible if one is willing to make auxiliary assumptions. As this is the usual situation in macroeconomics, the fiscal theory isn't really unique in this regard. Cochrane agreed with the spirit of Friedman's remark, drawing the analogy to the quantity theory, which is an identity and hence similarly untestable unless one makes additional assumptions (for example about the behavior of velocity). While not denying that the theory was testable in principle, however, Cochrane cautioned against making inferences based on simple reduced-form methods, for example, by examining which variables lead others in estimated vector autoregressions.

Frederic Mishkin also agreed with Friedman, emphasizing that a legitimate test of the theory requires some exogenous change in the economic environment, like those that Milton Friedman and Anna Schwartz attempted to identify in their monetary history. Ben Bernanke suggested 
that a major fiscal reform, for example a restructuring of the social security system, might provide a useful test case for the fiscal theory.

Herschel Grossman questioned whether non-Ricardian fiscal regimes are possible. He used as an example the individual borrower who cannot mortgage the same house twice, and he argued that the government cannot sell more debt at a given point in time unless it credibly promises to increase future surpluses. Cochrane disagreed, noting that changes in the price level effectively allow the government to change the real value of its debt. By analogy, an individual could issue more nominal claims against his real assets, at the expense of earlier purchasers of those claims.

Mishkin suggested that in the United States, in practice, the monetary authority moves first and the fiscal authority follows. He doubted therefore that the fiscal theory could be a good model of postwar U.S. inflation, although it might well be relevant in other contexts. Michael Woodford disagreed, noting that the Federal Reserve cannot and does not ignore the fiscal side of the economy.

Marvin Goodfriend expressed the view that it will not be fruitful to try to find a purely fiscal explanation of U.S. inflation. As long as there is a transactions demand for money in the economy, monetary policy will have some role to play in the control of the price level. 

